\title{
Baseline Characterization Database Verification Report PCEA Billet XPC01D3-36
}

\author{
David T. Rohrbaugh
}

May 2017

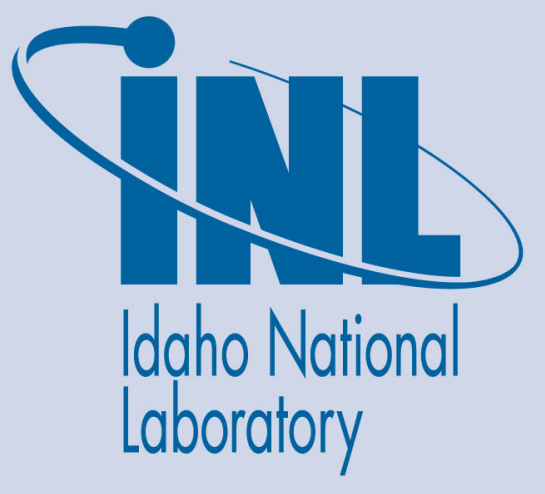

The INL is a U.S. Department of Energy National Laboratory operated by Battelle Energy Alliance 


\title{
Baseline Characterization Database Verification Report PCEA Billet XPC01D3-36
}

\author{
David T. Rohrbaugh
}

May 2017

Idaho National Laboratory Idaho Falls, Idaho 83415

http://www.inl.gov

Prepared for the

U.S. Department of Energy

Under DOE Idaho Operations Office

Contract DE-AC07-05ID14517 
TEM-10200-1

$03 / 01 / 2012$

ENGINEERING CALCULATIONS AND ANALYSIS

INL/MIS-17-41825

Rev. 06

Title:

Baseline Characterization Database Verification Report - PCEA Billet XPC01D3-36

ECAR No.: 3677

Rev. No.: 0

Project No::

32138

Date: $05 / 02 / 2017$

Independent Peer

Reviewer ${ }^{2}$ :

Performer: David Rohrbaugh

D520

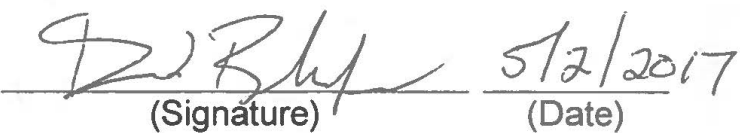

Checker $1 ._{\text {W. }}$
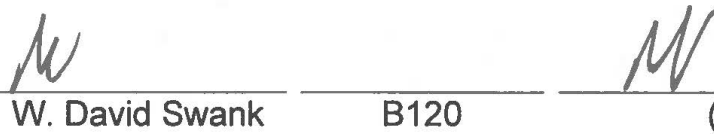

(Signature)

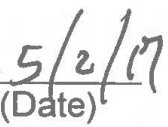

CUI Reviewer:

Yes $\square$ or $\mathrm{No}^{5} \otimes$

N/A

N/A

\begin{abstract}
Yes
\end{abstract}

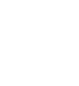

Manager $^{3}$

Scott McBride

D520

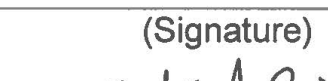

(Date)

Solt Whide

$5 \cdot 1 \cdot 2017$

Owner: William Windes

B120

(Signature)

(Date)

Nuclear Safety":

Cognizant Engineer":

N/A

Quality Assurance:

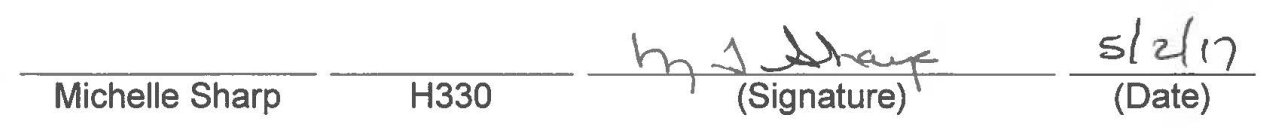

1. Confirmation of completeness, mathematical accuracy, and correctness of data and appropriateness of assumptions.

2. Concurrence of method or approach. See definition in LWP-10106.

3. Concurrence of procedure compliance. Concurrence with method/approach and conclusion.

4. Concurrence with the document's assumptions and input information. See definition of acceptance in LWP-10200.

5. Does the document contain CUI material? Please check either yes or no. 
TEM-10200-1

$03 / 01 / 2012$

ENGINEERING CALCULATIONS AND ANALYSIS

Page 1 of 32

Rev. 06

Title: $\quad$ Baseline Characterization Database Verification Report - PCEA Billet XPC01D3-36

ECAR No.: 3677

Rev. No.:

Project No.: $\quad 32138$

Date: $05 / 02 / 2017$

REVISION LOG

\begin{tabular}{|c|c|c|l|}
\hline Rev. & Date & Affected Pages & \multicolumn{1}{c|}{ Revision Description } \\
\hline 0 & $05 / 02 / 2017$ & All & Newly issued document. \\
\hline & & & \\
\hline & & & \\
\hline & & & \\
\hline & & & \\
\hline & & & \\
\hline & & & \\
\hline & & & \\
\hline & & & \\
\hline
\end{tabular}


TEM-10200-1

$03 / 01 / 2012$

ENGINEERING CALCULATIONS AND ANALYSIS

Page 2 of 32

Rev. 06

Title:

Baseline Characterization Database Verification Report - PCEA Billet XPC01D3-36

ECAR No.: 3677

Rev. No.: 0

Project No:

32138

Date: $05 / 02 / 2017$

\begin{tabular}{|l|c|}
\hline 1. Quality Level (QL) No. & 2 \\
\hline 2. QL Determination No. & RTC-000029 \\
\hline 3. Engineering Job (EJ) No. & NA \\
\hline 4. SSC ID & NA \\
\hline 5. Building & IRC \\
\hline 6. Site Area & REC \\
\hline
\end{tabular}

7. Objective/Purpose:

The purpose of this engineering calculations and analysis report is to present the data being collected in the Baseline Graphite Characterization Program, which is directly tasked with supporting Idaho National Laboratory's research and development efforts on the Advanced Reactor Technologies Program. This program is populating a comprehensive database that will reflect the baseline properties of nuclear-grade graphite with regard to individual grade, billet, and position within individual billets. The physical and mechanical property information being collected will be transferred to the Nuclear Data Management and Analysis System and, from that database, will help populate the handbook of property data available to member nations of the Generation IV International Forum.

Transfer of these data from the applicable technical lead to the dissemination databases available to other end users requires a full review of the test procedures and data collection efforts through an analysis of the multiple summary spreadsheets and values being collected. This report represents the analysis for PCEA billet XPC01D3-36 and facilitates release of associated data to the Nuclear Data Management and Analysis System custodians.

8. If revision, please state the reason and list sections and/or pages being affected:

NA

9. Conclusions/Recommendations:

Based on a review of the data spreadsheets compiled from physical and mechanical property measurements on nuclear-grade graphite billet PCEA XPC01D3-36, no notable errors or omissions were noted that will preclude the transfer of these data to the Nuclear Data Management and Analysis System site for storage.

In addition to a full visual review of the data files to determine whether or not obvious errors, such as missing information, were made with the data collected, graphical representations were made of individual evaluations in order to provide a means to spot anomalies. The techniques employed are an adequate means of ensuring that the comprehensive amount of data collected reflect the intended values of interest. A review of the data indicates that the files, as submitted, are fully representative of the measured properties of the graphite billets being tested, as outlined in the applicable test procedures and program plans. 
Title: $\quad$ Baseline Characterization Database Verification Report - PCEA Billet XPC01D3-36

$\begin{array}{lllll}\text { ECAR No.: } 3677 & \text { Rev. No.: } 0 & \text { Project No.: } 32138 & \text { Date: } 05 / 02 / 2017\end{array}$

\section{CONTENTS}

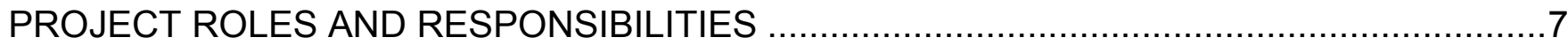

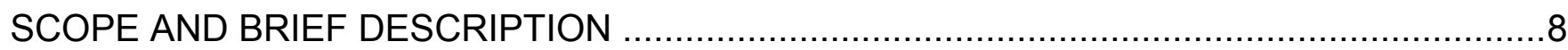

DESIGN OR TECHNICAL PARAMETER INPUT AND SOURCES ..................................

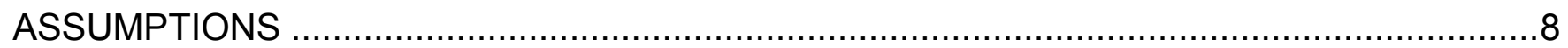

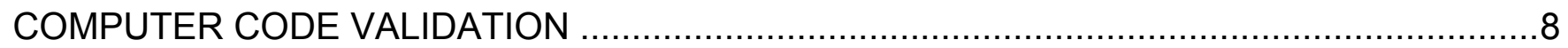

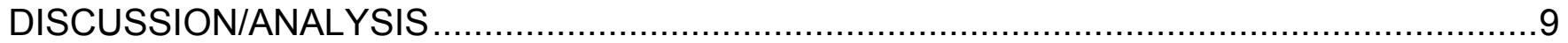

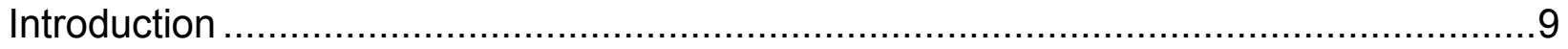

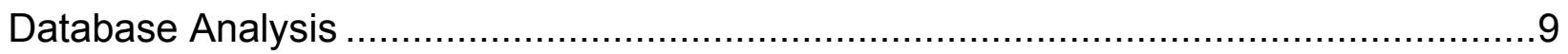

Compression Specimen Database (PCEA XPC01D3-36C) ........................................11

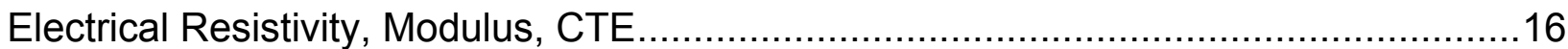

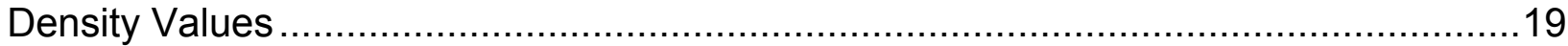

Flexural Specimen Database (PCEA XPC01D3-36F) ..........................................20

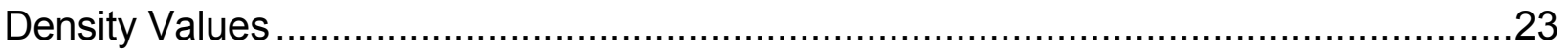

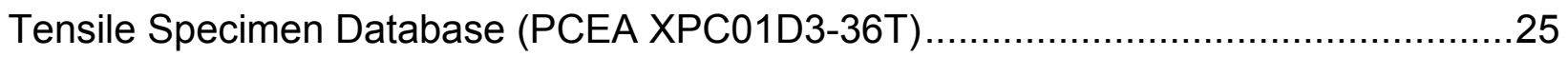

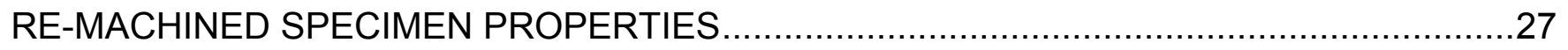

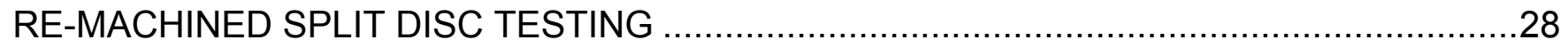

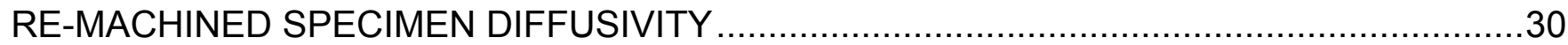

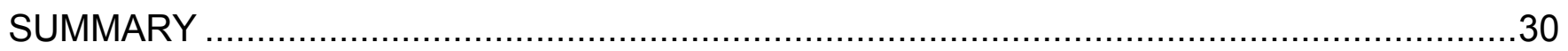

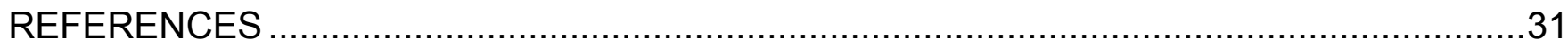

Appendix A Additional Compression Specimen Database Plots (PCEA XPC01D3-36C)1 Appendix B Additional Flexural Specimen Database Plots (PCEA XPC01D3-36F) ........1

Appendix C Additional Tensile Specimen Database Plots (PCEA XPC01D3-36T).........1 
Rev. 06

Title: $\quad$ Baseline Characterization Database Verification Report - PCEA Billet XPC01D3-36

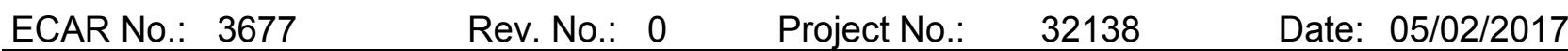

\section{FIGURES}

Figure 1. The three types of mechanical test specimens that will be machined from stock graphite and provide the basis for material property evaluations.

Figure 2. Individual specimen extraction and tracking identification from PCEA XPC01D336.

Figure 3. Compressive load at maximum load $(\mathrm{N})$, mean $=8,233.1$, standard deviation $=$ 619.31.

Figure 4.Compressive stress at maximum load $(\mathrm{MPa})$, mean $=65.0$, standard deviation $=$ 4.89

Figure 5. Displacement at maximum load $(\mathrm{mm})$, mean $=-0.7320$, standard deviation $=$ 0.1378 .

Figure 6. Compressive strain $(\mathrm{mm} / \mathrm{mm})$, mean $=0.0288$, standard deviation $=0.0054$. 13

Figure 7. Fracture categorization results and description. 14

Figure 8. Maximum load $(\mathrm{N})$, mean $=-2,213.2$, standard deviation $=281.5$. 15

Figure 9. Maximum flexure stress $(\mathrm{MPa})$, mean $=44.0$, standard deviation $=5.6$. 16

Figure 10. Electrical resistivity $(\mu \Omega-\mathrm{m})$, mean $=7.6$, standard deviation $=0.3$. 17

Figure 11. Young's modulus by sonic velocity method $(\mathrm{GPa})$, mean $=13.0$, standard deviation $=0.6$.

Figure 12 . Shear modulus by sonic velocity method $(\mathrm{GPa})$, mean $=5.0$, standard deviation $=$ 0.2 .

Figure 13. Young's modulus by sonic resonance method $(\mathrm{GPa})$, mean $=10.8$, standard deviation $=0.5$.

Figure 14. Mean coefficient of thermal expansion (1/K).

Figure 15. Density $\left(\mathrm{g} / \mathrm{cm}^{\wedge} 3\right)$, mean $=1.8324$, standard deviation $=0.0070 \ldots \ldots \ldots \ldots \ldots \ldots \ldots \ldots \ldots \ldots \ldots \ldots \ldots \ldots . . .20$

Figure 16. Average thickness $(\mathrm{mm})$, mean $=8.122$, standard deviation $=0.0304 \ldots \ldots \ldots \ldots \ldots \ldots . .21$

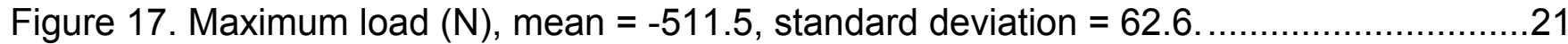

Figure 18. Maximum flexure stress $(\mathrm{MPa})$, mean $=29.3$, standard deviation $=3.6$. 
Title: $\quad$ Baseline Characterization Database Verification Report - PCEA Billet XPC01D3-36

$\begin{array}{lllll}\text { ECAR No.: } 3677 & \text { Rev. No.: } 0 & \text { Project No.: } 32138 & \text { Date: } 05 / 02 / 2017\end{array}$

Figure 19. Mid-span deflection at maximum load (um), mean $=-0.4251$, standard deviation $=$ 0.052 .

Figure 20. Density $\left(\mathrm{g} / \mathrm{cm}^{\wedge} 3\right)$, mean $=1.8374$, standard deviation $=0.0065$. .23

Figure 21. Flexural vibration mode Young's modulus $(\mathrm{GPa})$, mean $=10.8$, standard deviation $=0.58$

Figure 22. Torsional vibration mode shear modulus $(\mathrm{GPa})$, mean $=4.6$, standard deviation $=$ 0.14 .

Figure 23. Minimum gauge diameter $(\mathrm{mm})$, mean $=9.527$, standard deviation $=0.0058 \ldots \ldots . .25$

Figure 24. Maximum load $(\mathrm{N})$, mean $=1,309.6$, standard deviation $=236.07 \ldots \ldots \ldots \ldots \ldots \ldots \ldots \ldots \ldots \ldots \ldots$

Figure 25. Stress at break $(\mathrm{MPa})$, mean $=18.3$, standard deviation $=3.31 \ldots \ldots \ldots \ldots \ldots \ldots \ldots \ldots \ldots \ldots \ldots \ldots \ldots . .26$

Figure 26. Average strain at break $(\%)$, mean $=0.28$, standard deviation $=0.06 \ldots \ldots \ldots \ldots \ldots \ldots . .27$

Figure 27. Unstressed specimen remnants from tensile specimens are re-machined into

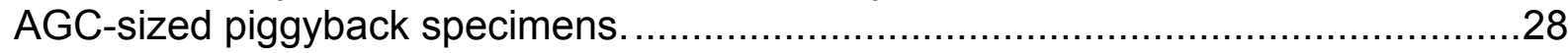

Figure 28. Splitting disc tensile strength $(\mathrm{MPa})$, mean $=17.3$, standard deviation $=1.17 \ldots \ldots .29$

Figure 29. Split disc compressive load at max load $(\mathrm{N})$, mean $=2,355.8$, standard deviation $=159.9$.

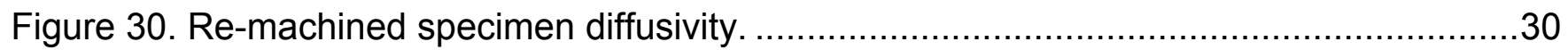

Figure A-1. Average length $(\mathrm{mm})$, mean $=25.393$, standard deviation $=0.0060 \ldots \ldots \ldots \ldots \ldots \ldots \ldots$

Figure A-2. Average diameter $(\mathrm{mm})$, mean $=12.702$, standard deviation $=0.0043 \ldots \ldots \ldots \ldots \ldots . .1$

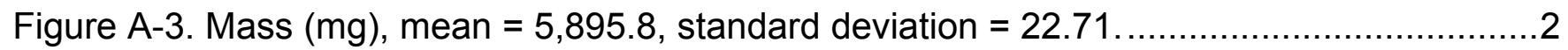

Figure A-4. Volume $\left(\mathrm{mm}^{\wedge} 3\right)$, mean $=3,217.6$, standard deviation $=2.16 \ldots \ldots \ldots \ldots \ldots \ldots \ldots \ldots \ldots . . .2$

Figure A-5. Mid-span deflection at maximum load (um), mean $=-0.7208$, standard deviation $=0.0661$.

Figure A-6. Elapsed time at maximum load $(\mathrm{sec})$, mean $=92.3$, standard deviation $=8.45 \ldots \ldots .3$

Figure B-1. Elapsed time at maximum load $(\mathrm{sec})$, mean $=39.8$, standard deviation $=4.84 \ldots \ldots .1$

Figure B-2. Average width $(\mathrm{mm})$, mean $=15.882$, standard deviation $=0.0060 \ldots \ldots \ldots \ldots \ldots \ldots \ldots \ldots \ldots \ldots \ldots \ldots \ldots$

Figure B-3. Average length $(\mathrm{mm})$, mean $=79.384$, standard deviation $=0.0093 \ldots \ldots \ldots \ldots \ldots \ldots . .2$ 
Rev. 06

Title: $\quad$ Baseline Characterization Database Verification Report - PCEA Billet XPC01D3-36

$\begin{array}{lllll}\text { ECAR No.: } 3677 \quad \text { Rev. No.: } 0 & \text { Project No.: } 32138 \quad \text { Date: } 05 / 02 / 2017\end{array}$

Figure C-1. Modulus (automatic Young's) (GPa), mean $=9.4$, standard deviation $=0.52 \ldots \ldots \ldots 1$

Figure C-2. Ultimate tensile strength $(\mathrm{MPa})$, mean $=18.4$, standard deviation $=3.31 \ldots \ldots \ldots \ldots 1$

Figure C-3. Load at break $(\mathrm{N})$, mean $=1,308.6$, standard deviation $=235.65 \ldots \ldots \ldots \ldots \ldots \ldots \ldots \ldots \ldots \ldots \ldots \ldots \ldots \ldots \ldots$

Figure C-4. Strain 1 at break $(\mathrm{mm} / \mathrm{mm})$, mean $=0.0028$, standard deviation $=0.0006 \ldots \ldots \ldots \ldots .2$

Figure C-5. Strain 2 at break $(\mathrm{mm} / \mathrm{mm})$, mean $=0.0029$, standard deviation $=0.0006 \ldots \ldots \ldots . .3$

Figure C-6. Split disc extension $(\mathrm{mm})$, mean $=1.1197$, standard deviation $=0.0357 \ldots \ldots \ldots \ldots . .3$

Figure C-7. Split disc deflection $(\mathrm{mm})$, mean $=-0.3445$, standard deviation $=0.0349 . \ldots \ldots \ldots . .4$ 
Rev. 06

Title: $\quad$ Baseline Characterization Database Verification Report - PCEA Billet XPC01D3-36

ECAR No.: 3677

Rev. No.: 0

Project No:

32138

Date: $05 / 02 / 2017$

PROJECT ROLES AND RESPONSIBILITIES

\begin{tabular}{|c|c|c|c|}
\hline Project Role & Name (Typed) & Organization & Pages covered (if applicable) \\
\hline Performer & David Rohrbaugh & D520 & All \\
\hline Checker $^{\mathrm{a}}$ & W. David Swank & B120 & All \\
\hline Independent Reviewer ${ }^{b}$ & NA & & \\
\hline CUI Reviewer ${ }^{\mathrm{c}}$ & NA & & All \\
\hline Manager $^{d}$ & Scott McBride & D520 & All \\
\hline Requestor ${ }^{\mathrm{e}}$ & William Windes & B120 & All \\
\hline Nuclear Safety & NA & & \\
\hline Document Owner ${ }^{\mathrm{e}}$ & William Windes & B120 & All \\
\hline Quality Assurance & Michelle Sharp & H330 & All \\
\hline
\end{tabular}
a. Confirmation of completeness, mathematical accuracy, and correctness of data and appropriateness of assumptions.
b. Concurrence of method or approach. See definition in LWP-10106.
c. Concurrence with the document's markings in accordance with LWP-11202.
d. Concurrence of procedure compliance. Concurrence with method/approach and conclusion.
e. Concurrence with the document's assumptions and input information. See definition of acceptance in LWP-10200.

NOTE: $\quad$ Delete or mark "NA" for project roles not engaged. Include ALL personnel and their roles listed above in the eCR system. The list of the roles above is not all inclusive. If needed, the list can be extended or reduced. 
TEM-10200-1

$03 / 01 / 2012$

ENGINEERING CALCULATIONS AND ANALYSIS

Page 8 of 32

Rev. 06

Title:

Baseline Characterization Database Verification Report - PCEA Billet XPC01D3-36

ECAR No.: 3677

Rev. No.: 0

Project No:

32138

Date: $05 / 02 / 2017$

\section{SCOPE AND BRIEF DESCRIPTION}

This engineering calculations and analysis report is a validity evaluation of the physical and mechanical property databases collected on a billet of nuclear grade graphite (i.e., PCEA Billet XPC01D3-36) in support of the Advanced Reactor Technologies Baseline Graphite Characterization Program. ${ }^{1,2}$ Millions of raw data points that have been collected during testing and quantification analyses for these billets, the summary scalar property values and supplementary traceability data are collected into comprehensive spreadsheets. Data sets are comprised of single billets of graphite for any given grade, organized by mechanical test specimen type and further subdivided into individual spreadsheet tabs according to the specific test or evaluation being performed.

This report is not a direct analysis of properties and will not provide information on the validity or performance characteristics of the graphite itself. Rather, it is intended as a verification of the completeness of actual data collected in accordance with PLN-3467, "Baseline Graphite Characterization Plan: Electromechanical Testing," and its representation of the measurement and test results with sole regard to the graphite billets under evaluation.

\section{DESIGN OR TECHNICAL PARAMETER INPUT AND SOURCES}

Mechanical and physical property testing is carried out in accordance with PLN-3348, "Graphite Mechanical Testing," PLN-3467, "Baseline Graphite Characterization Plan: Electromechanical Testing," and PLN-3267, "AGC-2 Characterization Plan."

\section{ASSUMPTIONS}

None.

\section{COMPUTER CODE VALIDATION}

Data collection and storage is organized as reported in PLN-3467 and Idaho National Laboratory (INL)/EXT-10-19910, ${ }^{5}$ Baseline Graphite Characterization: First Billet. Individual computers being used run Windows XP operating systems and store data on Microsoft Office Excel 2007 spreadsheets.

Control of individual test equipment is carried out by proprietary Netzsch software (IRC C-20) or Instron's Bluehill (Version 2) software (load frames in IRC B-11). Both software suites are commercially available packages. Updates and data transfers/integration are handled outside of INL's network system on a dedicated local area network.

The comprehensive interface between data collection, evaluation, and storage computers is handled through the customized LabVIEW-based Graphite Mechanical Properties Data Acquisition Software (Version 4.0). The Baseline Graphite Characterization Program's version control and operability checks are documented and validated in a registered laboratory notebook, LAB 2143, "Baseline Graphite Characterization." All pertinent lifecycle documentation is recorded in accordance with LWP-20000-01, "Conduct of Research Plan." Validation of commercial packages is handled via integrated system checks specific to each new element or upgrade as appropriate. 
TEM-10200-1

$03 / 01 / 2012$

ENGINEERING CALCULATIONS AND ANALYSIS

Page 9 of 32

Rev. 06

Title:

Baseline Characterization Database Verification Report - PCEA Billet XPC01D3-36

ECAR No.: 3677

Rev. No.: 0

Project No.:

32138

Date: $05 / 02 / 2017$

\section{DISCUSSIONIANALYSIS}

\section{Introduction}

The Advanced Reactor Technologies Project Graphite Research and Development Program is generating the extensive amount of quantitative data necessary for predicting the behavior and operating performance of the available nuclear graphite grades. To determine in-service behavior of graphite for the latest proposed designs, two main programs are underway. The first, the Advanced Graphite Creep (AGC) Program, provides a set of tests that are designed to evaluate the irradiated properties and behavior of nuclear-grade graphite over a large spectrum of conditions based on the operating environment of the very high-temperature reactor core. ${ }^{1} \mathrm{~A}$ limited amount of data can be generated on irradiated material because of the limited availability of space within the Advanced Test Reactor and the geometric constraints placed on the AGC specimens that will be inserted. To supplement the AGC data set, the Baseline Graphite Characterization Program provides additional data that will characterize inherent property variability in nuclear-grade graphite without the testing constraints of the AGC Program. ${ }^{2}$ This variability in properties is a natural artifact of graphite due to the geologic raw materials that are used in its production. This variability is being quantified not only within a single billet of as-produced graphite, but also from billets within a single lot, billets from different lots of the same grade, and across different billets of numerous grades of nuclear graphite that are presently available.

This particular report covers the release of physical and mechanical property data from a billet of PCEA graphite. The graphite billet, PCEA XPC01D3-36, is a block of extruded graphite with a large grain structure. The main baseline mechanical properties database for this billet, plots of which are included throughout this report, are comprised solely of scalar results from each of the different evaluations (i.e., mechanical testing and physical properties) in summary form, and consists of tabbed spreadsheets being occupied by over 44,000 cells of individual characteristic or property values and associated tagging information.

This report is intended as a validation review of the graphite billet, PCEA XPC01D3-36. It is not an analysis of property characteristics or trends beyond the evaluation necessary to determine if the collected data is reflective of the properties of this particular graphite billet. It is an acceptance of the test methods used, data calculations and conversions being carried out, and review of values from the standpoint of determining whether or not they reflect anomalous behavior that must be further investigated.

Ultimately, this report provides justification for transfer of this data set into a storage and analysis system that is available for internal and external analysts to utilize in evaluating the relevant characteristics and performance of nuclear-grade graphite.

\section{Database Analysis}

The multitude of data sets being generated for the Baseline Graphite Characterization Program consist of properties collected on standard American Society of Testing and Materials (ASTM) Internationalbased mechanical test specimens as shown in Figure 1. Details of specimen tracking, traceability, process flow, and the techniques being employed to facilitate those activities is provided in detail in INL/EXT-10-19910 . For ease of reviewing the applicable data in this report, an example of a sectioning 
TEM-10200-1

$03 / 01 / 2012$

ENGINEERING CALCULATIONS AND ANALYSIS

Page 10 of 32

Rev. 06

Title: $\quad$ Baseline Characterization Database Verification Report - PCEA Billet XPC01D3-36

ECAR No.: 3677

Rev. No.: $0 \quad$ Project No.: 32138

Date: $05 / 02 / 2017$

diagram for PCEA graphite, along with the applicable specimen identification codes, is provided in Figure 2. This figure is representative of a single sub-wedge of graphite from this billet.

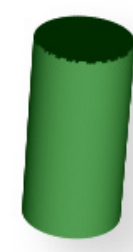

Compressive Specimen

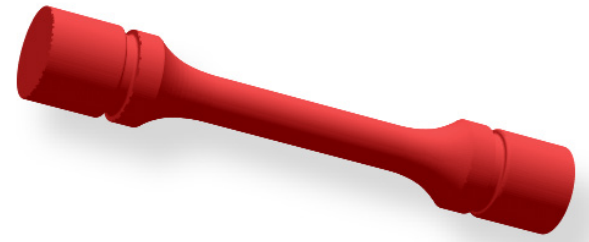

Tensile Specimen

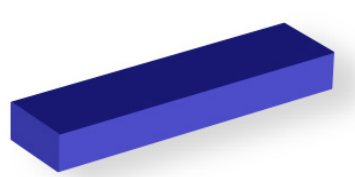

Flexural

Specimen

Figure 1. The three types of mechanical test specimens that will be machined from stock graphite and provide the basis for material property evaluations.

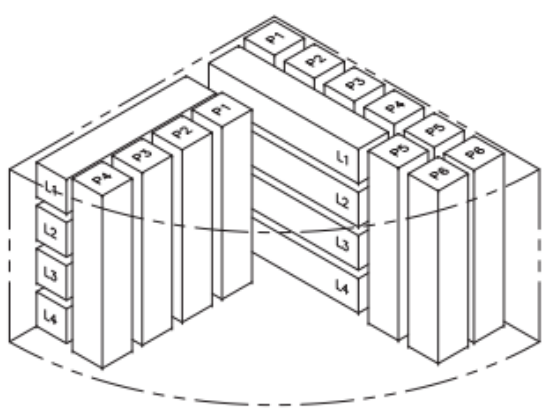

$\frac{\text { ISOMETRIC VIEW }}{\text { (SUB WEDGE "A" AND "C" }}$

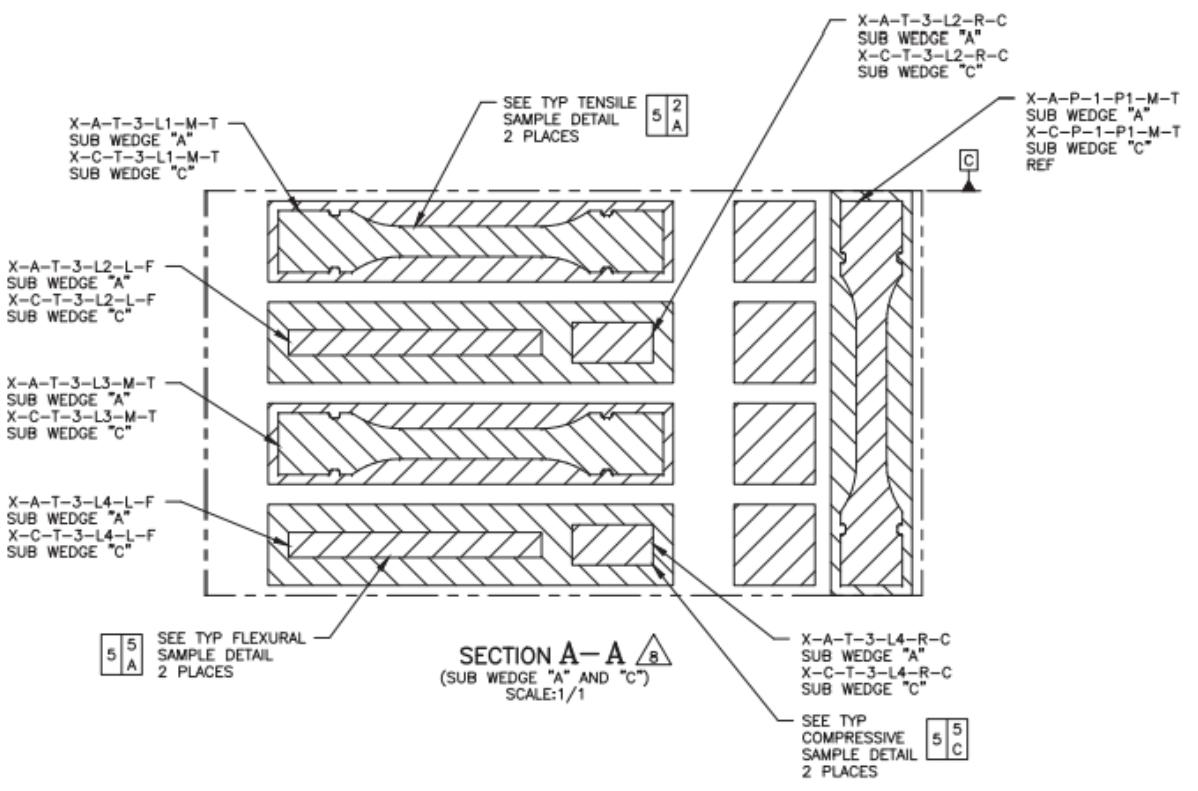

Figure 2. Individual specimen extraction and tracking identification from PCEA XPC01D3--36. 
TEM-10200-1

$03 / 01 / 2012$

ENGINEERING CALCULATIONS AND ANALYSIS

Page 11 of 32

Rev. 06

Title:

Baseline Characterization Database Verification Report - PCEA Billet XPC01D3-36

ECAR No.: 3677

Rev. No.: 0

Project No.:

32138

Date: $05 / 02 / 2017$

Sections of this report cover each of the individual databases for this billet, are divided by mechanical test specimen type (i.e., compressive, flexural, and tensile), and are organized so they present data in graphical form. The graphic representations are not sorted in any way aside from the actual order in which they were tested, which was randomized for the express purpose of minimizing test anomalies based on actual test timeframes. Some expectation of variation in the property values exists, but individual data points that fall within a reasonable property value range are considered acceptable. Comparisons of extreme values with other associated properties (e.g., a comparison of maximum tensile load values with measured strain to determine whether they are related by the expected elastic modulus) are carried out where applicable. Each of these comparisons and analyses may not be explicitly included in the text of this report, but the process control charts with standard deviation values and/or property trend charts for the various characteristics being measured are included $( \pm 1,2$, and 3 standard deviations are represented by the yellow, orange, and red dotted lines and the mean is represented by the green line).

One of the clear goals of the Baseline Graphite Characterization Program is to identify and quantify inter-billet variation, so it seems counterintuitive to verify data by making a property comparison using appropriate graphic representations to ensure there is limited variation in the reported values. The focus of this analysis, however, is to compare values from complete data sets in order to quickly identify outlying points. One example would be a "zero" value for a specific property—quickly identifiable on a test result trend graph-providing an indication that the specific spreadsheet cell is improperly empty. Another example would be a large disparity between a limited number of points on that same test result trend graph that result from missing values in other cells (e.g., dimensional measurements from which final properties are calculated). This verification will couple those observations with a comprehensive data scan of individual points in order to determine whether the data set can be considered complete and the scalar summary points provided to the Nuclear Data Management and Analysis System are appropriately representative of the billet under evaluation.

\section{Compression Specimen Database (PCEA XPC01D3-36C)}

\section{Compression Testing}

Compression testing was performed per ASTM C695-15, ${ }^{6}$ and PLN-3467. Figure 3 shows the maximum applied load for each of the 107 compression specimens from billet XPC01D3-36. As was mentioned previously, some variation in graphite properties is expected, and this variation is reflected in the difference in test frame loading. The compressive strength values (Figure 4) correlate directly with the recorded load values, confirming the stress calculations were performed correctly. An additional check of critical property values is the measured deflection (Figure 5) of the loading surface, or upper platen, as measured by a calibrated deflectometer. Within geometric variations, the deflection should reflect the calculated compressive strain as shown in Figure 6. 
TEM-10200-1

$03 / 01 / 2012$

ENGINEERING CALCULATIONS AND ANALYSIS

Page 12 of 32

Rev. 06

Title: $\quad$ Baseline Characterization Database Verification Report - PCEA Billet XPC01D3-36

ECAR No.: 3677

Rev. No.: 0

Project No.:

32138

Date: $05 / 02 / 2017$

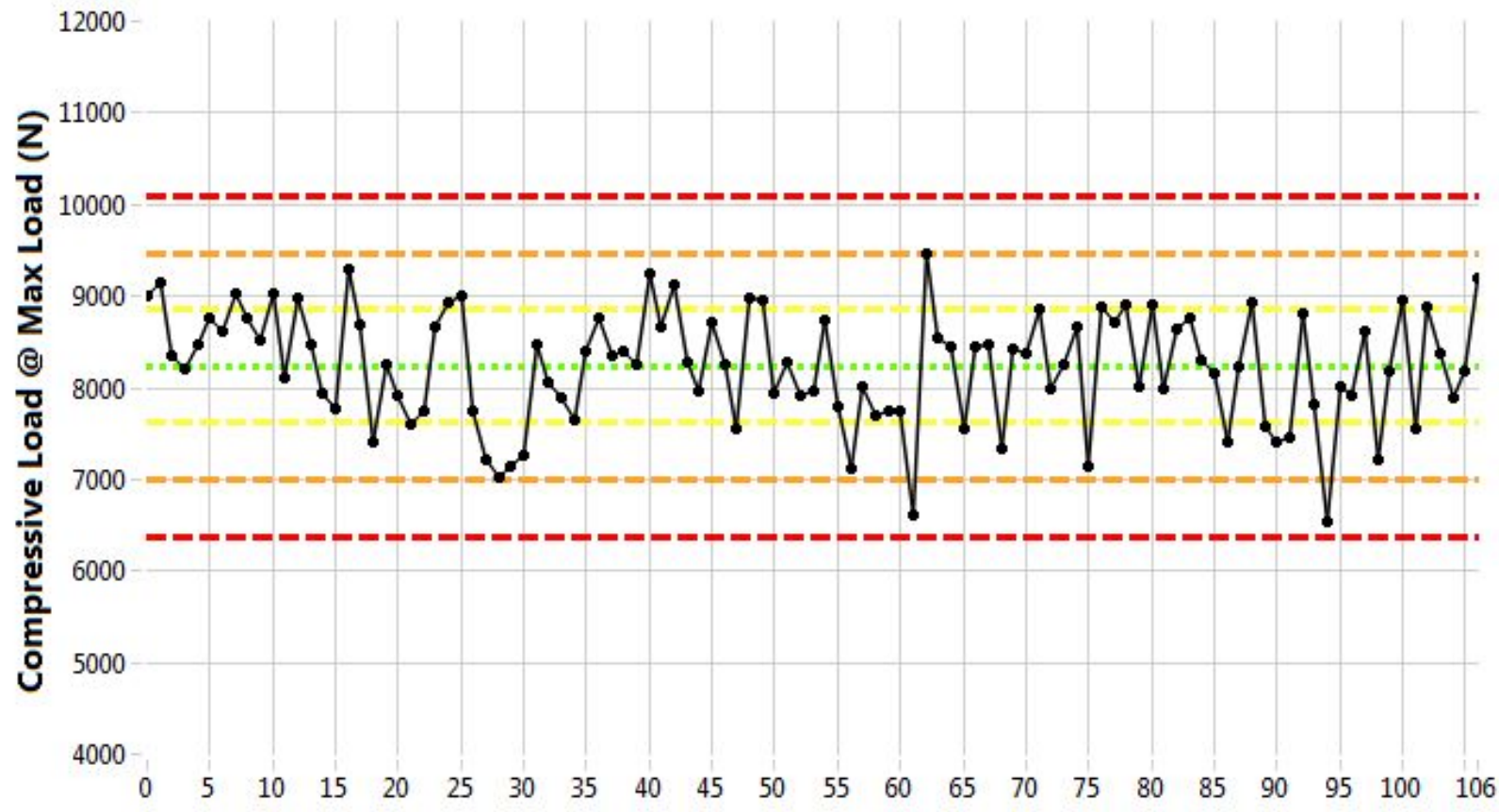

Figure 3. Compressive load at maximum load $(\mathrm{N})$, mean $=8,233.1$, standard deviation $=619.31$.

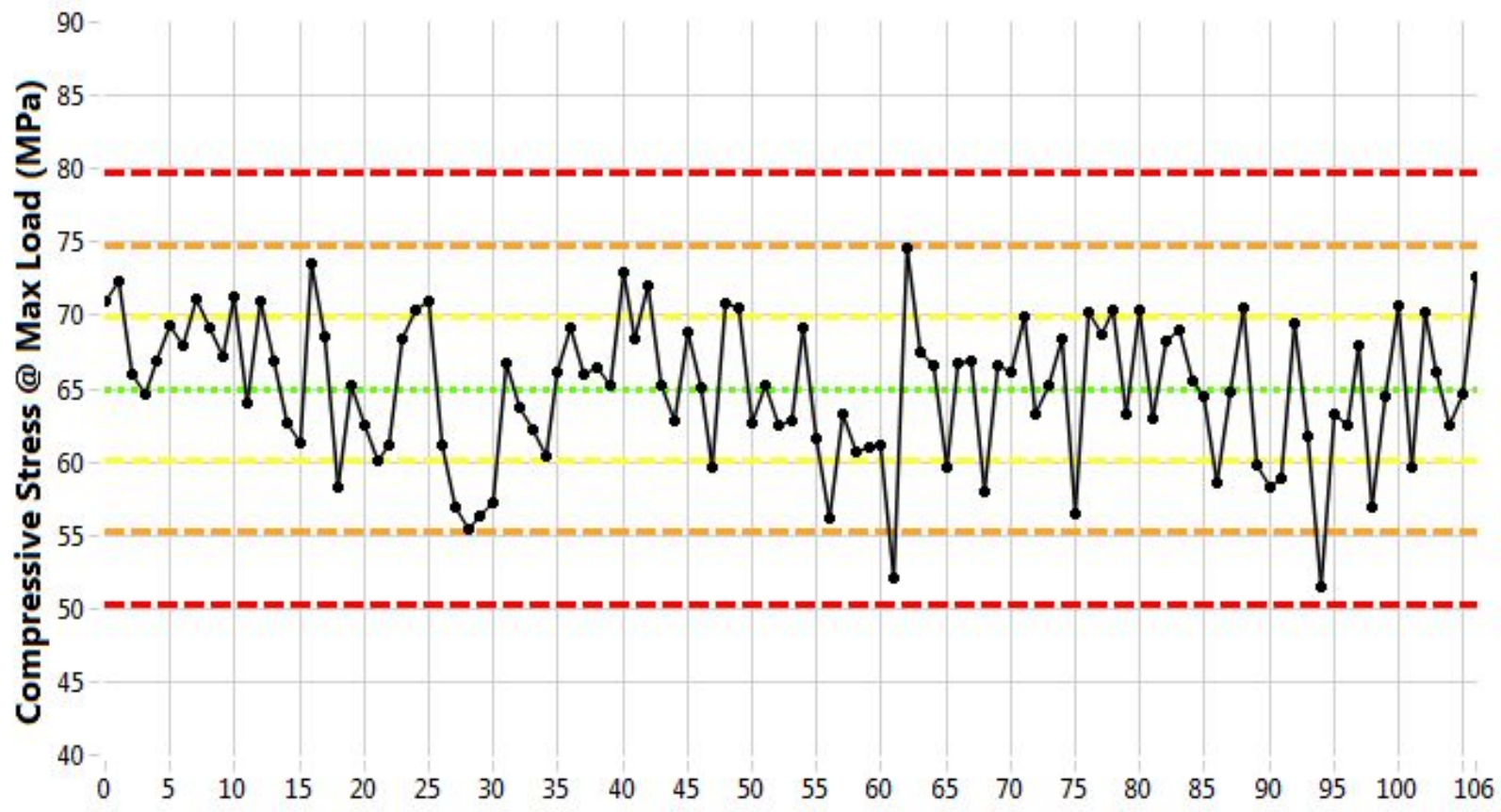

Figure 4.Compressive stress at maximum load $(\mathrm{MPa})$, mean $=65.0$, standard deviation $=4.89$. 
TEM-10200-1

$03 / 01 / 2012$

ENGINEERING CALCULATIONS AND ANALYSIS

Page 13 of 32

Rev. 06

Title: $\quad$ Baseline Characterization Database Verification Report - PCEA Billet XPC01D3-36

ECAR No.: 3677

Rev. No.: 0

Project No.: $\quad 32138$

Date: $05 / 02 / 2017$

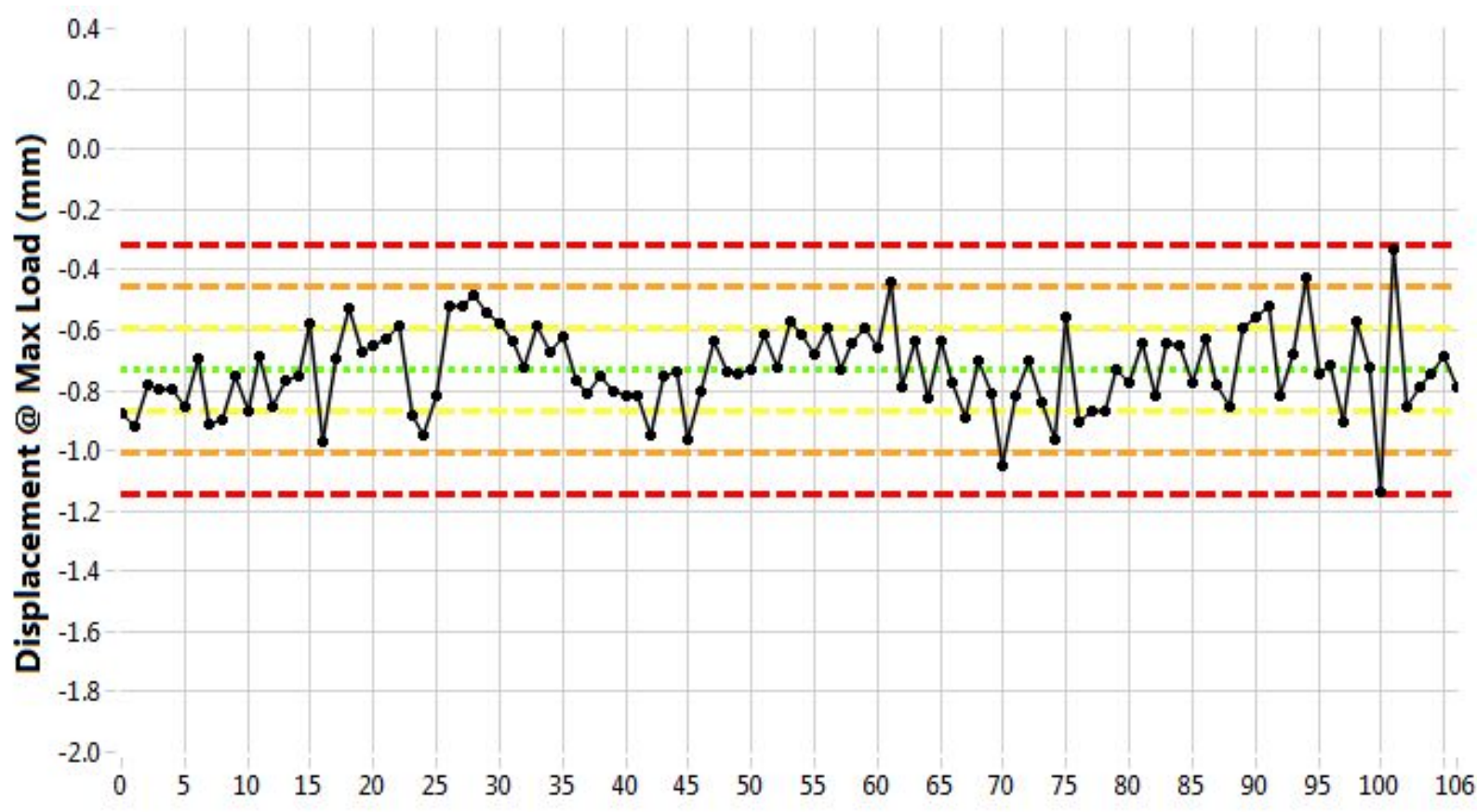

Figure 5. Displacement at maximum load $(\mathrm{mm})$, mean $=-0.7320$, standard deviation $=0.1378$.

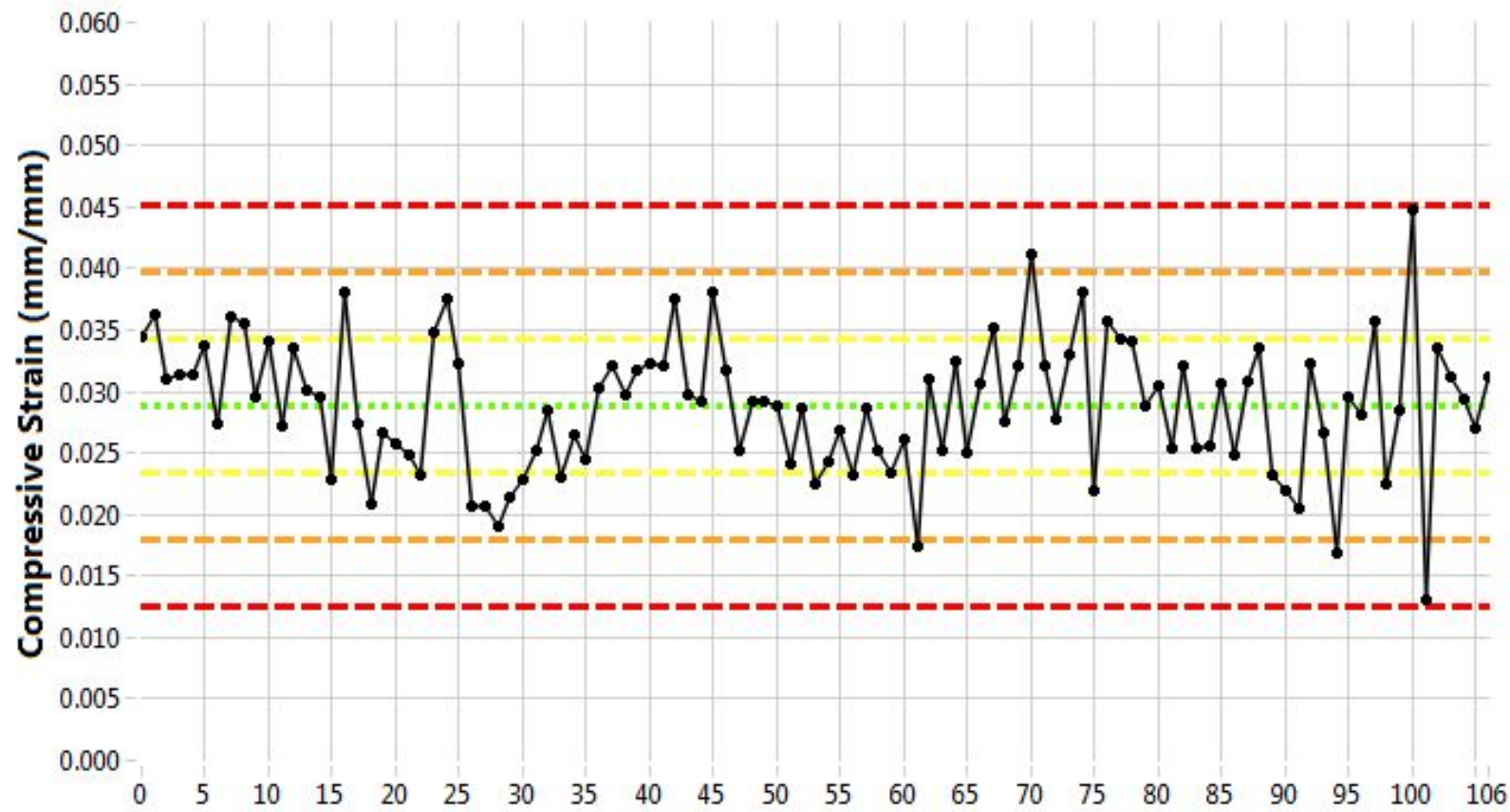

Figure 6. Compressive strain $(\mathrm{mm} / \mathrm{mm})$, mean $=0.0288$, standard deviation $=0.0054$. 
Rev. 06

Title: $\quad$ Baseline Characterization Database Verification Report - PCEA Billet XPC01D3-36

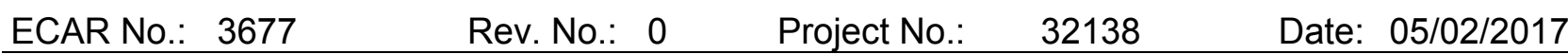

\section{Fracture Surface Categorization}

Resulting fracture surfaces from compressive specimens offer an additional opportunity to collect scalar data that can be sorted with respect to graphite type and position. To allow for consistency in what is essentially a qualitative attribute, a description of each of the fracture types is provided to the user of the Graphite Mechanical Properties Data Acquisition Software. A screen shot of this categorization, along with distribution of recorded fracture categories for each of the 107 compressive specimens from PCEA XPC01D3-36 (with no anomalous values indicative of an unallowable characterization), is provided in Figure 7.
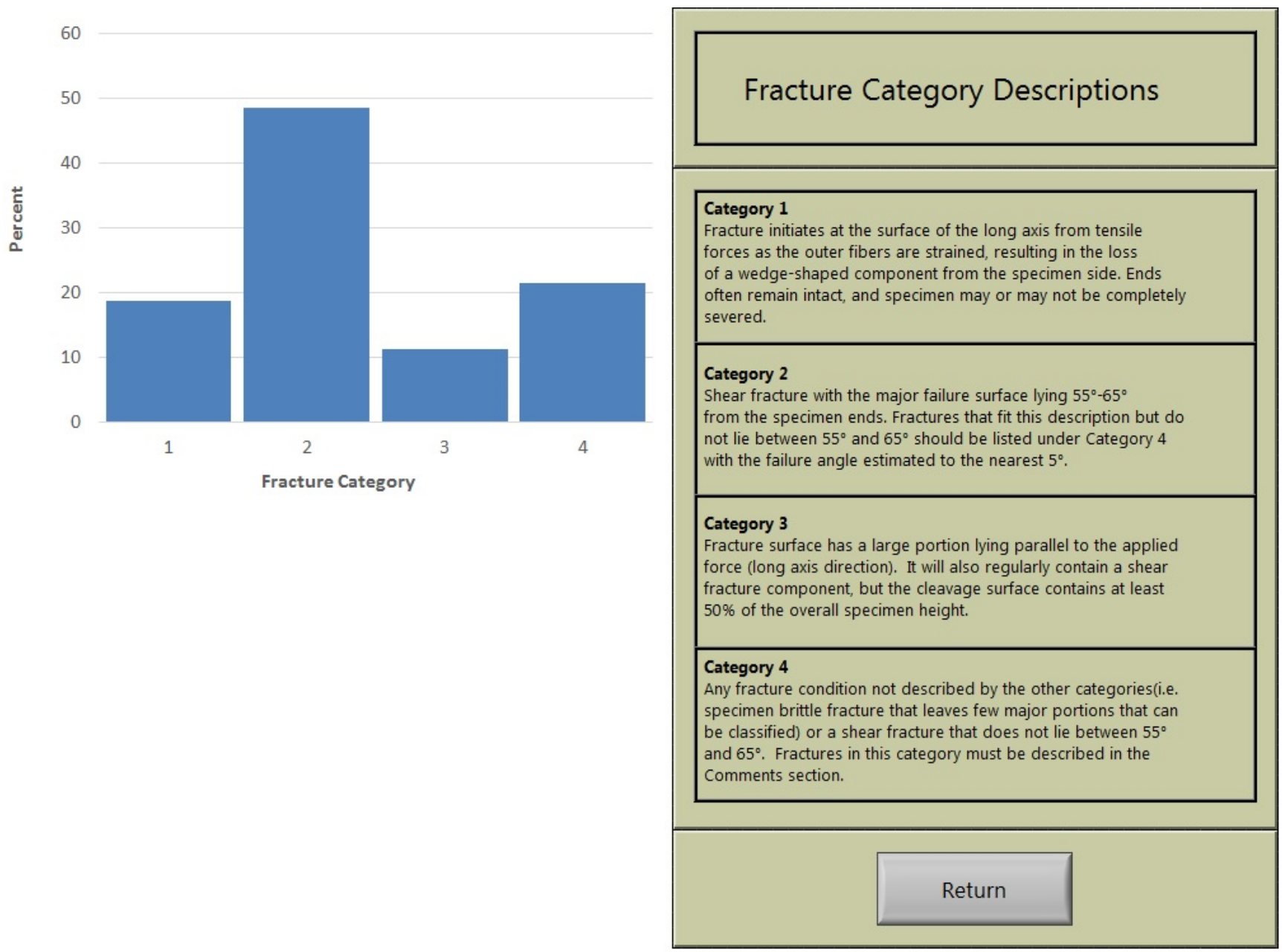

Figure 7. Fracture categorization results and description. 
TEM-10200-1

$03 / 01 / 2012$

ENGINEERING CALCULATIONS AND ANALYSIS

Page 15 of 32

Rev. 06

Title: $\quad$ Baseline Characterization Database Verification Report - PCEA Billet XPC01D3-36

ECAR No.: 3677

Rev. No.: $0 \quad$ Project No.: 32138

Date: $05 / 02 / 2017$

\section{Three-Point Bend Testing}

Forty-five of the compression specimens were held back from compression testing, specifically for three-point bend testing. These data were subsequently kept in the compression data spreadsheet file. The three-point bend test was recently adopted for evaluating carbon and graphite products under ASTM Standard D7972-14, ${ }^{16}$. The constraints prescribed by the standard are discussed in PLN-3348. Figure 8 and Figure 9 show the inverse relationship between the maximum load and maximum stress for the 45 specimens that were broken using the three-point bend method. These charts show that specimen number 34 is more than three standard deviations from the mean. However, with the amount of material variability that PCEA exhibits, these data were accepted as part of the data set.

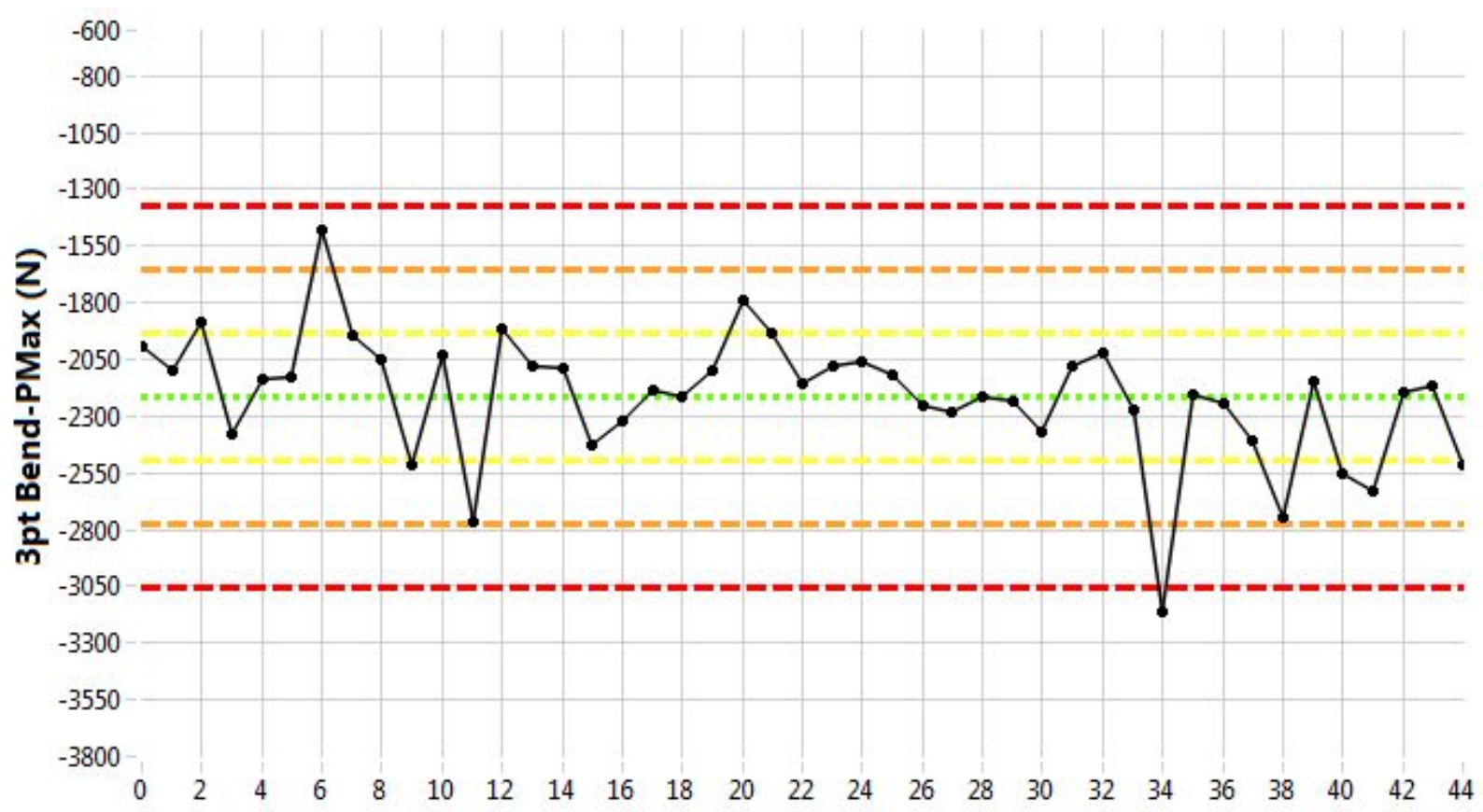

Figure 8. Maximum load $(\mathrm{N})$, mean $=-2,213.2$, standard deviation $=281.5$. 
TEM-10200-1

$03 / 01 / 2012$

ENGINEERING CALCULATIONS AND ANALYSIS

Page 16 of 32

Rev. 06

Title: $\quad$ Baseline Characterization Database Verification Report - PCEA Billet XPC01D3-36

ECAR No.: 3677

Rev. No.: 0

Project No.:

32138

Date: $05 / 02 / 2017$

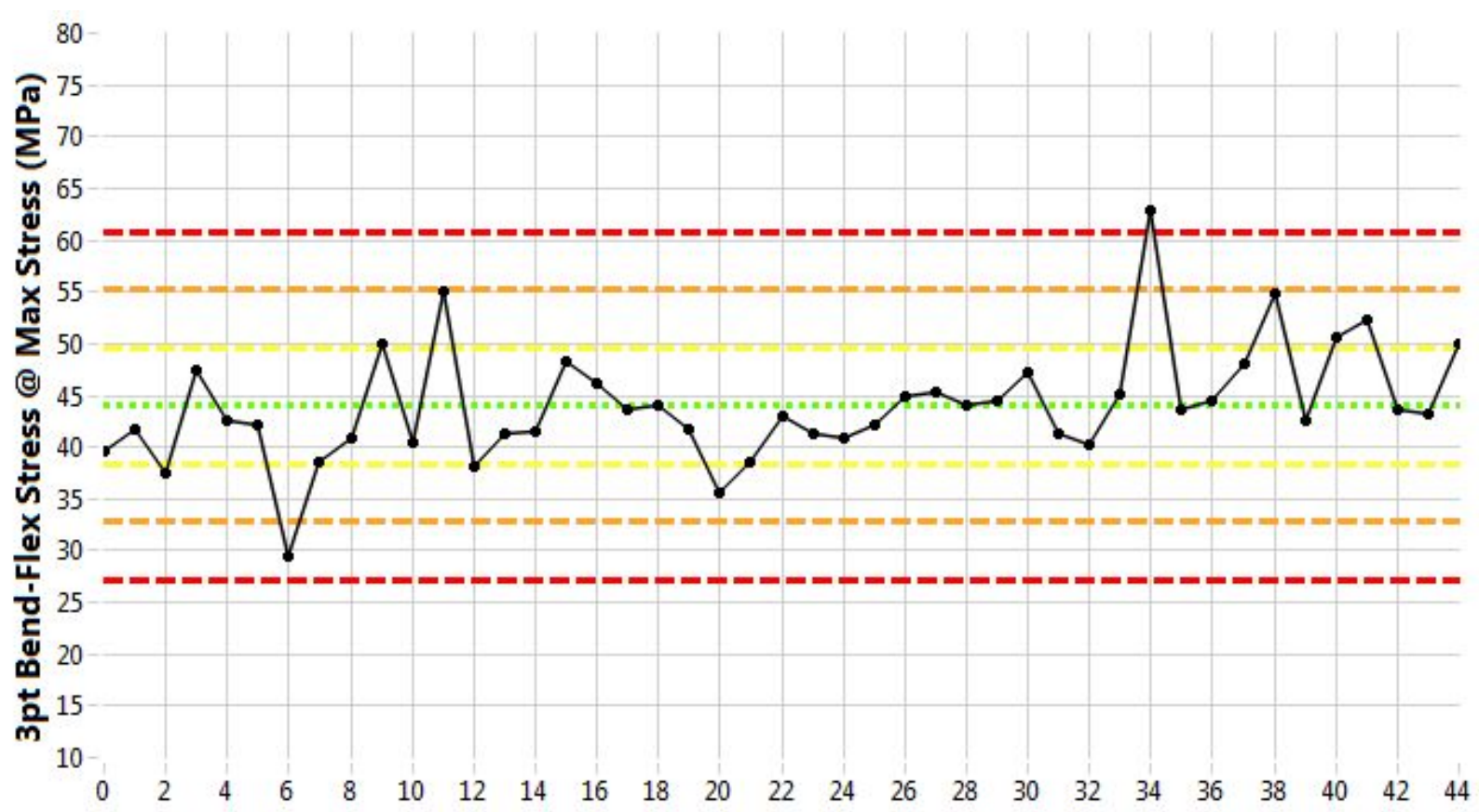

Figure 9. Maximum flexure stress $(\mathrm{MPa})$, mean $=44.0$, standard deviation $=5.6$.

\section{Electrical Resistivity, Modulus, CTE}

Electrical resistivity, Young's and shear modulus by sonic velocity, Young's modulus by sonic resonance, and coefficient of thermal expansion tests were performed on the 45 three-point bend specimens before they were broken. These tests were carried out via the appropriate ASTM standards. $^{8,10,11,12,14}$ Charts of those data are shown in Figure 10 through Figure 14. 
TEM-10200-1

$03 / 01 / 2012$

Rev. 06

Title: $\quad$ Baseline Characterization Database Verification Report - PCEA Billet XPC01D3-36

ECAR No.: 3677

Rev. No.: 0

Project No.: $\quad 32138$

Date: $05 / 02 / 2017$

10.0

9.5

9.0

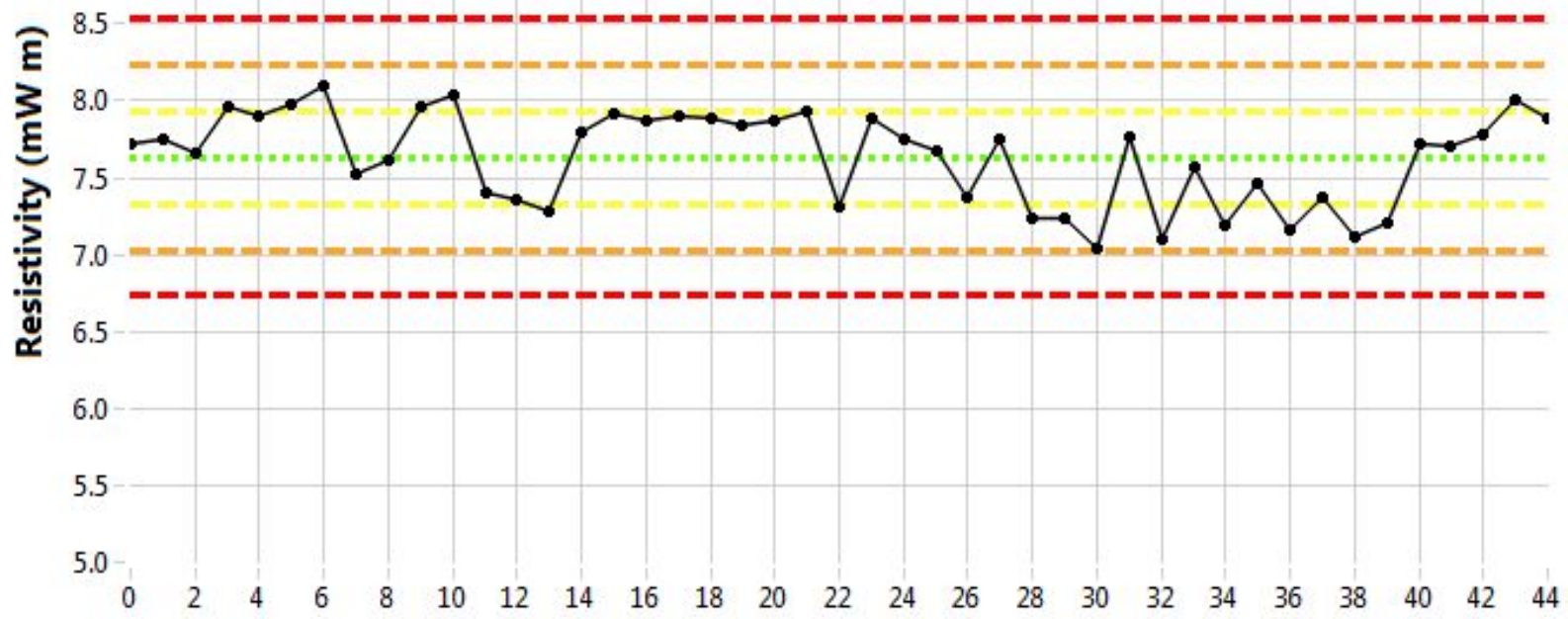

Figure 10. Electrical resistivity $(\mu \Omega-\mathrm{m})$, mean $=7.6$, standard deviation $=0.3$.

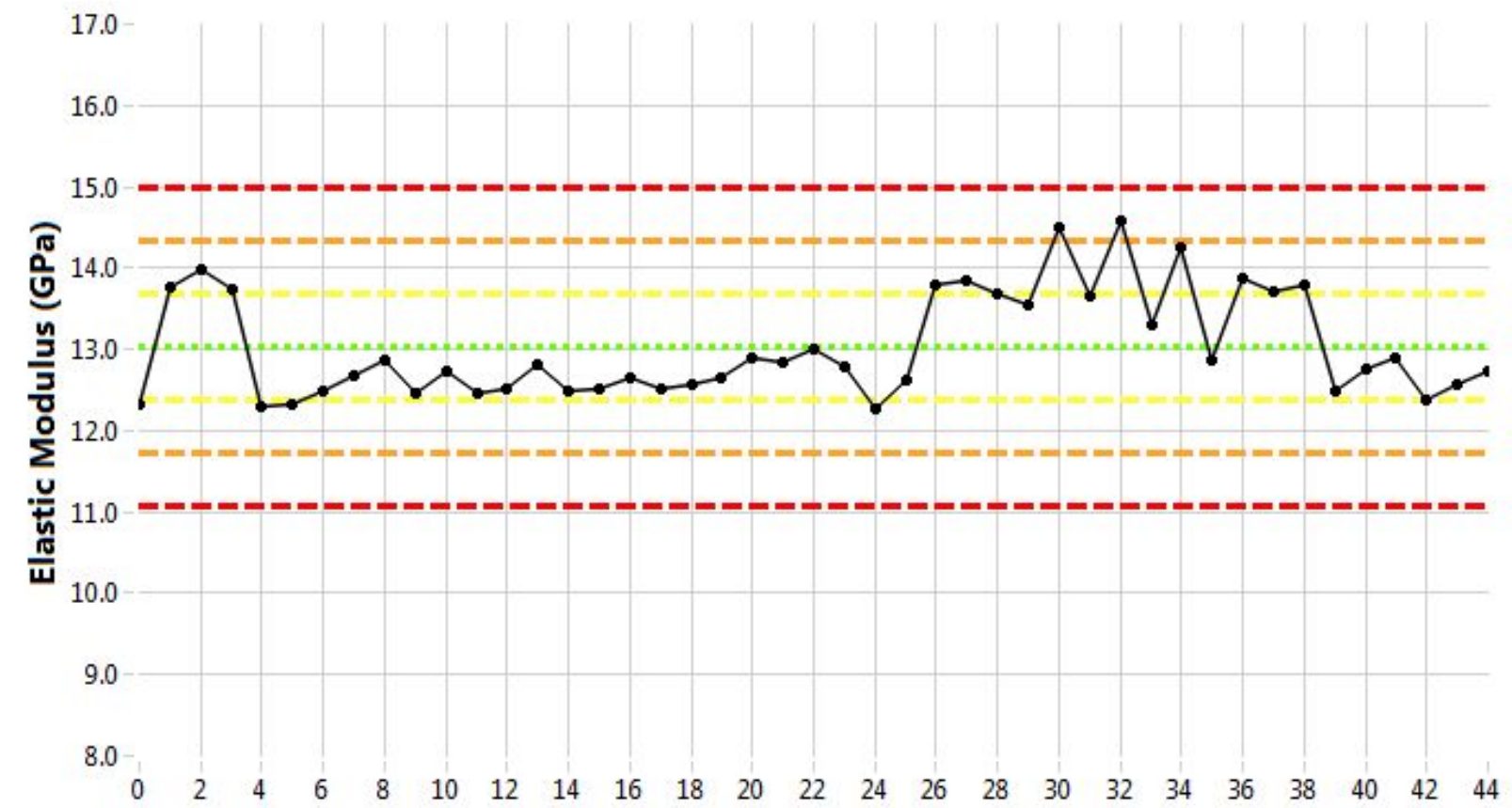

Figure 11. Young's modulus by sonic velocity method $(G P a)$, mean $=13.0$, standard deviation $=0.6$. 
TEM-10200-1

$03 / 01 / 2012$

ENGINEERING CALCULATIONS AND ANALYSIS

Page 18 of 32

Rev. 06

Title: $\quad$ Baseline Characterization Database Verification Report - PCEA Billet XPC01D3-36

ECAR No.: 3677

Rev. No.: 0

Project No.: 32138

Date: $05 / 02 / 2017$

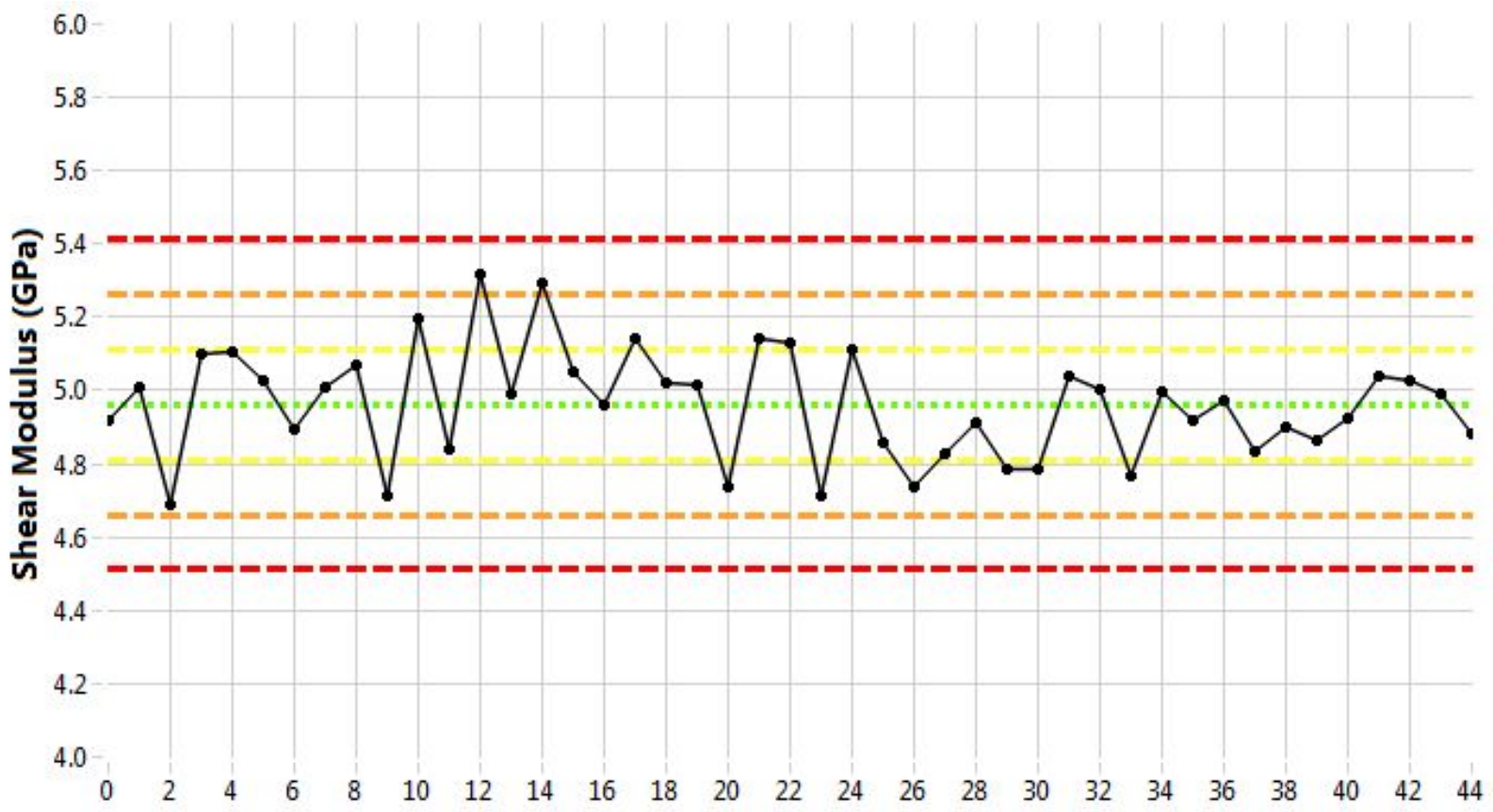

Figure 12 . Shear modulus by sonic velocity method $(\mathrm{GPa})$, mean $=5.0$, standard deviation $=0.2$.

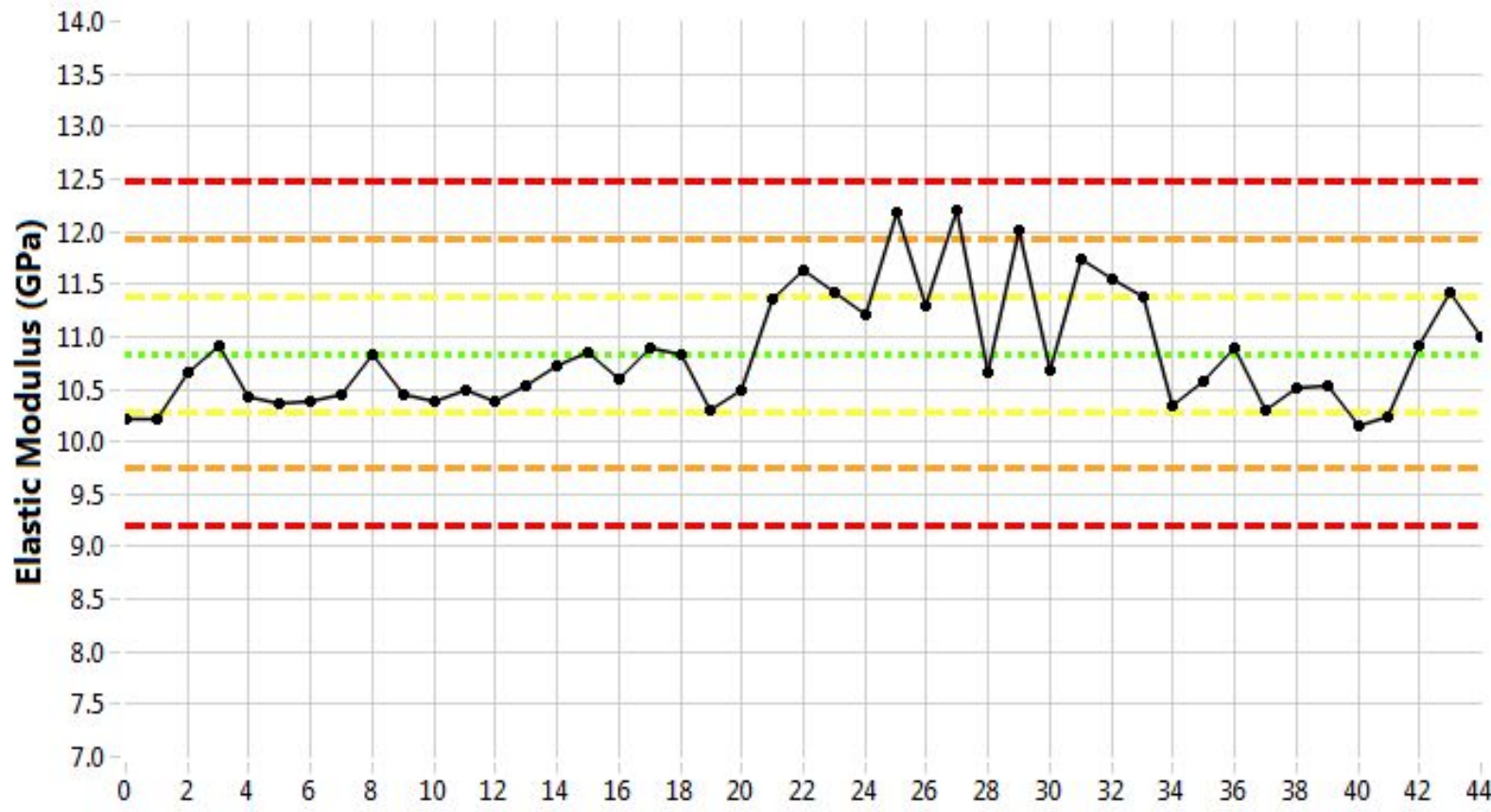

Figure 13. Young's modulus by sonic resonance method $(G P a)$, mean $=10.8$, standard deviation $=0.5$. 
TEM-10200-1

$03 / 01 / 2012$

ENGINEERING CALCULATIONS AND ANALYSIS

Page 19 of 32

Rev. 06

Title: $\quad$ Baseline Characterization Database Verification Report - PCEA Billet XPC01D3-36

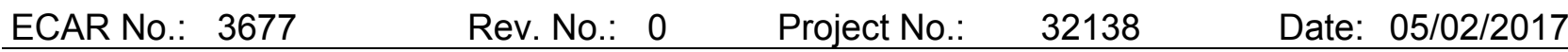

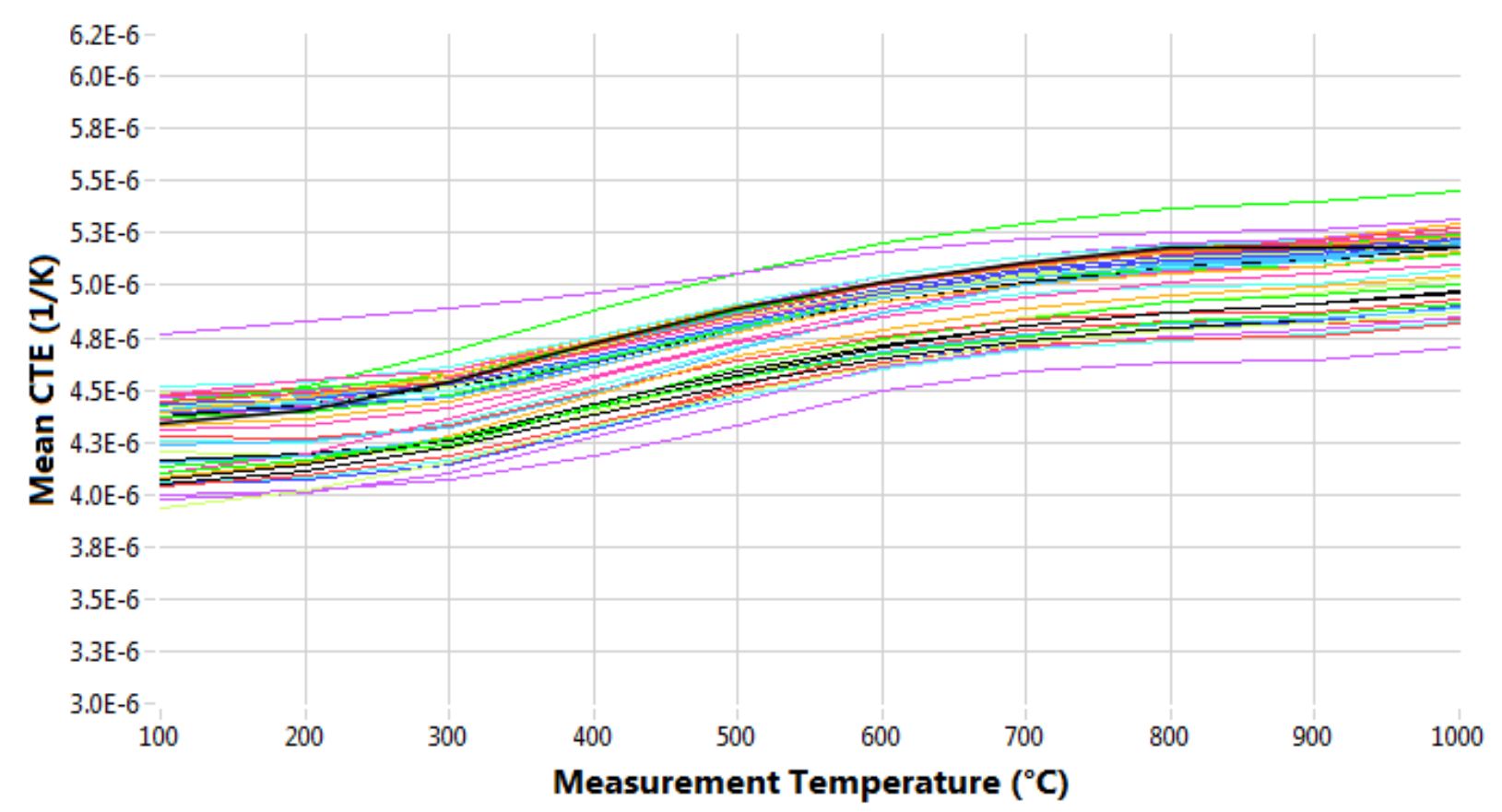

Figure 14. Mean coefficient of thermal expansion (1/K).

\section{Density Values}

The relatively simple geometric shape of the compressive specimens provides an opportunity to collect density data (per ASTM C559-90 ${ }^{7}$ ) for a large portion of the specimens extracted from each billet. While not a true performance property, density measurements are relatively straightforward to collect and are often reflective of bulk mechanical properties. The density values recorded for the compression specimens (Figure 15) show no anomalous values outside of the expected material and measurement variation. 
TEM-10200-1

$03 / 01 / 2012$

ENGINEERING CALCULATIONS AND ANALYSIS

Page 20 of 32

Rev. 06

Title: $\quad$ Baseline Characterization Database Verification Report - PCEA Billet XPC01D3-36

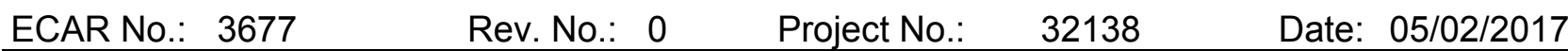

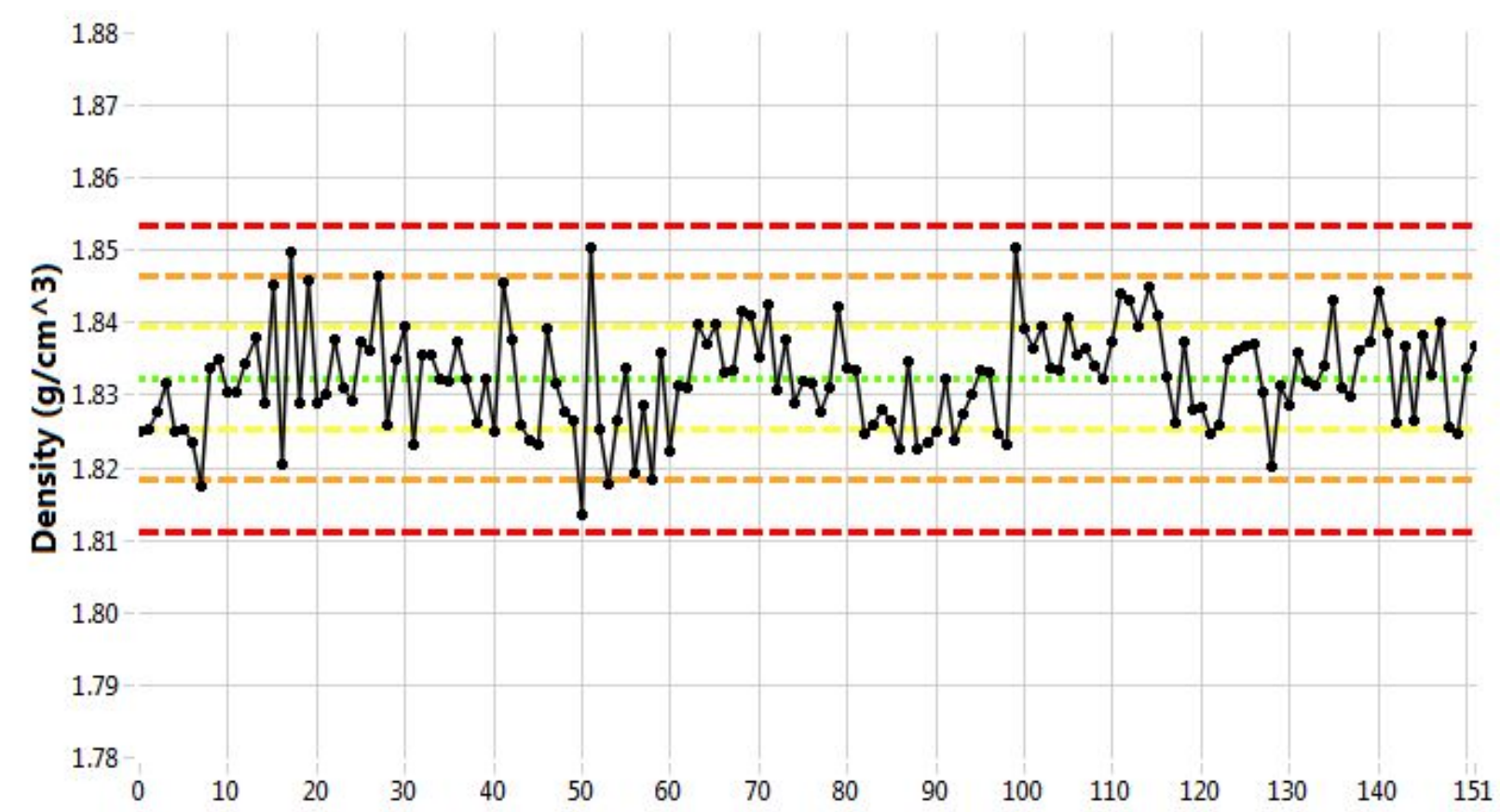

Figure 15. Density $\left(\mathrm{g} / \mathrm{cm}^{\wedge} 3\right)$, mean $=1.8324$, standard deviation $=0.0070$.

\section{Flexural Specimen Database (PCEA XPC01D3-36F)}

\section{Flexural Testing}

Flexural testing was performed per ASTM C651-91, ${ }^{9}$ with clarifications to ambiguities in the standard identified in PLN-3467. ${ }^{3}$ Similar to the presentation of the compression specimen results, test validation lies not only in the documented adherence to applicable test plans and standards, but also in the noted correlations between recorded test properties and analyses for extreme or anomalous values.

Additional verification of test conditions can be accomplished through an analysis of the physical characteristics of the specimens. Figure 16 shows the measured thicknesses for all flexural specimens tested. This plot shows eight points that lie more than three standard deviations below the sample mean. Regardless of this fact, these eight specimens all met the size requirements imposed by the ASTM standard. Moreover, their corresponding flexure test results, such as maximum load, maximum stress and deflection, all fell within a reasonable envelope. Because of this, the flexure data were deemed to be acceptable, and are included in the data set. These low thickness specimens are highlighted in the flexural test results plots in Figure 17, Figure 18, and Figure 19.

Figure 17 and Figure 18 also show the relationship between flexural load and recorded flexural stress for the 128 specimens tested in flexure from PCEA XPC01D3-36. Further comparisons and verification can be made with measured deflection (Figure 19), which will reflect an additional correlation with stress values through material elastic constants. 
TEM-10200-1

$03 / 01 / 2012$

ENGINEERING CALCULATIONS AND ANALYSIS

Page 21 of 32

Rev. 06

Title: $\quad$ Baseline Characterization Database Verification Report - PCEA Billet XPC01D3-36

ECAR No.: 3677

Rev. No.: 0

Project No.:

32138

Date: $05 / 02 / 2017$

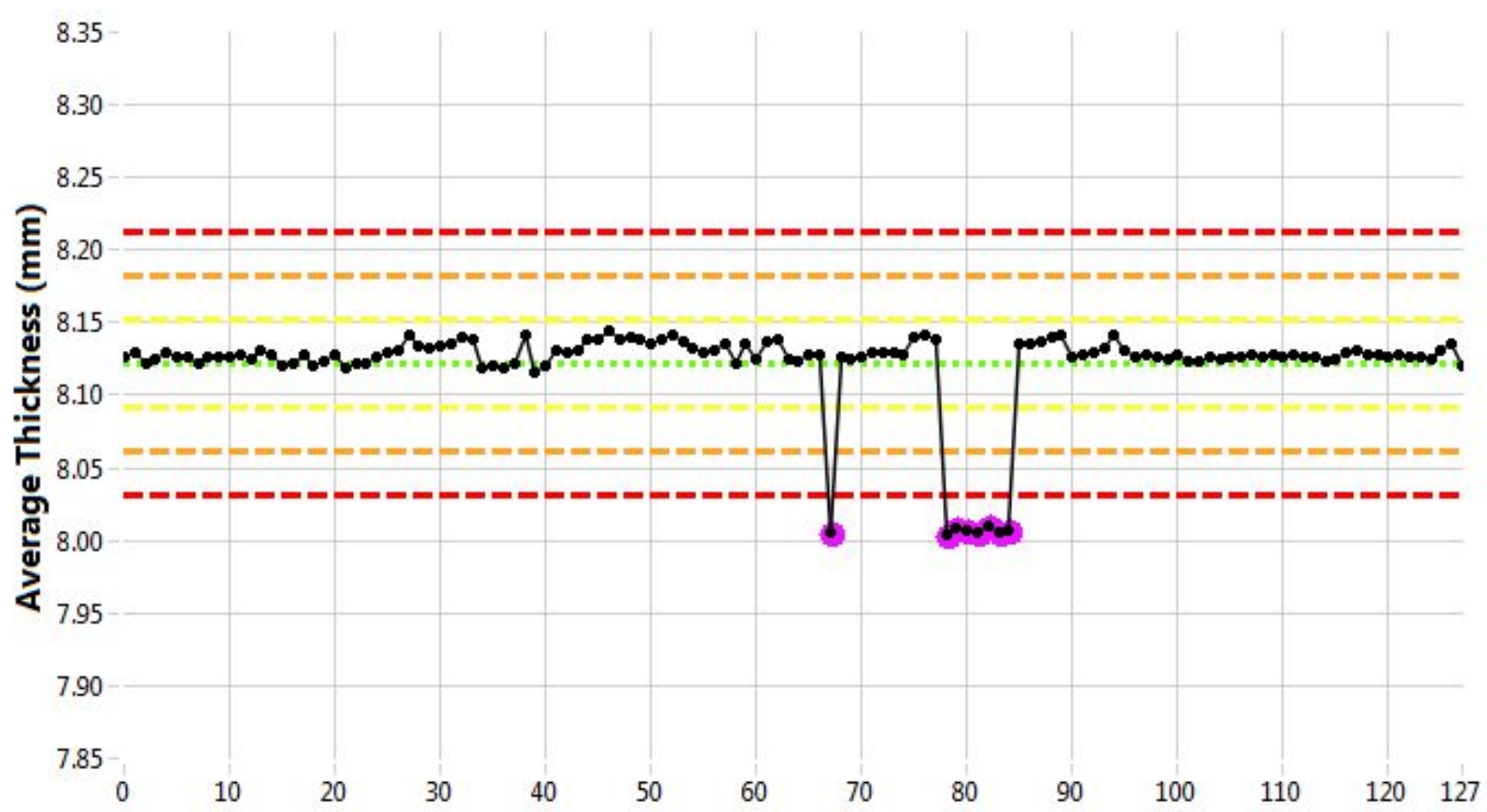

Figure 16. Average thickness $(\mathrm{mm})$, mean $=8.122$, standard deviation $=0.0304$.

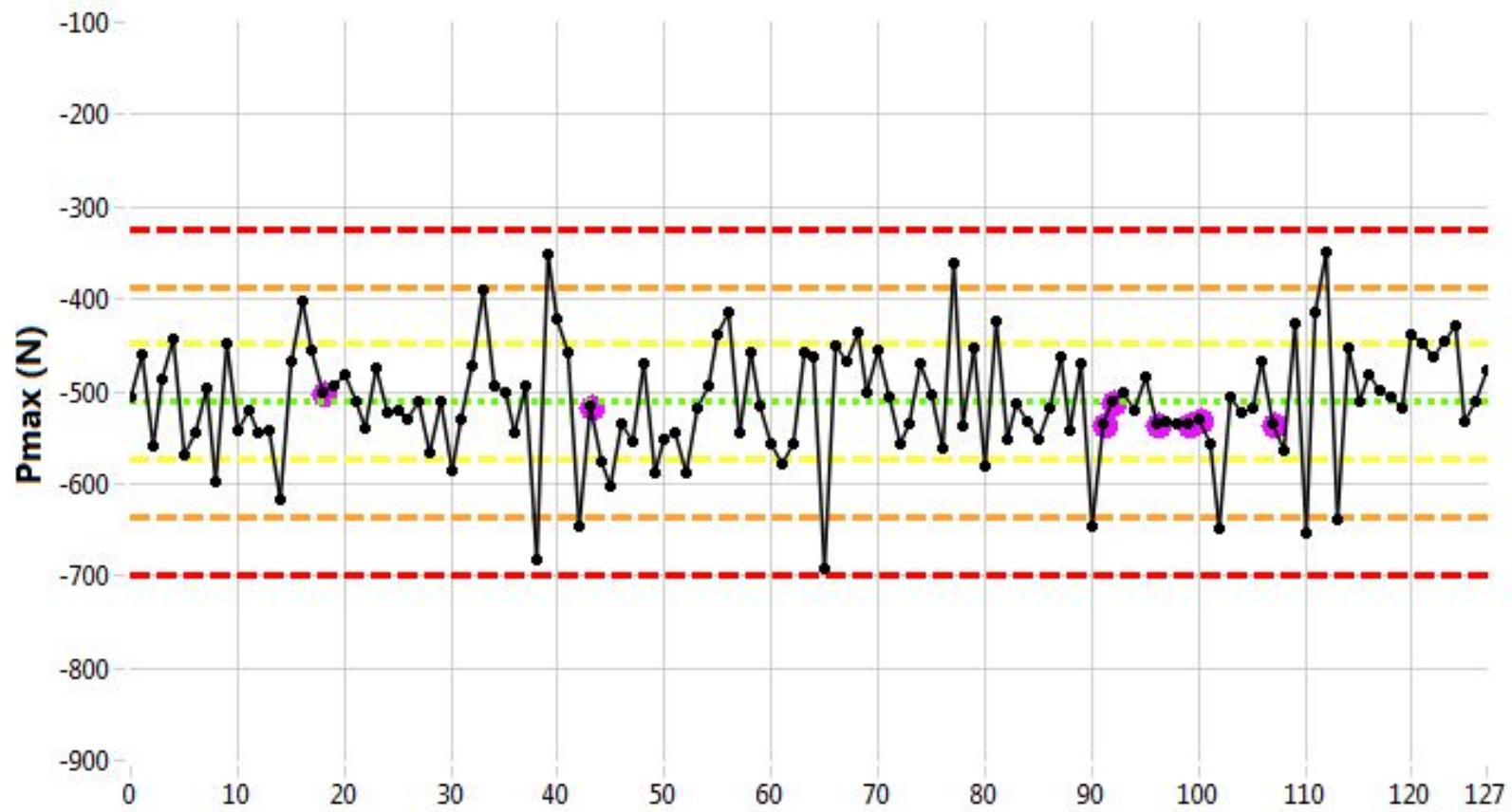

Figure 17. Maximum load $(\mathrm{N})$, mean $=-511.5$, standard deviation $=62.6$. 
TEM-10200-1

$03 / 01 / 2012$

ENGINEERING CALCULATIONS AND ANALYSIS

Page 22 of 32

Rev. 06

Title: $\quad$ Baseline Characterization Database Verification Report - PCEA Billet XPC01D3-36

ECAR No.: 3677

Rev. No.: 0

Project No.:

32138

Date: $05 / 02 / 2017$

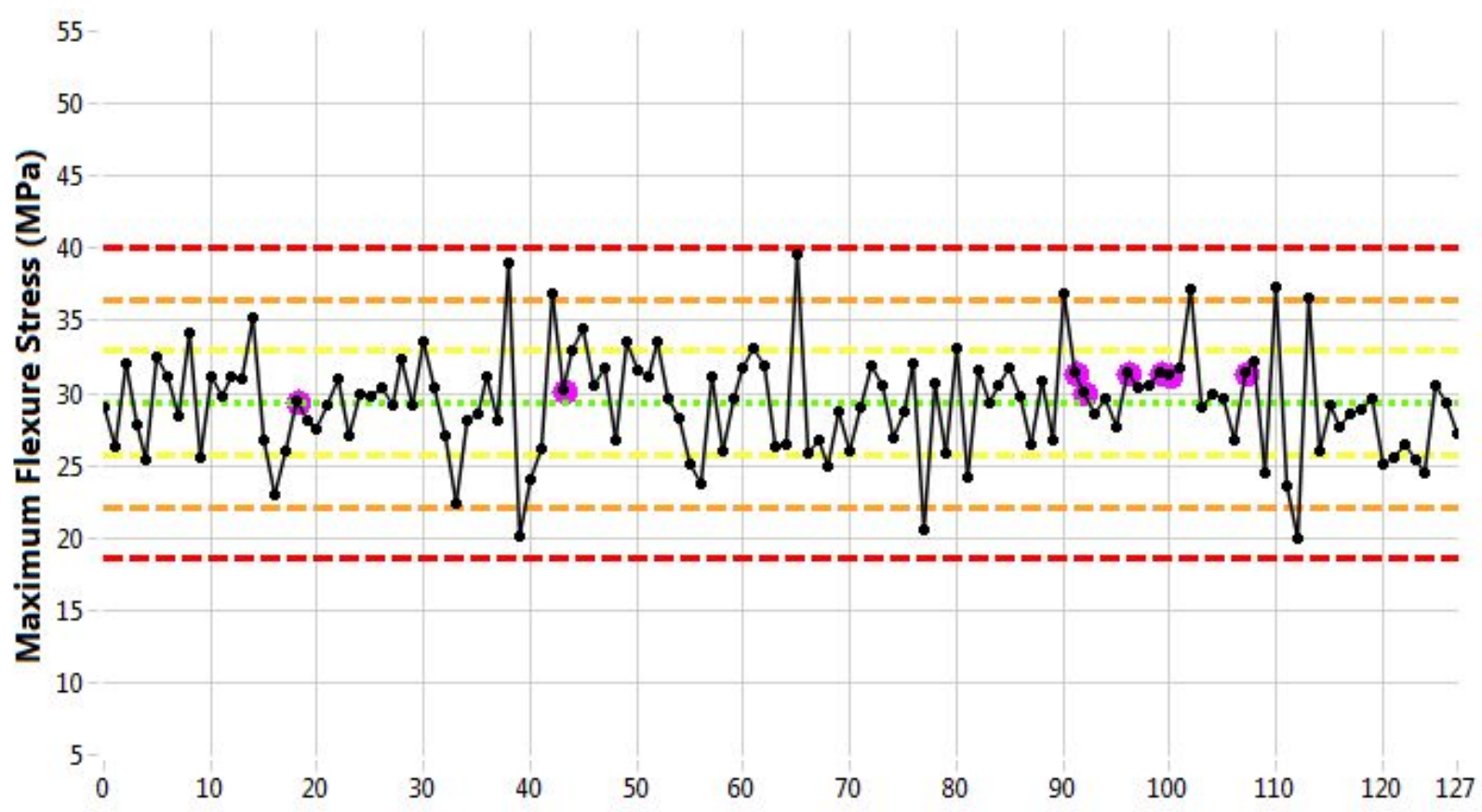

Figure 18. Maximum flexure stress $(\mathrm{MPa})$, mean $=29.3$, standard deviation $=3.6$.

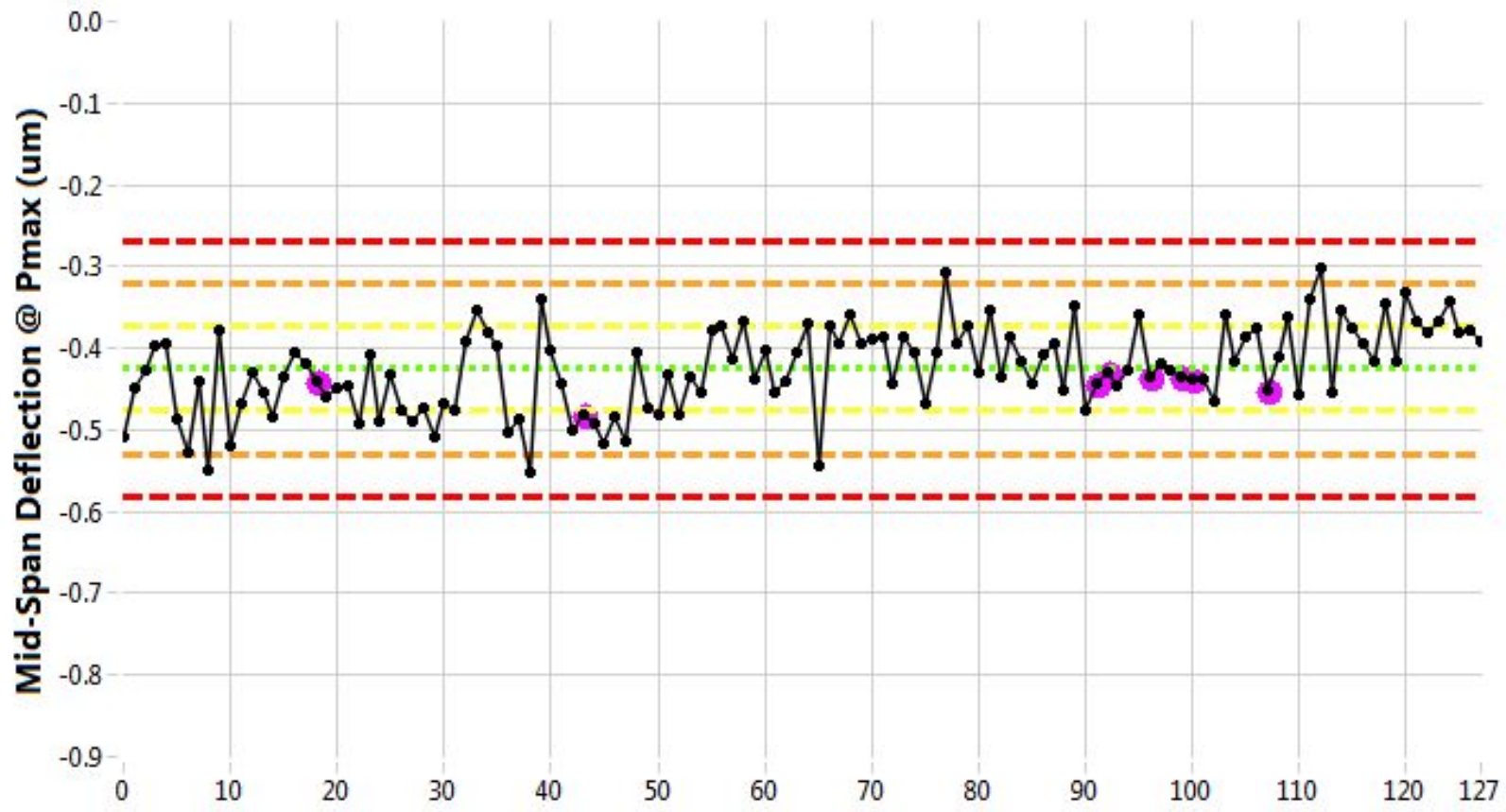

Figure 19. Mid-span deflection at maximum load (um), mean $=-0.4251$, standard deviation $=0.052$. 
TEM-10200-1

$03 / 01 / 2012$

ENGINEERING CALCULATIONS AND ANALYSIS

Page 23 of 32

Rev. 06

Title: $\quad$ Baseline Characterization Database Verification Report - PCEA Billet XPC01D3-36

ECAR No.: 3677

Rev. No.: $0 \quad$ Project No.: 32138

Date: $05 / 02 / 2017$

\section{Density Values}

Similar to the compression specimens, the flexural specimens' geometry facilitated an opportunity to make density measurements. Figure 20 shows density from the flexural specimens. All flexural specimens' data and associated deviations compare well with the compression specimens' density data.

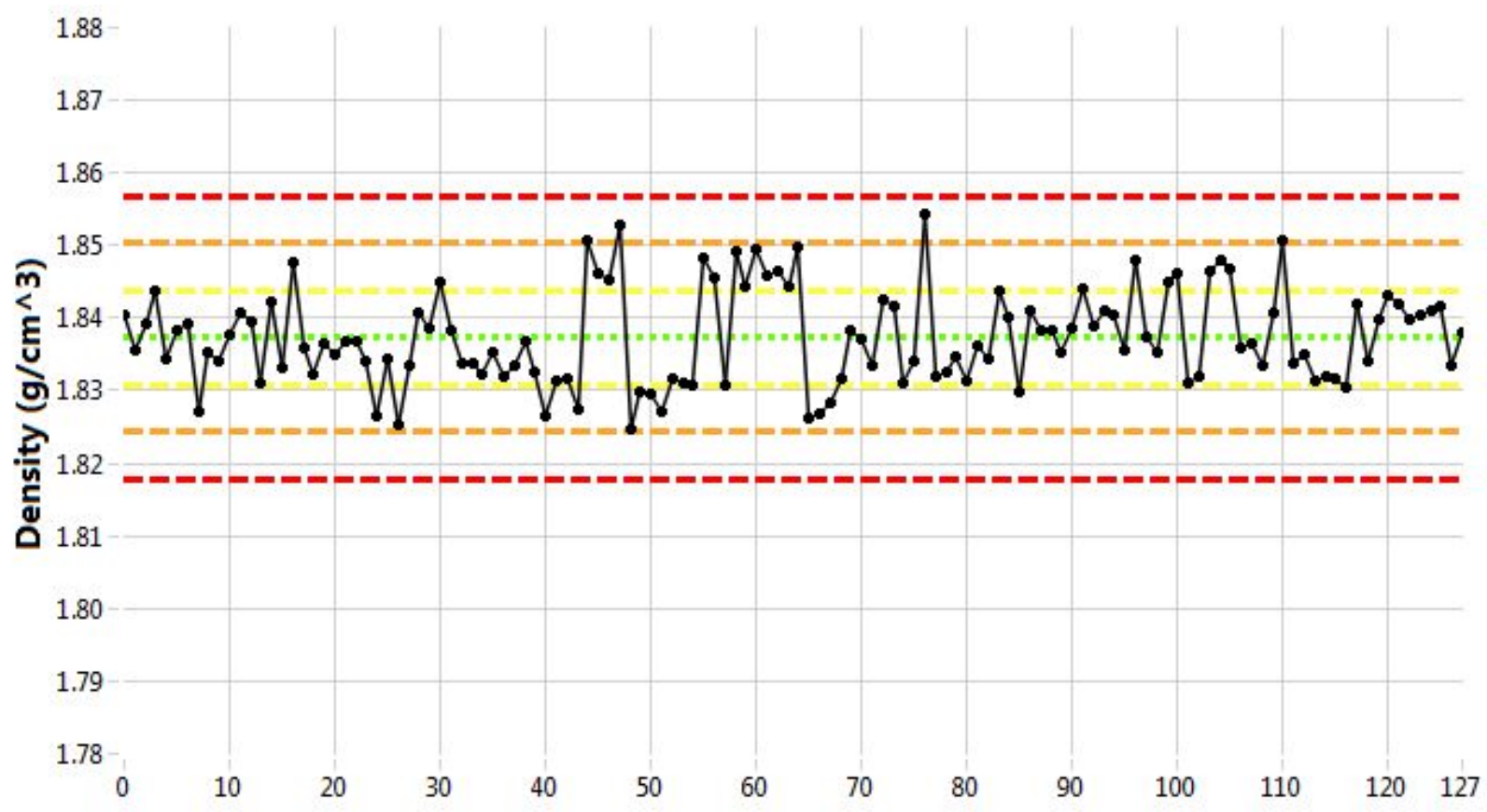

Figure 20. Density $\left(\mathrm{g} / \mathrm{cm}^{\wedge} 3\right)$, mean $=1.8374$, standard deviation $=0.0065$.

\section{Fundamental Frequency}

The precise parallelepiped geometry of flexural specimens renders them particularly valuable for accurate measurements of fundamental frequency to collect elastic constants for both dynamic Young's modulus and shear modulus (ASTM C747-93 ${ }^{10}$ ). Values for fundamental frequency-based moduli, both in flexural and torsional modes, (shown in Figure 21 and Figure 22) are calculated from the equations provided in ASTM C1259-08. ${ }^{11}$ These data all fell within \pm 3 standard deviations from their respective means. 
TEM-10200-1

$03 / 01 / 2012$

ENGINEERING CALCULATIONS AND ANALYSIS

Page 24 of 32

Rev. 06

Title: $\quad$ Baseline Characterization Database Verification Report - PCEA Billet XPC01D3-36

ECAR No.: 3677

Rev. No.: 0

Project No.:

32138

Date: $05 / 02 / 2017$

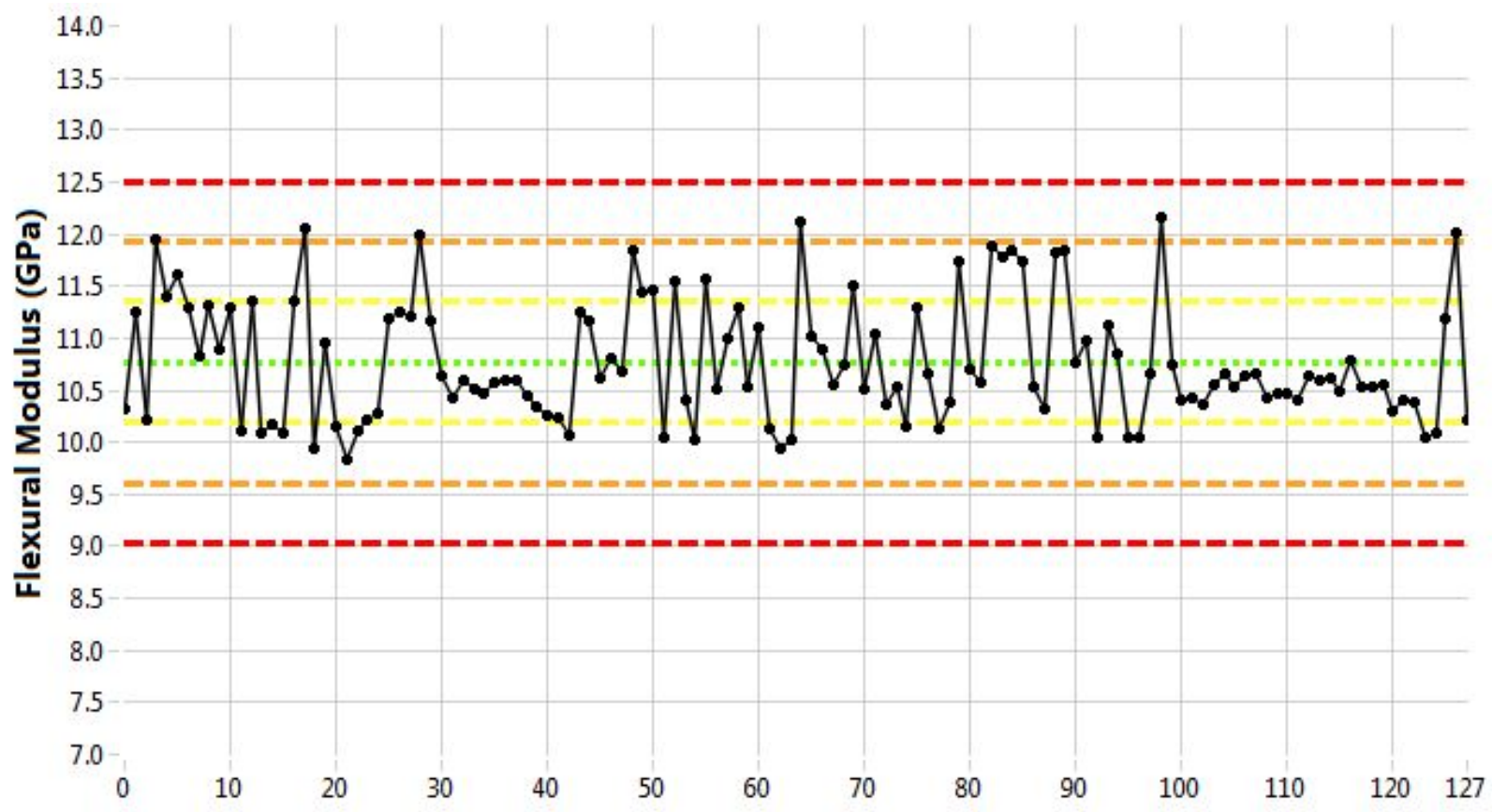

Figure 21. Flexural vibration mode Young's modulus $(\mathrm{GPa})$, mean $=10.8$, standard deviation $=0.58$.

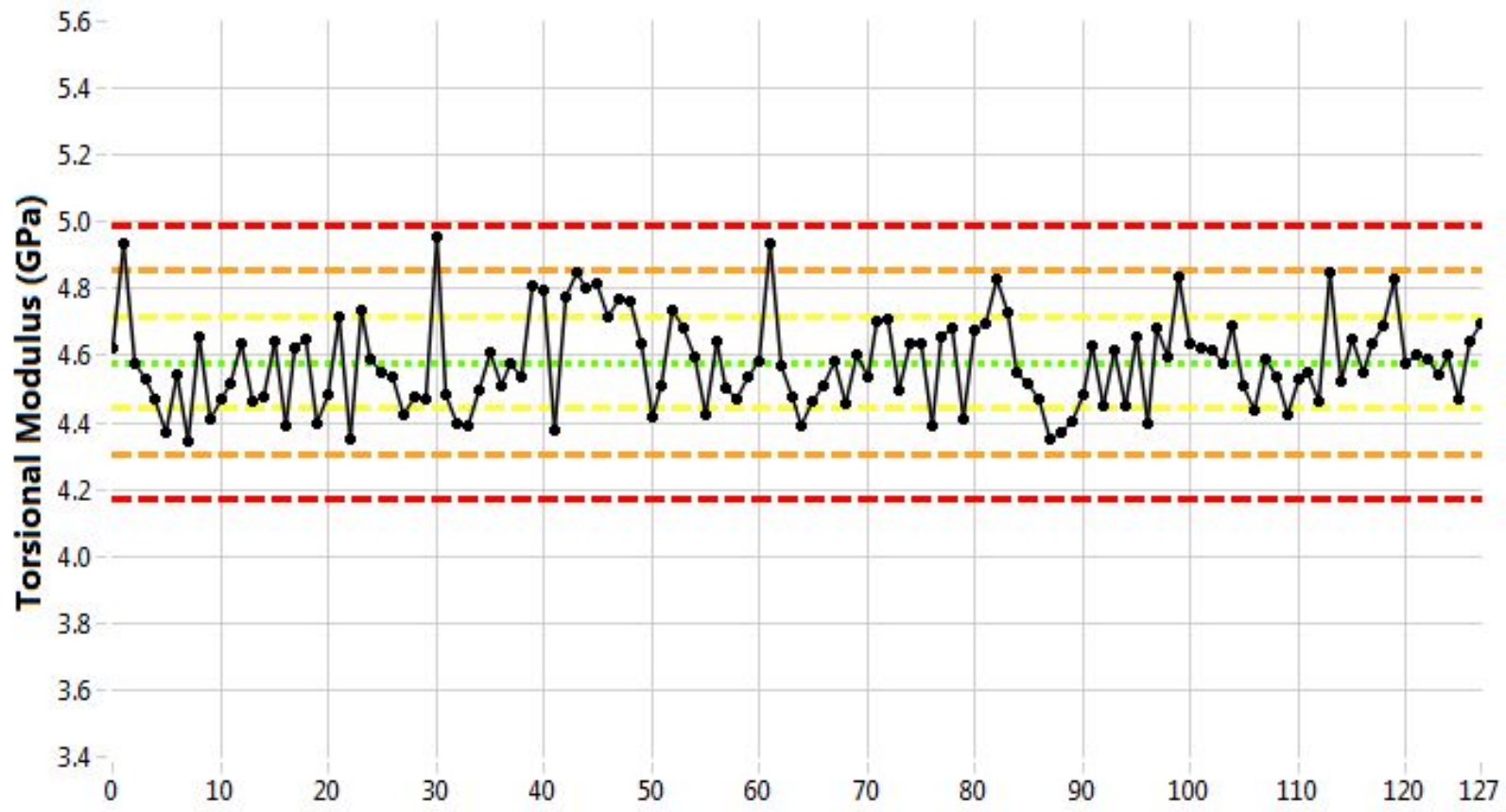

Figure 22. Torsional vibration mode shear modulus $(\mathrm{GPa})$, mean $=4.6$, standard deviation $=0.14$. 
TEM-10200-1

$03 / 01 / 2012$

ENGINEERING CALCULATIONS AND ANALYSIS

Page 25 of 32

Rev. 06

Title: $\quad$ Baseline Characterization Database Verification Report - PCEA Billet XPC01D3-36

ECAR No.: 3677

Rev. No.: $0 \quad$ Project No.: 32138

Date: $05 / 02 / 2017$

Tensile Specimen Database (PCEA XPC01D3-36T)

\section{Tensile Testing}

Tensile testing was performed per ASTM C749-08. ${ }^{15}$ Data verification follows the principles discussed in previous sections. As with other specimen types, data verification lies not only in documented adherence to applicable test plans and standards, but in noted correlations between recorded test properties and analyses for outlying values. Additional verification of test conditions can be carried out through an analysis of ancillary physical characteristics. The custom measurement software used to capture tensile gauge diameters is programed to flag any measurement that deviates from the ASTM standard. Although Figure 23 shows the gauge diameter of two specimens fell outside of \pm 3 standard deviations, both of these specimens were within the tolerance defined by the ASTM.

Figure 24 and Figure 25 show the relationship between tensile load and recorded tensile stress for the 127 specimens tested in uniaxial tension from PCEA XPC01D3-36. Further comparisons and verification can be made with extensometer-based measured deflection (shown in Figure 26), which will reflect an additional correlation with stress values through material elastic constants. Comparing the extreme values again shows this relationship to be valid.

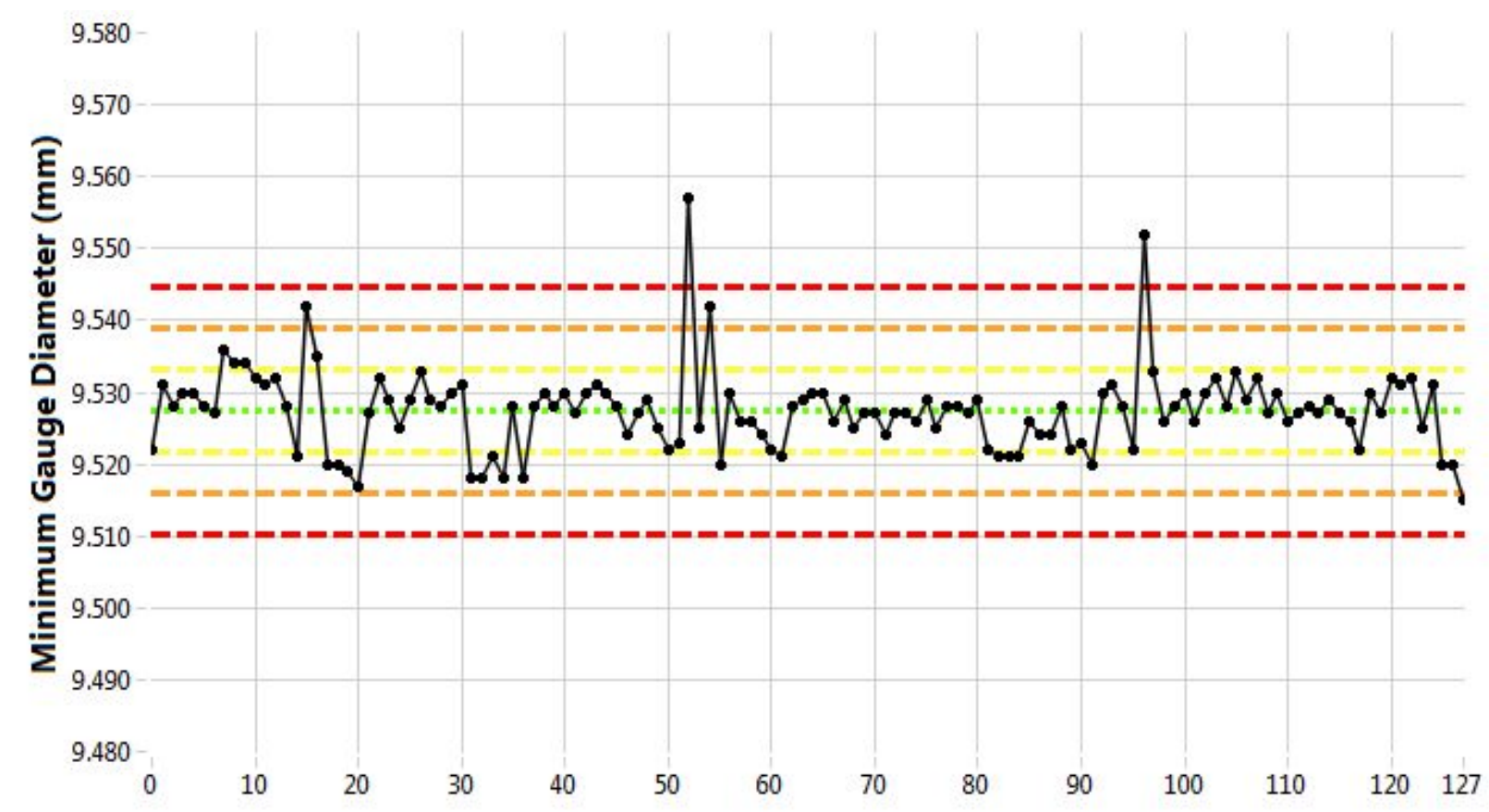

Figure 23. Minimum gauge diameter $(\mathrm{mm})$, mean $=9.527$, standard deviation $=0.0058$. 
TEM-10200-1

$03 / 01 / 2012$

ENGINEERING CALCULATIONS AND ANALYSIS

Page 26 of 32

Rev. 06

Title: $\quad$ Baseline Characterization Database Verification Report - PCEA Billet XPC01D3-36

ECAR No.: 3677

Rev. No.: 0

Project No.:

32138

Date: $05 / 02 / 2017$

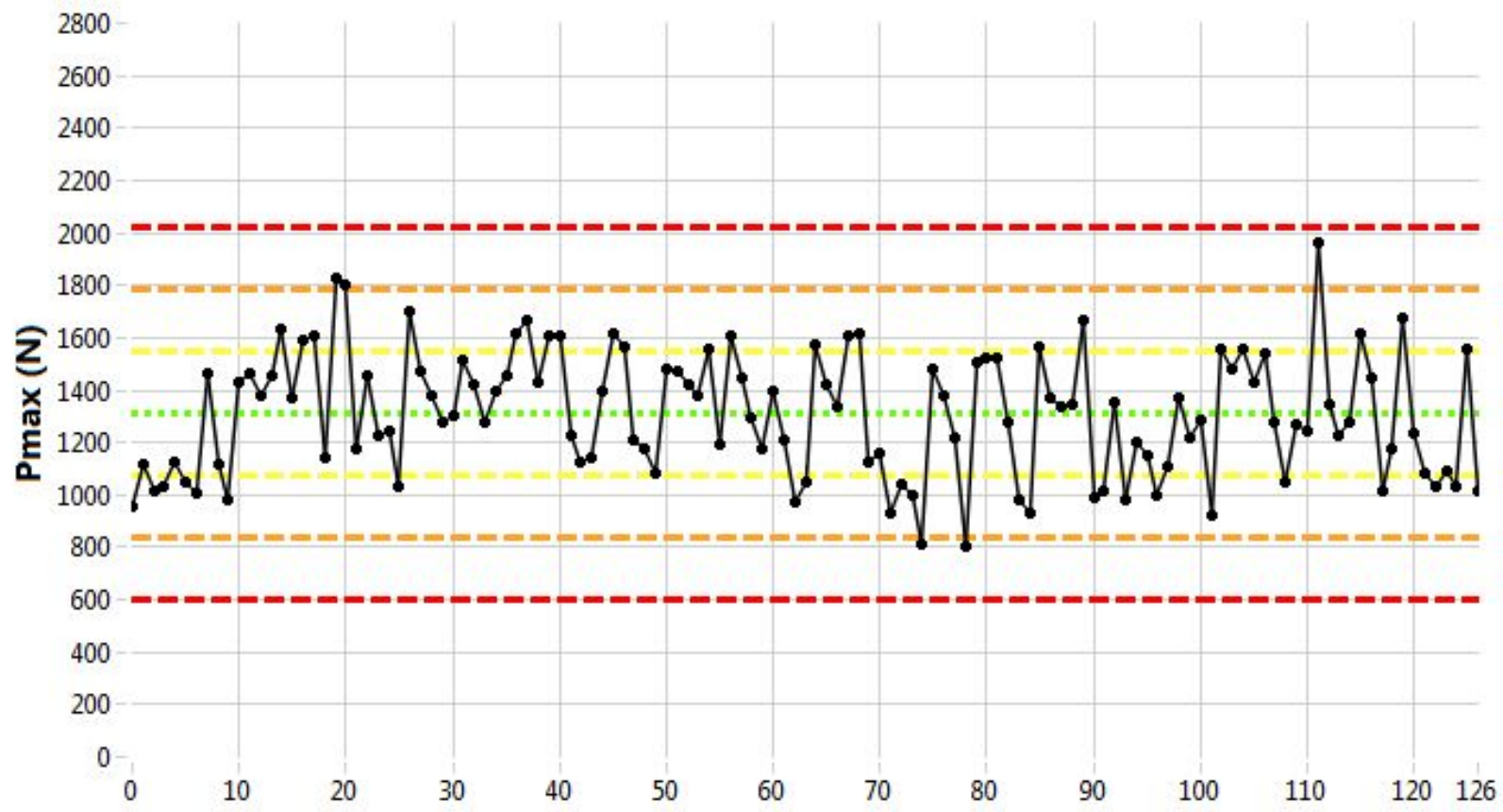

Figure 24. Maximum load $(\mathrm{N})$, mean $=1,309.6$, standard deviation $=236.07$.

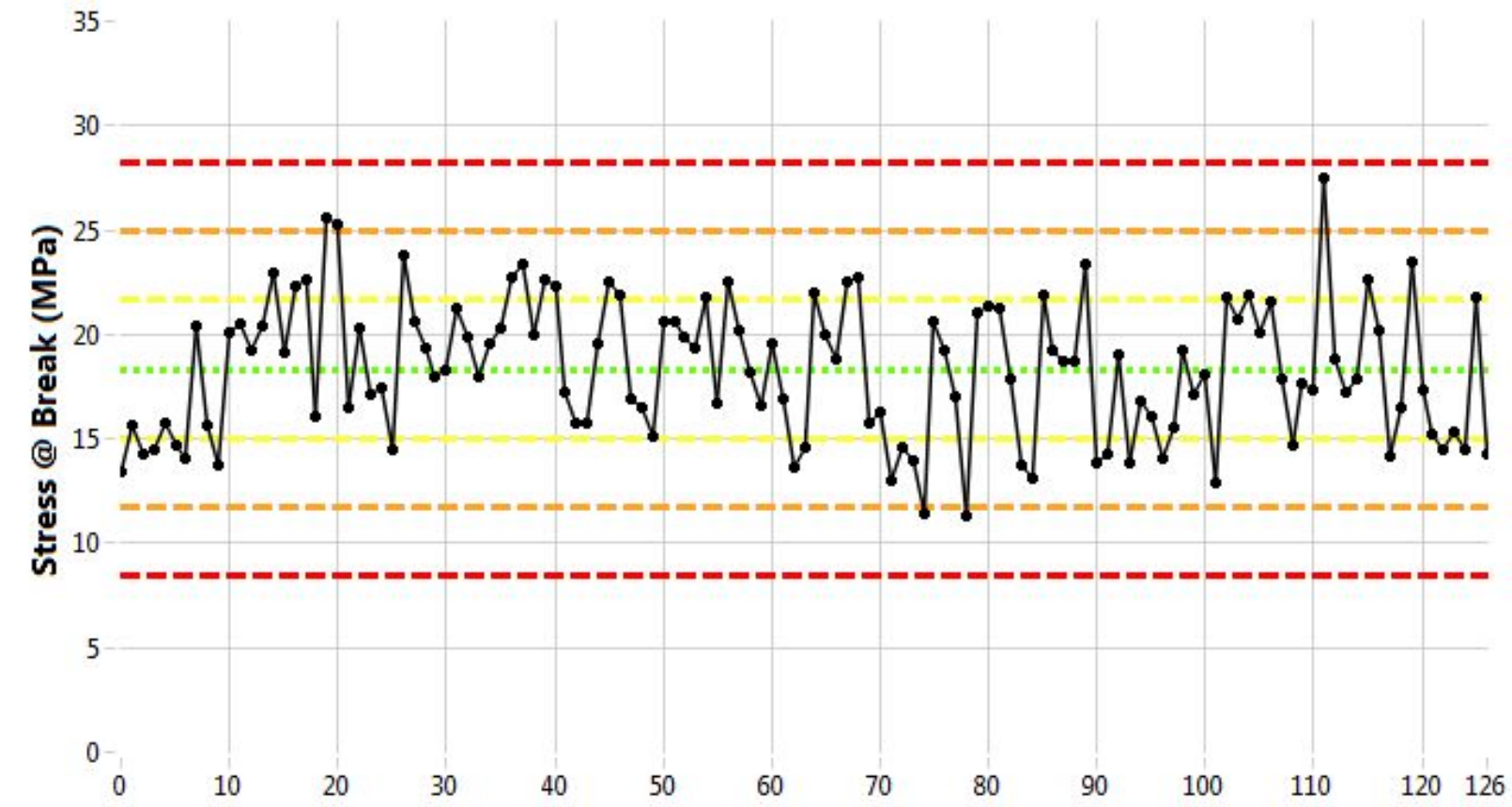

Figure 25. Stress at break $(\mathrm{MPa})$, mean $=18.3$, standard deviation $=3.31$. 
TEM-10200-1

$03 / 01 / 2012$

ENGINEERING CALCULATIONS AND ANALYSIS

Page 27 of 32

Rev. 06

Title: $\quad$ Baseline Characterization Database Verification Report - PCEA Billet XPC01D3-36

$\begin{array}{llllll}\text { ECAR No.: } 3677 & \text { Rev. No.: } & 0 & \text { Project No.: } 32138 \quad \text { Date: } 05 / 02 / 2017\end{array}$

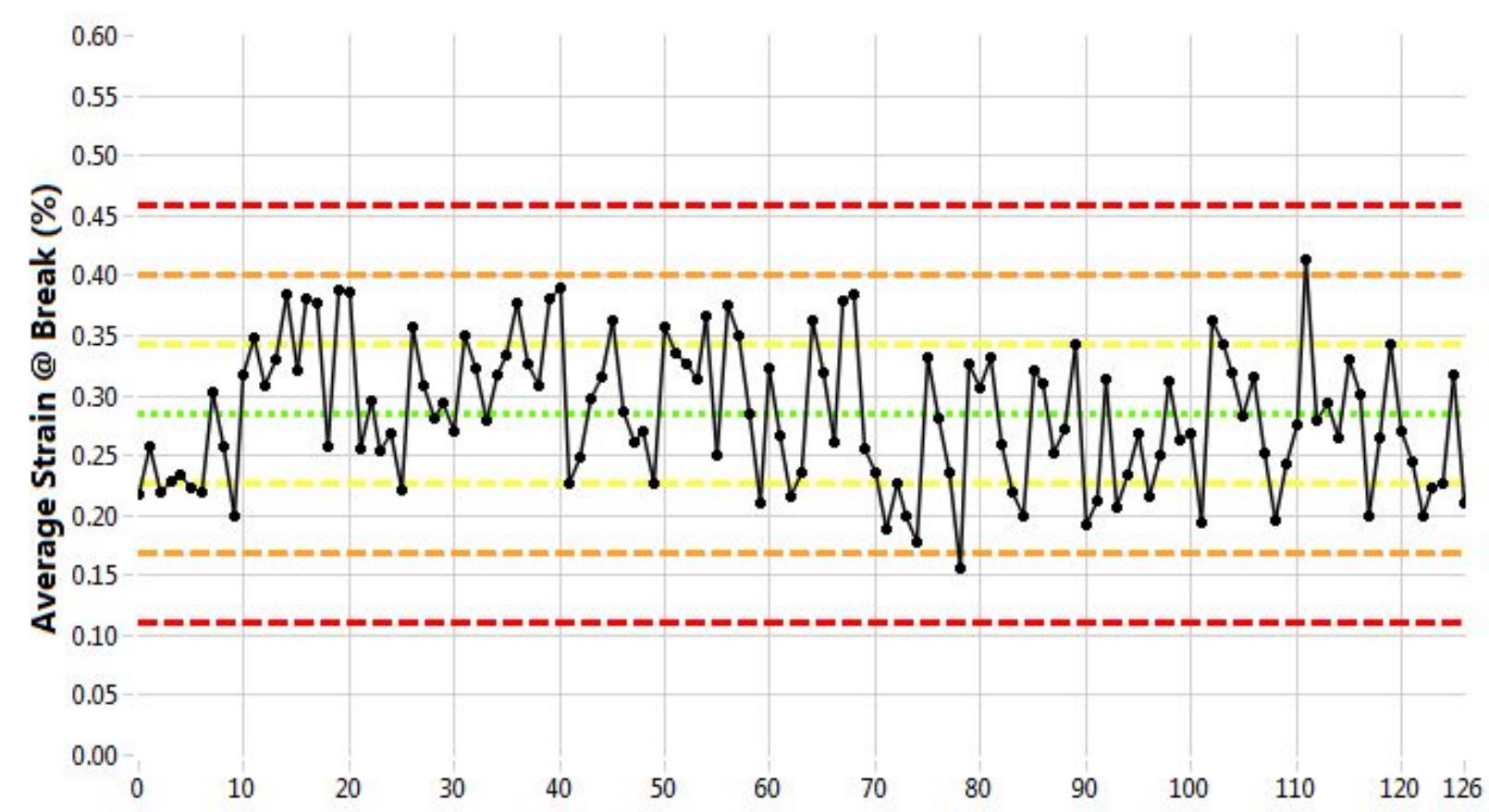

Figure 26. Average strain at break $(\%)$, mean $=0.28$, standard deviation $=0.06$.

\section{RE-MACHINED SPECIMEN PROPERTIES}

Two of the key components to direct comparisons between baseline and AGC data are (1) the analyses of specimens with similar geometries and (2) employment of similar test techniques for comprehensive validation. The geometry of the tensile specimens provides the opportunity to "re-machine" the unstressed sections of the specimen ends (shown in Figure 27) to the same dimensions as AGC piggyback specimens. A random cross-section of tensile specimens was re-machined in order to repeat tests on AGC-sized specimens (i.e., diffusivity and split disc testing). Using actual test specimens for re-machining enables continued employment of the specimen identification and tracking code system, because specimens are machined from tracked locations and can reuse the identification code. 
Rev. 06

Title:

Baseline Characterization Database Verification Report - PCEA Billet XPC01D3-36

ECAR No.: 3677

Rev. No.: 0

Project No:

32138

Date: $05 / 02 / 2017$

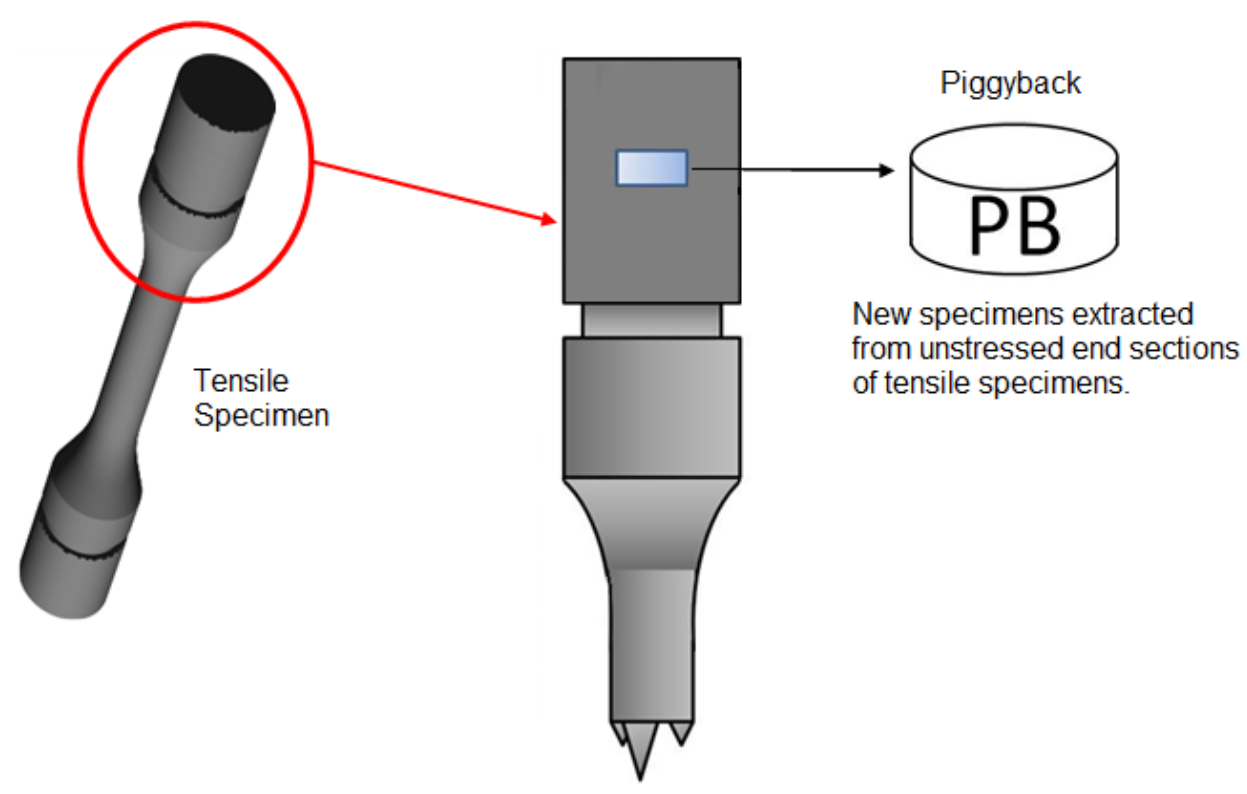

Figure 27. Unstressed specimen remnants from tensile specimens are re-machined into AGC-sized piggyback specimens.

\section{RE-MACHINED SPLIT DISC TESTING}

Disc splitting tensile strength testing was performed in accordance with PLN-3348, Revision 4 Section 6.1.1.5. This allows for a direct comparison of tensile data to data that were acquired through strict application of ASTM C749-08. Figure 27 and Figure 28 show strength and load data from the split disc testing. The mean value calculated from the split disc testing compared closely with that from traditional tensile testing (Figure 25) and even had a lower standard deviation. 
TEM-10200-1

$03 / 01 / 2012$

Rev. 06

Title: $\quad$ Baseline Characterization Database Verification Report - PCEA Billet XPC01D3-36

ECAR No.: 3677

Rev. No.: 0

Project No.: $\quad 32138$

Date: $05 / 02 / 2017$

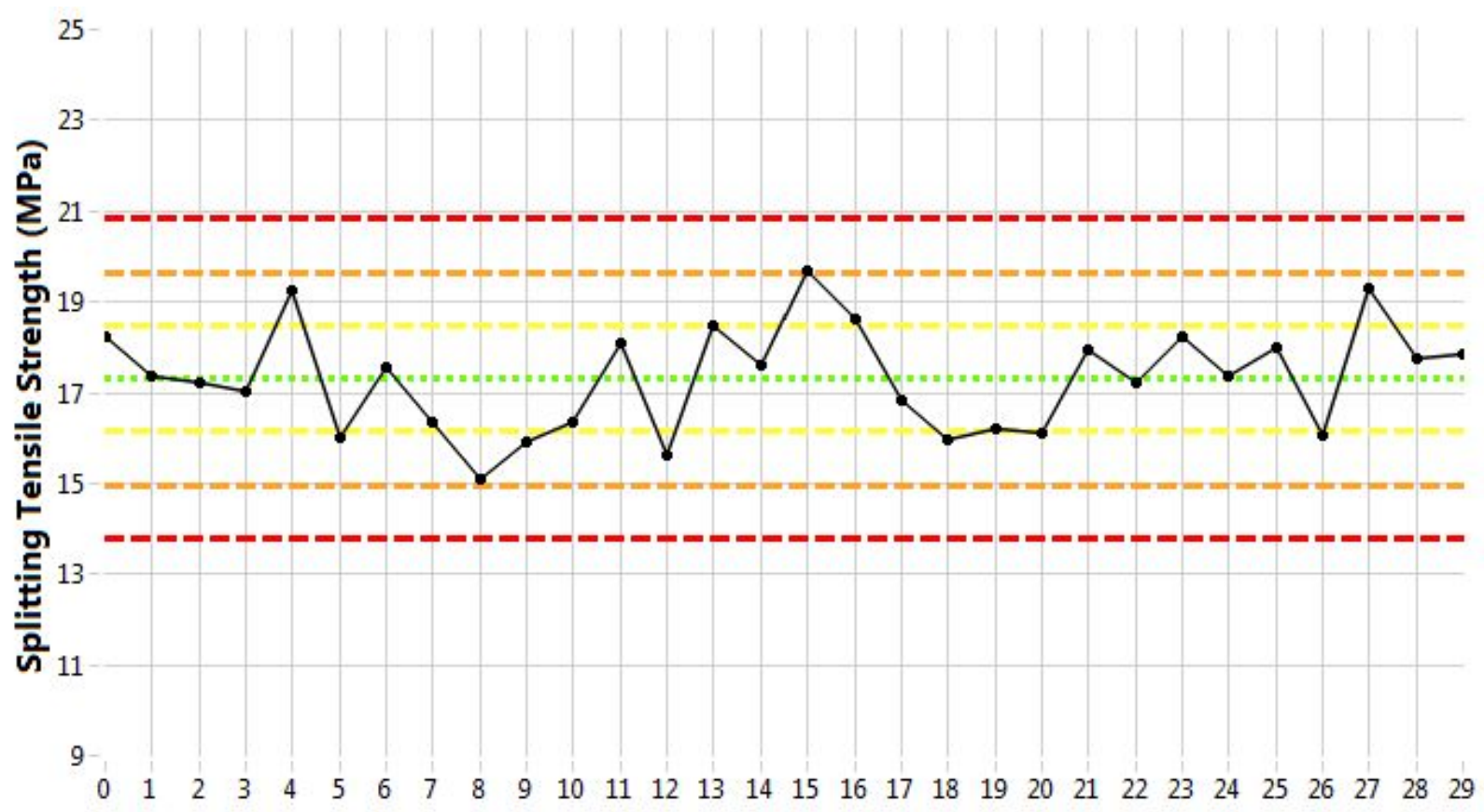

Figure 28. Disc splitting tensile strength $(\mathrm{MPa})$, mean $=17.3$, standard deviation $=1.17$.

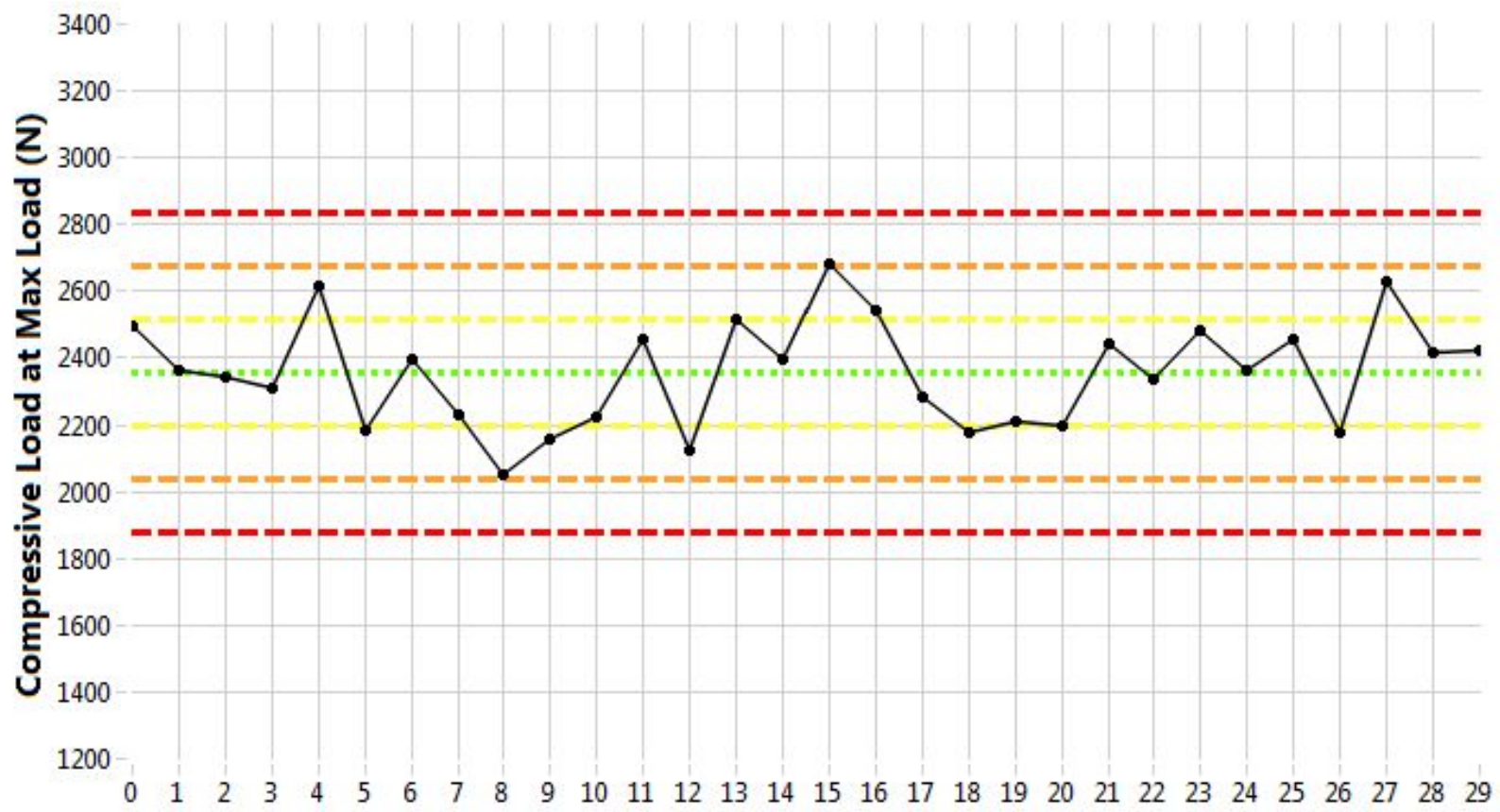

Figure 29. Disc splitting compressive load at max load $(\mathrm{N})$, mean $=2,355.8$, standard deviation $=159.9$. 
TEM-10200-1

$03 / 01 / 2012$

ENGINEERING CALCULATIONS AND ANALYSIS

Page 30 of 32

Rev. 06

Title: $\quad$ Baseline Characterization Database Verification Report - PCEA Billet XPC01D3-36

$\begin{array}{llllll}\text { ECAR No.: } 3677 & \text { Rev. No.: } & 0 & \text { Project No.: } 32138 & \text { Date: } & \text { 05/02/2017 }\end{array}$

\section{RE-MACHINED SPECIMEN DIFFUSIVITY}

Thermal diffusivity values are collected from the re-machined tensile specimens per ASTM E1461-07. ${ }^{13}$ Diffusion of heat through the specimen following application of thermal energy via a laser source demonstrates heat transfer characteristics and can be used to calculate thermal conductivity for design purposes. The resulting group of diffusivity values, revealing a tight grouping of thermal transfer characteristics, is shown in Figure 30.

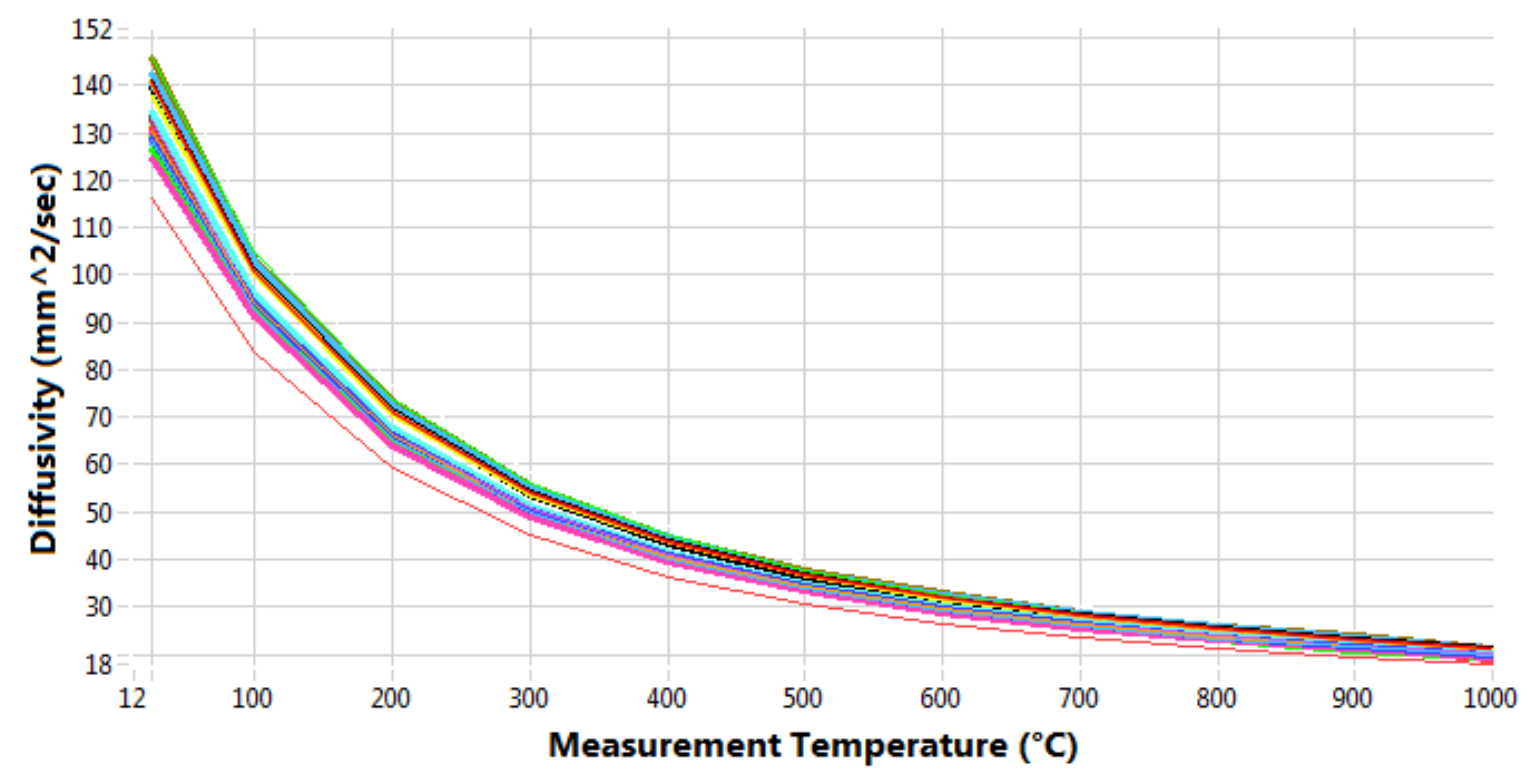

Figure 30. Re-machined specimen diffusivity.

\section{SUMMARY}

Comprehensive data sets for the PCEA billet XPC01D3-36 have been compiled into summary files of property scalar values. The data spreadsheet files are divided by mechanical test specimen type into three main sets: (1) compressive, (2) flexural, and (3) tensile. The multitude of tests and evaluations performed on each specimen type are individually tabbed in the main data set files.

In addition to a full visual review of the data files to determine if obvious errors were made with the data collected (e.g., missing information or otherwise blank cells), graphical representations were made of individual evaluations in order to provide a means to spot anomalies. A review of the data indicates that the files, as submitted, are fully representative of the measured properties of the graphite billets being tested, as outlined in the applicable test procedures and program plans. 
TEM-10200-1

$03 / 01 / 2012$

ENGINEERING CALCULATIONS AND ANALYSIS

Page 31 of 32

Rev. 06

Title: $\quad$ Baseline Characterization Database Verification Report - PCEA Billet XPC01D3-36

ECAR No.: 3677

Rev. No.: $0 \quad$ Project No.: 32138

Date: $05 / 02 / 2017$

\section{REFERENCES}

1. PLN-2497, 2010, “Graphite Technology Development Plan," Revision 1, October 2010.

2. PLN-3348, 2011, "Graphite Mechanical Testing," Revision 2, April 2011.

3. PLN-3467, 2011, "Baseline Graphite Characterization Plan: Electromechanical Testing," Revision 1, August 2011.

4. PLN-3267, 2010, "AGC-2 Characterization Plan,” Revision 0, March 2010.

5. Carroll, Mark, Joe Lord, and David Rohrbaugh, 2010, Baseline Graphite Characterization: First Billet, INL/EXT-10-19910, September 2010.

6. ASTM Standard C695-15, 2015, "Standard Test Method for Compressive Strength of Carbon and Graphite," ASTM International.

7. ASTM Standard C559-90, reapproved 2005, "Standard Test Method for Bulk Density by Physical Measurements of Manufactured Carbon and Graphite Articles," ASTM International.

8. ASTM Standard C769-09, 2009, "Standard Test Method for Sonic Velocity in Manufactured Carbon and Graphite Material for Use in Obtaining an Approximate Young's Modulus," ASTM International.

9. ASTM Standard C651-91, reapproved 2005, "Standard Test Method for Flexural Strength of Manufactured Carbon and Graphite Articles Using Four-Point Loading at Room Temperature," ASTM International, 2005.

10. ASTM Standard C747-93 (Reapproved 2005), "Standard Test Method for Moduli of Elasticity and Fundamental Frequencies of Carbon and Graphite Materials by Sonic Resonance," ASTM International.

11. ASTM Standard C1259-08, 2008, "Standard Test Method for Dynamic Young's Modulus, Shear Modulus, and Poisson's Ratio for Advanced Ceramics by Impulse Excitation of Vibration," ASTM International.

12. ASTM Standard C611-05, 2005, "Standard Test Method for Electrical Resistivity of Manufactured Carbon and Graphite Articles at Room Temperature," ASTM International.

13. ASTM Standard E1461-07, 2007, "Standard Test Method for Thermal Diffusivity by the Flash Method," ASTM International.

14. ASTM Standard E228-06, 2006, "Standard Test Method for Linear Thermal Expansion of Solid Materials with a Push Rod Dilatometer," ASTM International.

15. ASTM Standard C749-08, 2008, "Standard Test Method for Tensile Stress-Strain of Carbon and Graphite," ASTM International. 
TEM-10200-1

$03 / 01 / 2012$

ENGINEERING CALCULATIONS AND ANALYSIS

Page 32 of 32

Rev. 06

Title: $\quad$ Baseline Characterization Database Verification Report - PCEA Billet XPC01D3-36

$\begin{array}{llllll}\text { ECAR No.: } 3677 & \text { Rev. No.: } & 0 & \text { Project No.: } 32138 \quad \text { Date: } 05 / 02 / 2017\end{array}$

16. ASTM Standard D7972-14, 2014, "Standard Test Method for Flexural Strength of Manufactured Carbon and Graphite Articles Using Three-Point Loading at Room Temperature," ASTM International. 
TEM-10200-1

$03 / 01 / 2012$

ENGINEERING CALCULATIONS AND ANALYSIS

Page $A 1$ of $A 3$

Rev. 06

Title: $\quad$ Baseline Characterization Database Verification Report - PCEA Billet XPC01D3-36

ECAR No.: 3677

Rev. No.: 0

Project No.: $\quad 32138$

Date: $05 / 02 / 2017$

\section{Appendix A}

\section{Additional Compression Specimen Database Plots (PCEA XPC01D3-36C)}

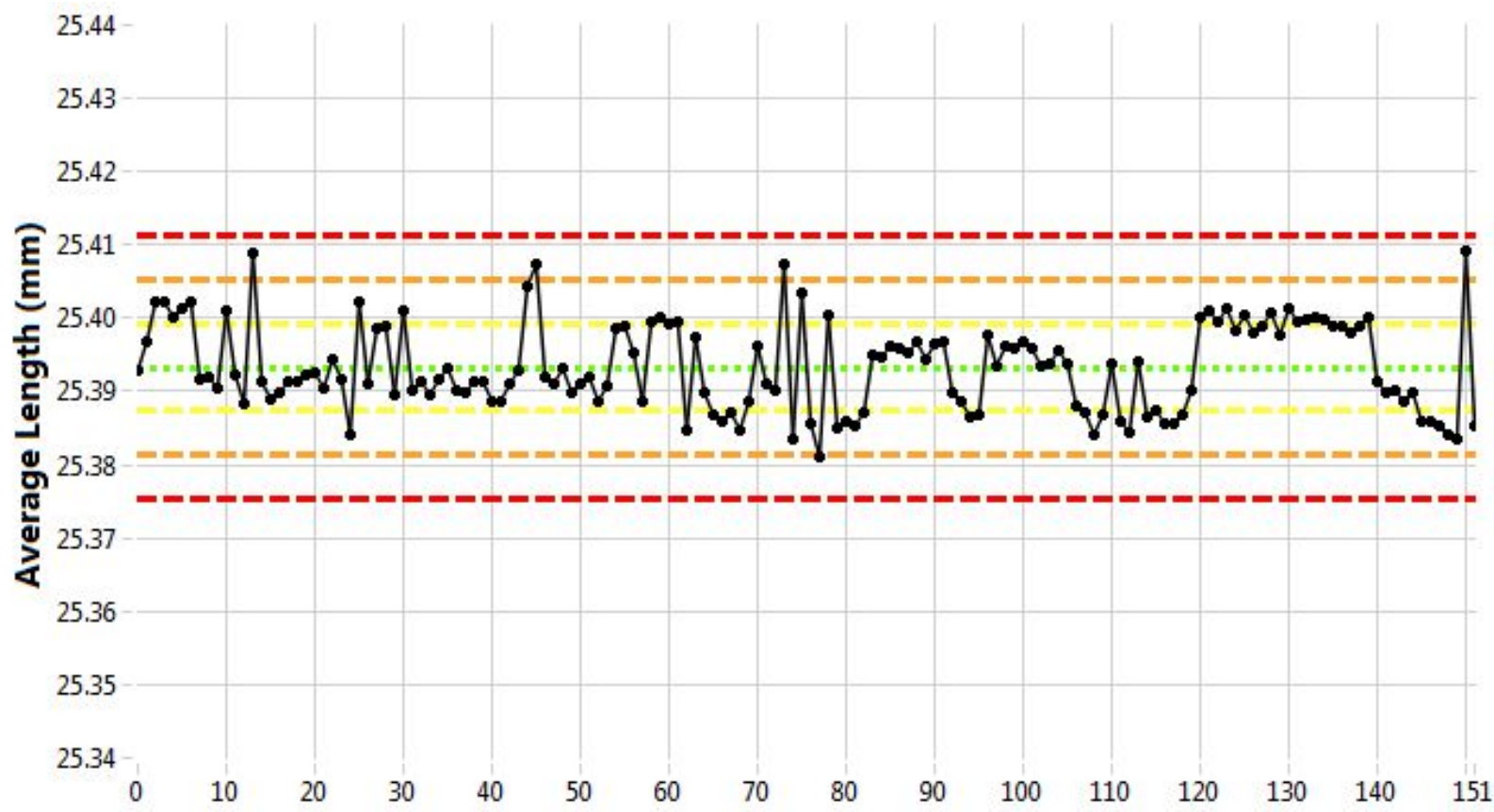

Figure A-1. Average length $(\mathrm{mm})$, mean $=25.393$, standard deviation $=0.0060$.

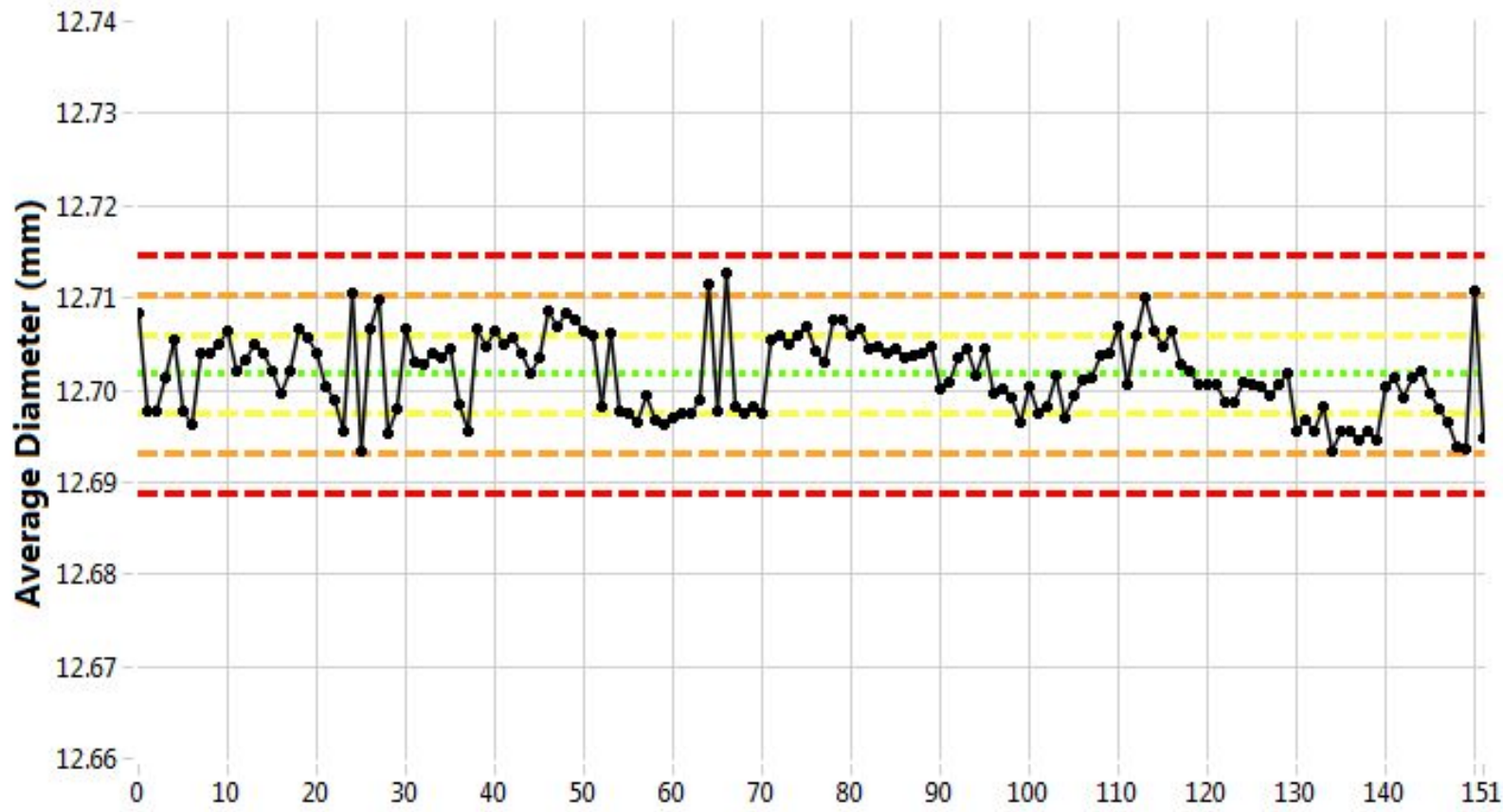

Figure A-2. Average diameter $(\mathrm{mm})$, mean $=12.702$, standard deviation $=0.0043$. 
TEM-10200-1

$03 / 01 / 2012$

ENGINEERING CALCULATIONS AND ANALYSIS

Page A2 of $A 3$

Rev. 06

Title: $\quad$ Baseline Characterization Database Verification Report - PCEA Billet XPC01D3-36

ECAR No.: 3677

Rev. No.: 0

Project No.:

32138

Date: $05 / 02 / 2017$

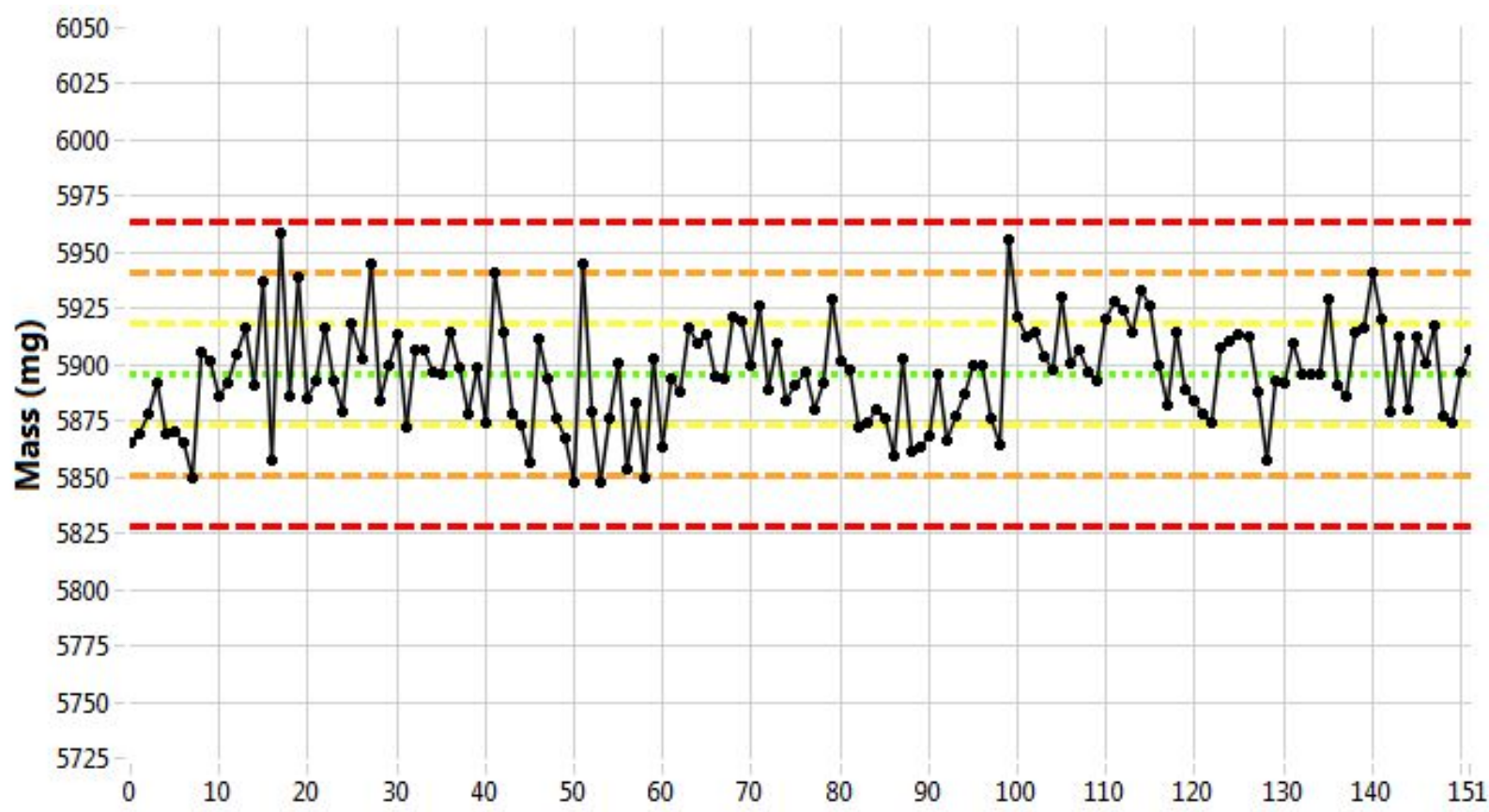

Figure A-3. Mass $(\mathrm{mg})$, mean $=5,895.8$, standard deviation $=22.71$.

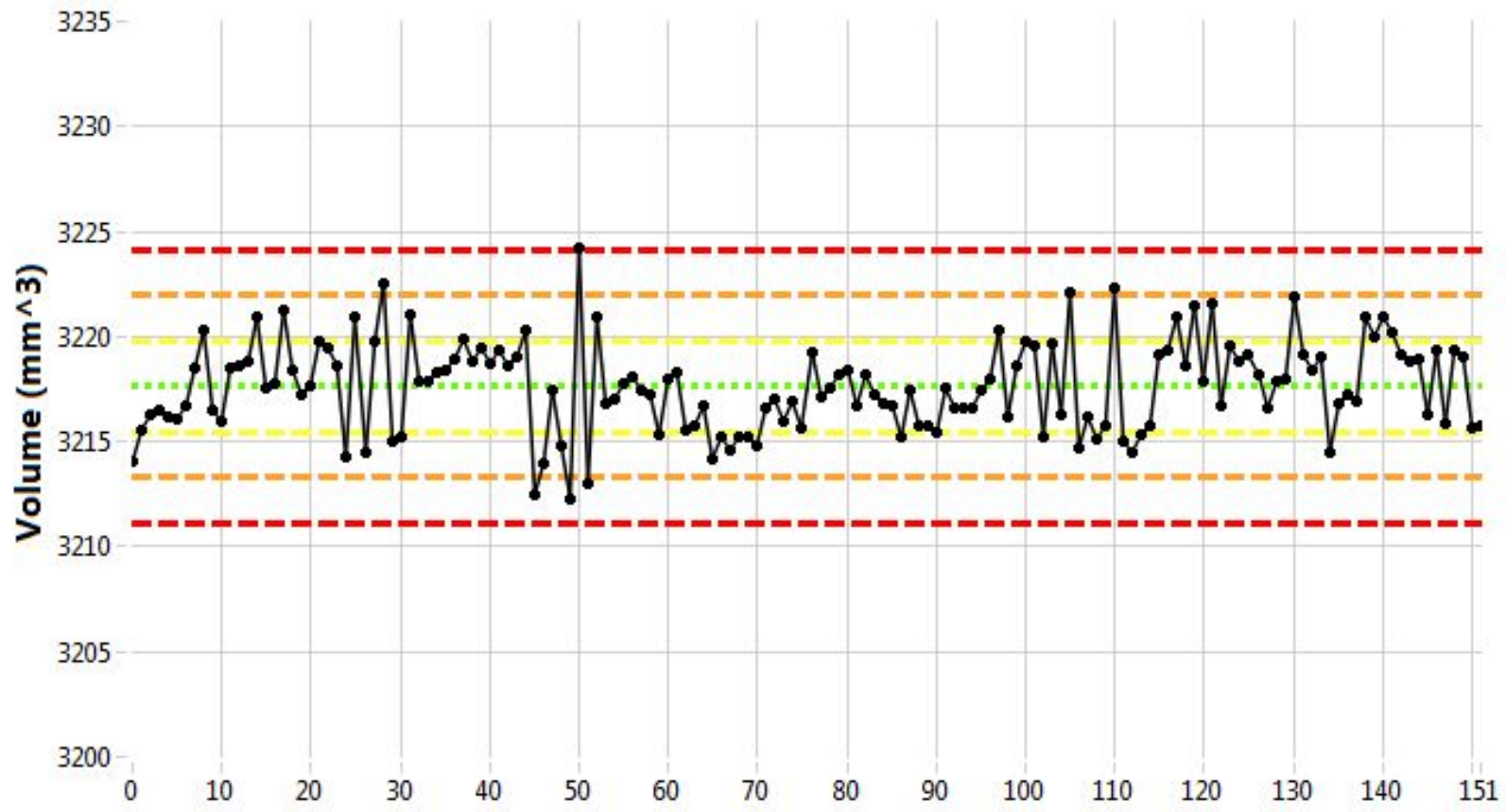

Figure A-4. Volume $\left(\mathrm{mm}^{\wedge} 3\right)$, mean $=3,217.6$, standard deviation $=2.16$. 
TEM-10200-1

$03 / 01 / 2012$

ENGINEERING CALCULATIONS AND ANALYSIS

Page $A 3$ of $A 3$

Rev. 06

Title: $\quad$ Baseline Characterization Database Verification Report - PCEA Billet XPC01D3-36

ECAR No.: 3677

Rev. No.: 0

Project No.: 32138

Date: $05 / 02 / 2017$

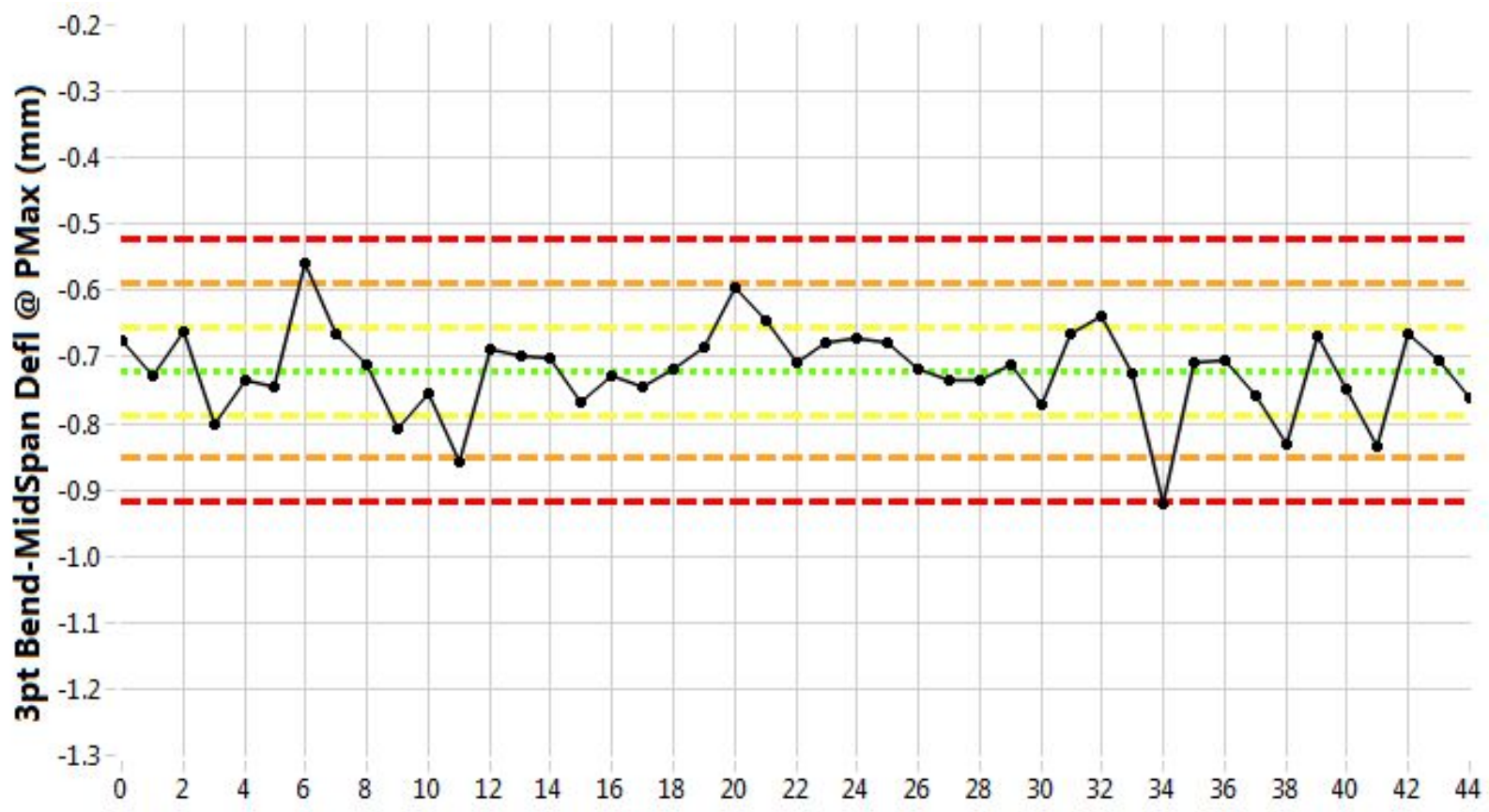

Figure A-5. Mid-span deflection at maximum load (um), mean $=-0.7208$, standard deviation $=0.0661$.

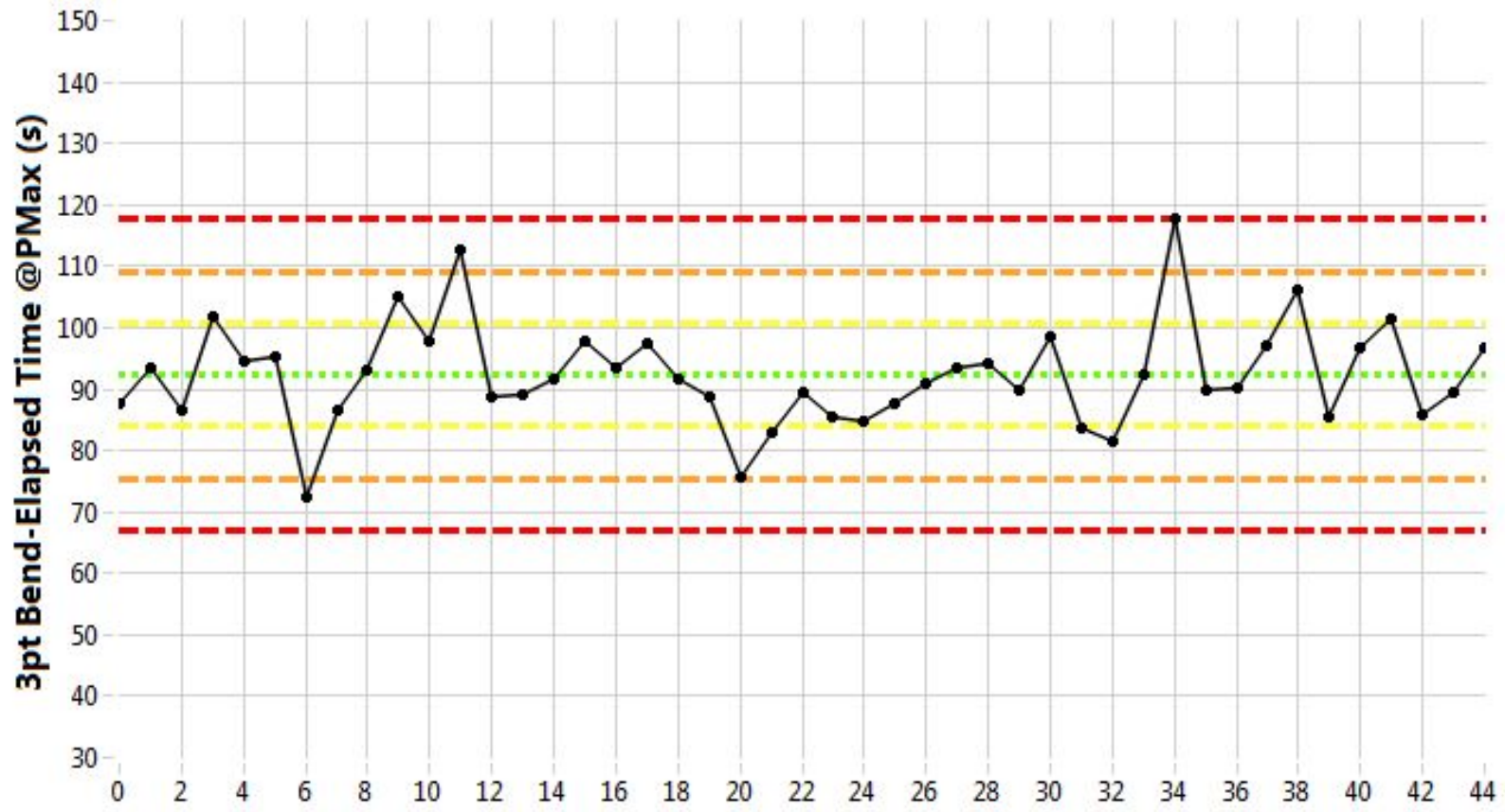

Figure A-6. Elapsed time at maximum load $(\mathrm{sec})$, mean $=92.3$, standard deviation $=8.45$. 
TEM-10200-1

$03 / 01 / 2012$

ENGINEERING CALCULATIONS AND ANALYSIS

Page B1 of B2

Rev. 06

Title: $\quad$ Baseline Characterization Database Verification Report - PCEA Billet XPC01D3-36

ECAR No.: 3677

Rev. No.: 0

Project No.: 32138

Date: $05 / 02 / 2017$

\section{Appendix B}

\section{Additional Flexural Specimen Database Plots (PCEA XPC01D3-36F)}

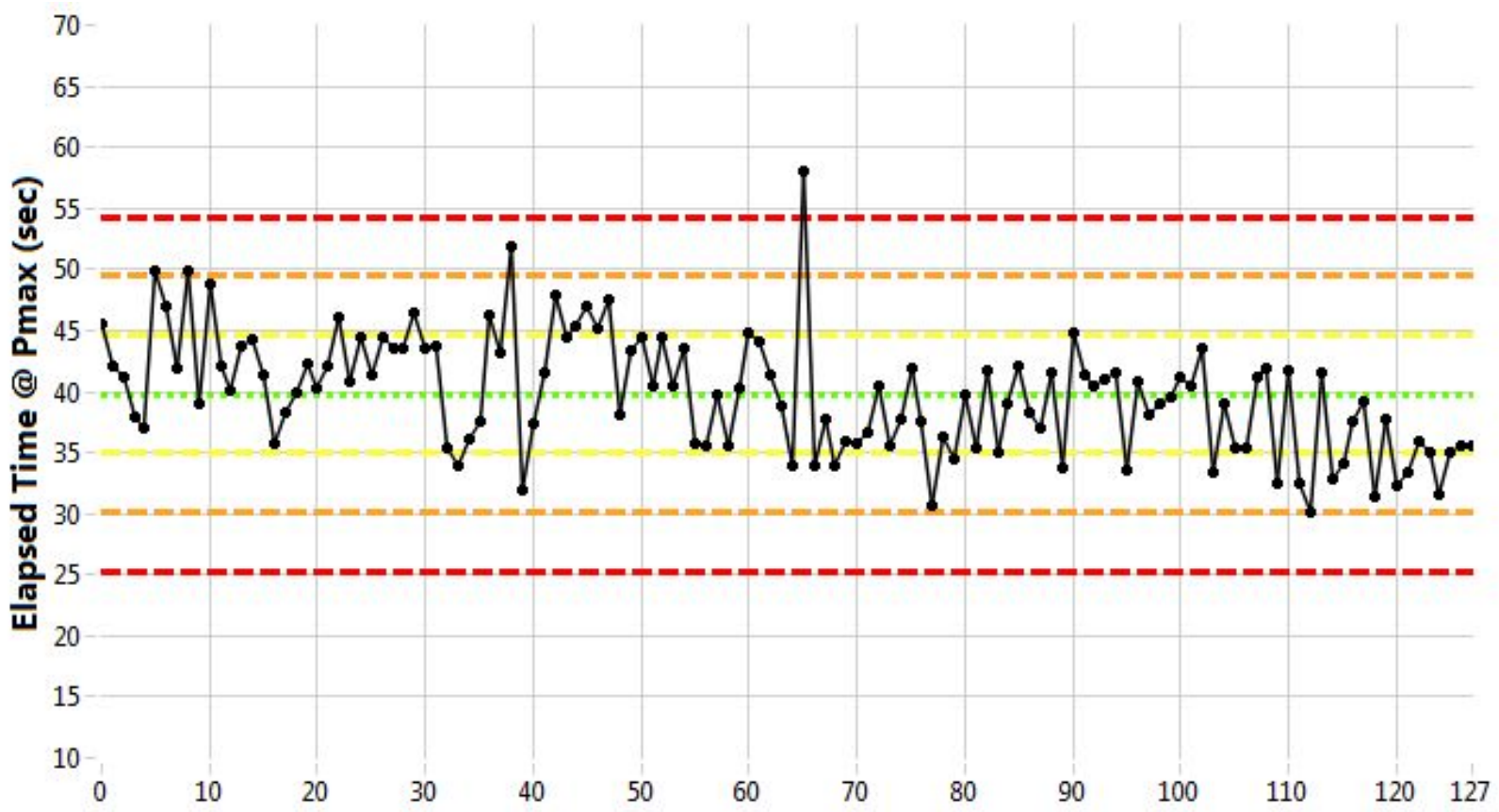

Figure B-1. Elapsed time at maximum load $(\mathrm{sec})$, mean $=39.8$, standard deviation $=4.84$.

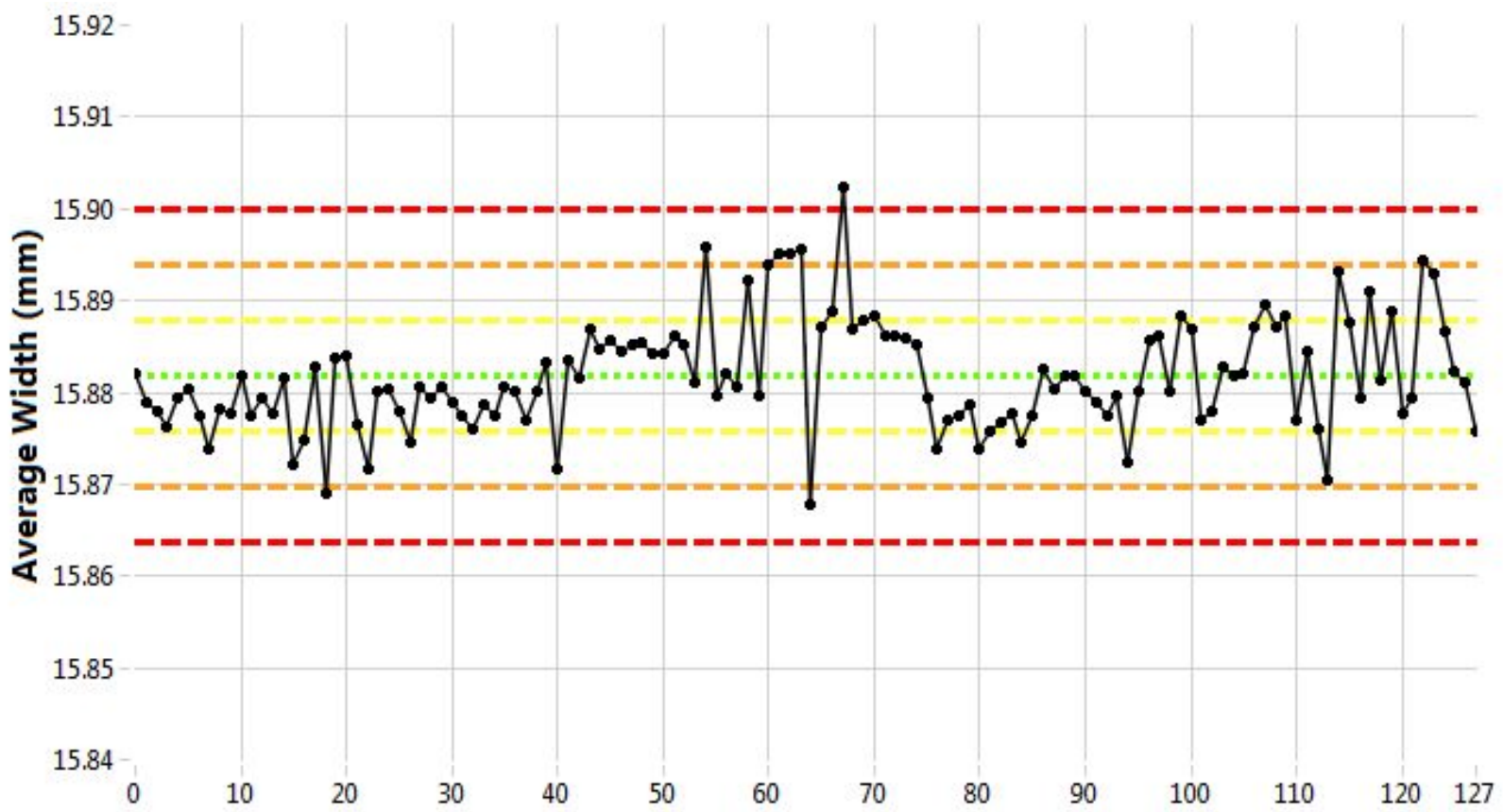

Figure B-2. Average width $(\mathrm{mm})$, mean $=15.882$, standard deviation $=0.0060$. 
TEM-10200-1

$03 / 01 / 2012$

ENGINEERING CALCULATIONS AND ANALYSIS

Page B2 of B2

Rev. 06

Title: $\quad$ Baseline Characterization Database Verification Report - PCEA Billet XPC01D3-36

ECAR No.: 3677

Rev. No.: 0

Project No.:

32138

Date: $05 / 02 / 2017$

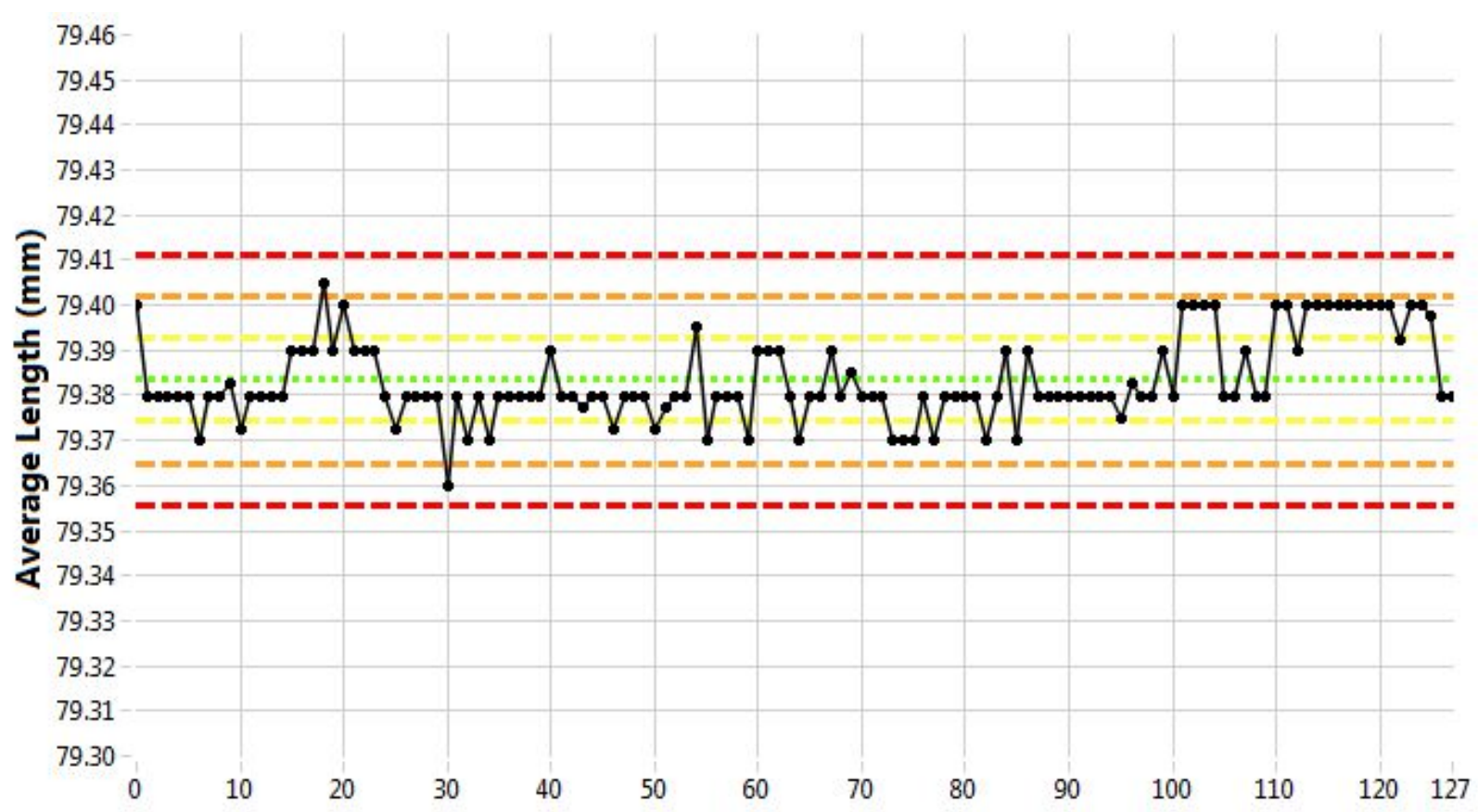

Figure B-3. Average length $(\mathrm{mm})$, mean $=79.384$, standard deviation $=0.0093$. 
TEM-10200-1

$03 / 01 / 2012$

Rev. 06

ENGINEERING CALCULATIONS AND ANALYSIS

Page $\mathrm{C} 1$ of $\mathrm{C} 4$

Title: $\quad$ Baseline Characterization Database Verification Report - PCEA Billet XPC01D3-36

ECAR No.: 3677

Rev. No.: 0

Project No.: 32138

Date: $05 / 02 / 2017$

\section{Appendix C}

\section{Additional Tensile Specimen Database Plots (PCEA XPC01D3-36T)}

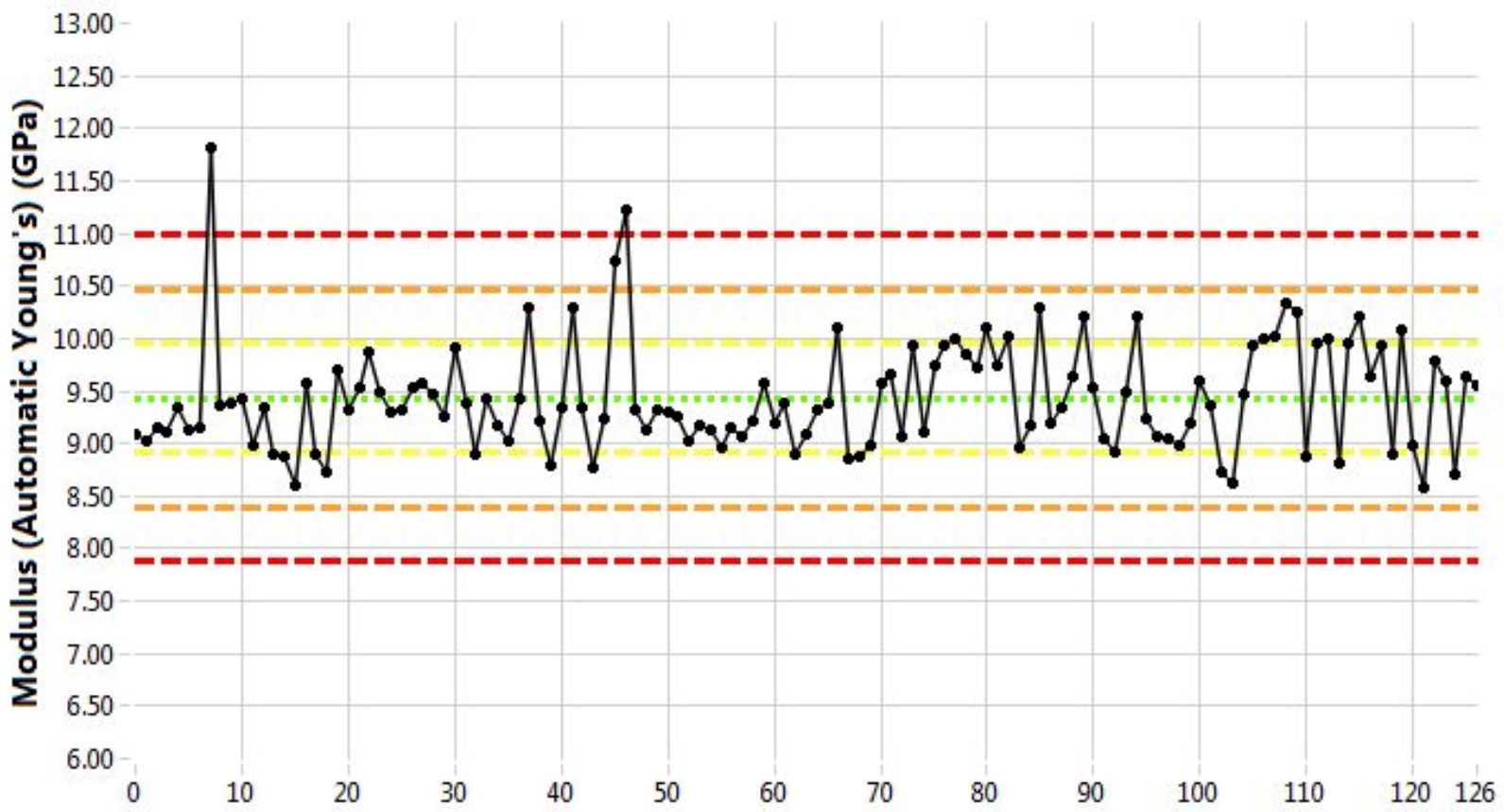

Figure C-1. Modulus (automatic Young's) (GPa), mean $=9.4$, standard deviation $=0.52$.

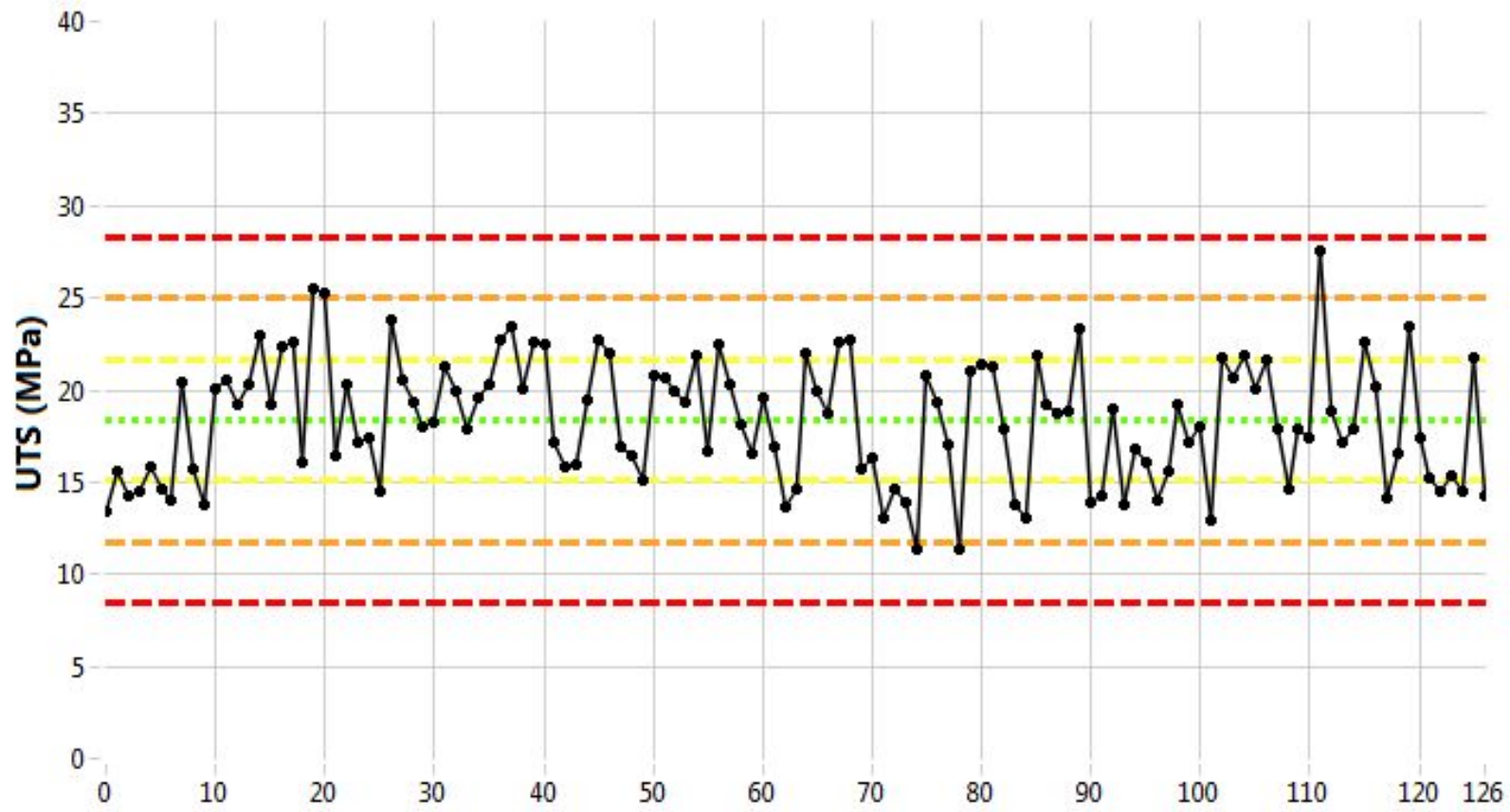

Figure C-2. Ultimate tensile strength $(\mathrm{MPa})$, mean $=18.4$, standard deviation $=3.31$. 
TEM-10200-1

$03 / 01 / 2012$

ENGINEERING CALCULATIONS AND ANALYSIS

Page $\mathrm{C} 2$ of $\mathrm{C} 4$

Rev. 06

Title: $\quad$ Baseline Characterization Database Verification Report - PCEA Billet XPC01D3-36

ECAR No.: 3677

Rev. No.: 0

Project No.:

32138

Date: $05 / 02 / 2017$

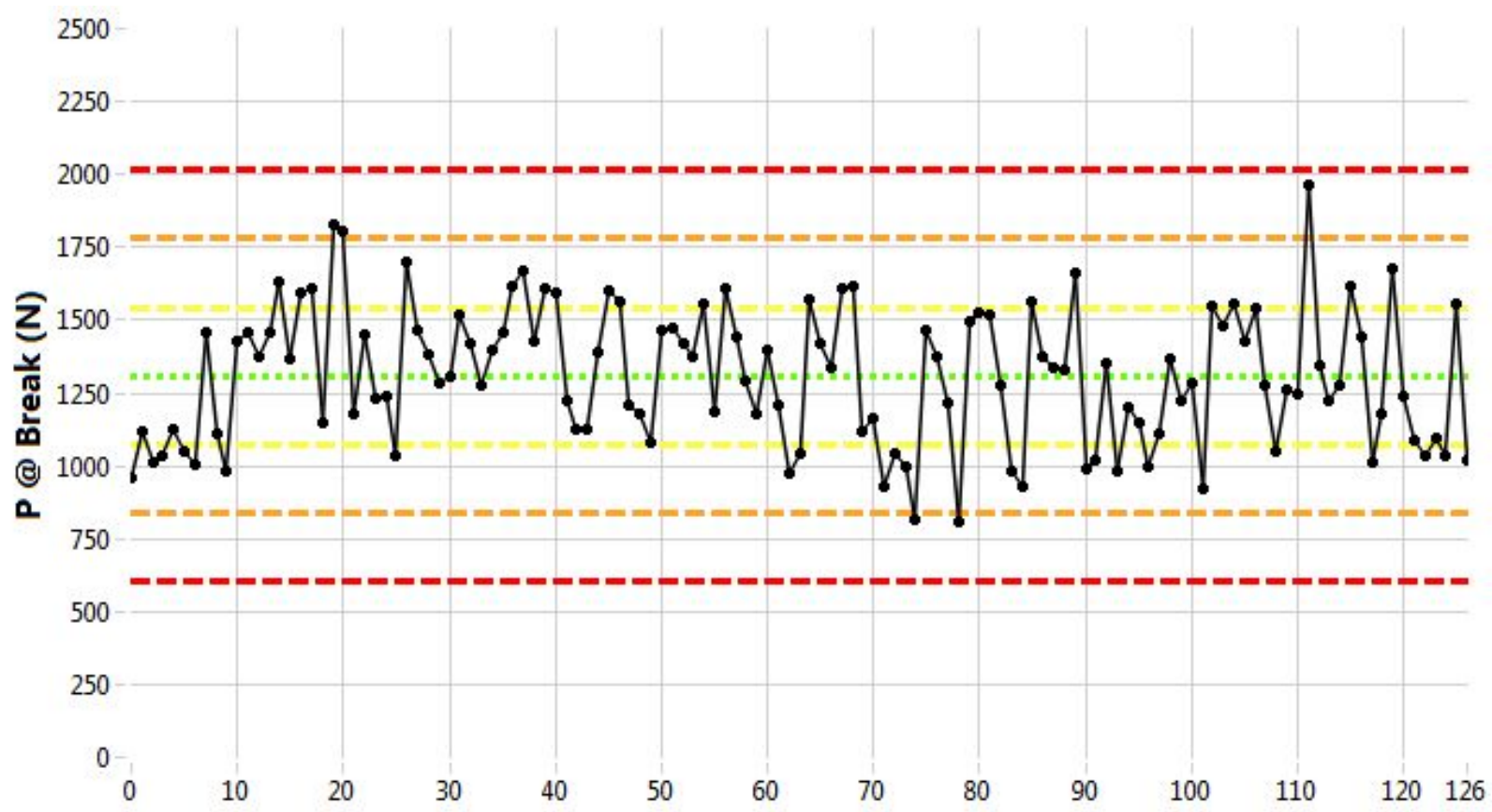

Figure C-3. Load at break $(\mathrm{N})$, mean $=1,308.6$, standard deviation $=235.65$.

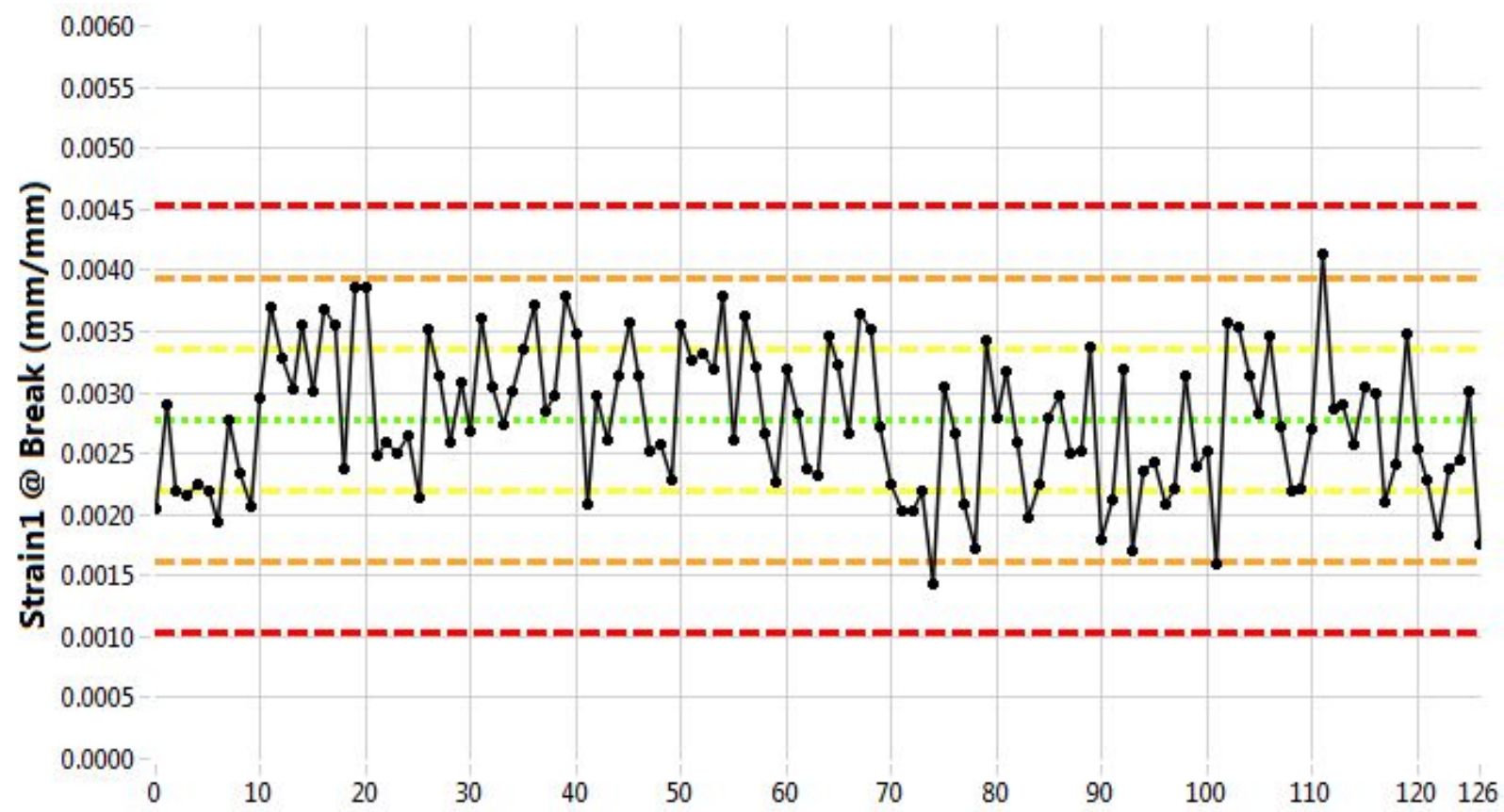

Figure C-4. Strain 1 at break $(\mathrm{mm} / \mathrm{mm})$, mean $=0.0028$, standard deviation $=0.0006$. 
TEM-10200-1

$03 / 01 / 2012$

Rev. 06

Title: $\quad$ Baseline Characterization Database Verification Report - PCEA Billet XPC01D3-36

ECAR No.: 3677

Rev. No.: 0

Project No.:

32138

Date: $05 / 02 / 2017$

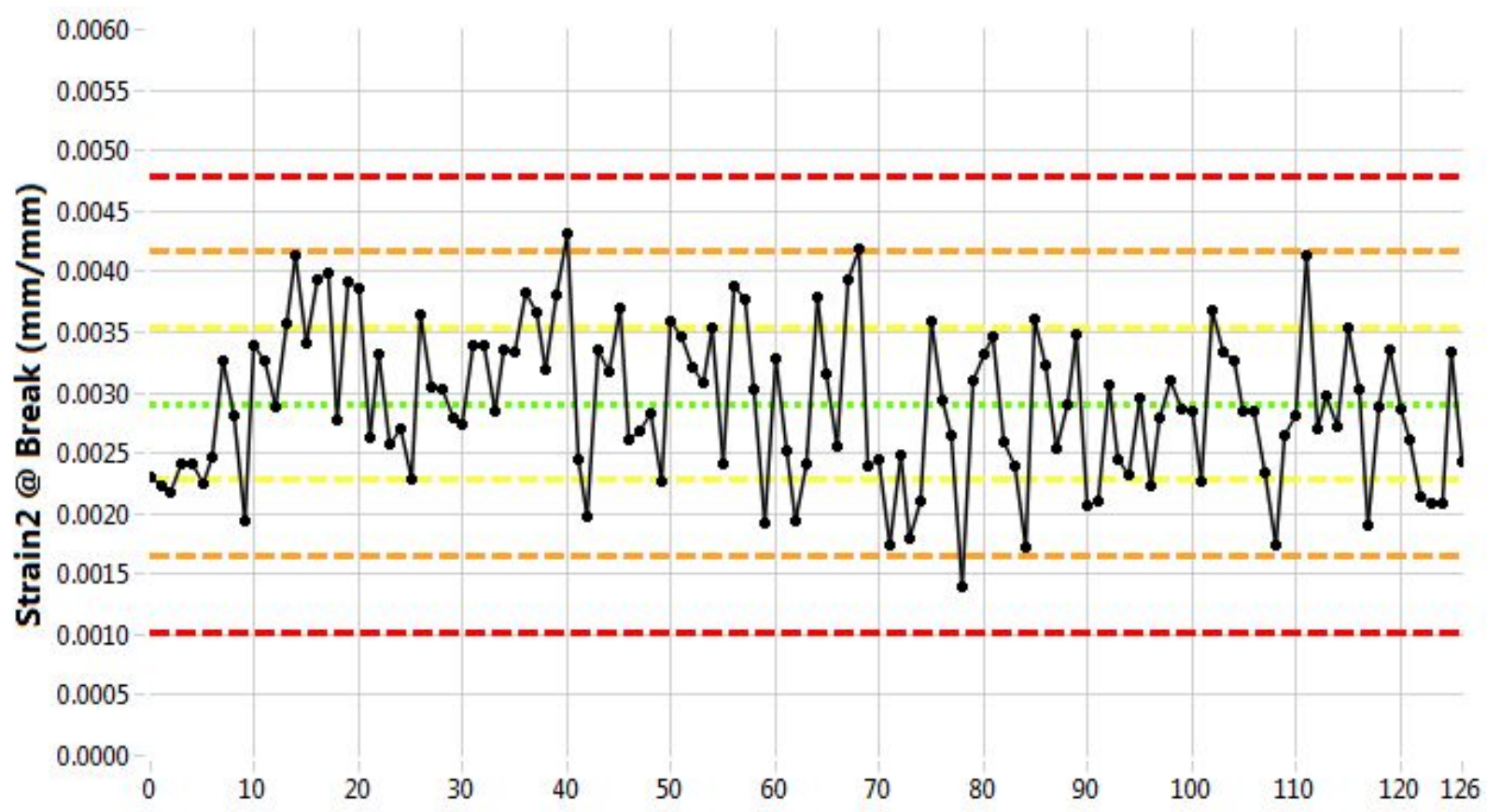

Figure C-5. Strain 2 at break $(\mathrm{mm} / \mathrm{mm})$, mean $=0.0029$, standard deviation $=0.0006$.

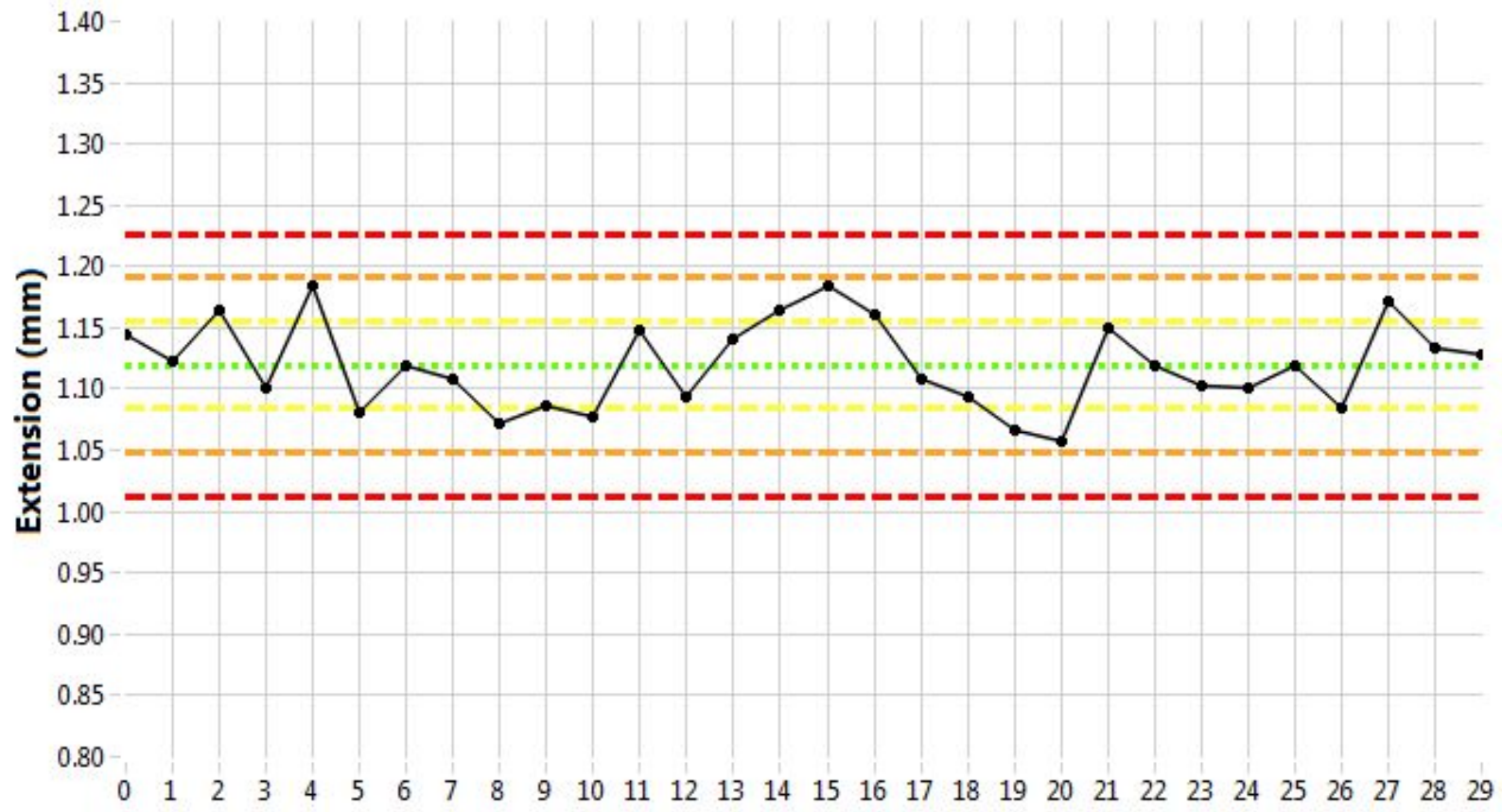

Figure C-6. Split disc extension $(\mathrm{mm})$, mean $=1.1197$, standard deviation $=0.0357$. 
TEM-10200-1

$03 / 01 / 2012$

Rev. 06

ENGINEERING CALCULATIONS AND ANALYSIS

Page $\mathrm{C} 4$ of $\mathrm{C} 4$

Title: $\quad$ Baseline Characterization Database Verification Report - PCEA Billet XPC01D3-36

ECAR No.: 3677

Rev. No.: 0

Project No::

32138

Date: $05 / 02 / 2017$

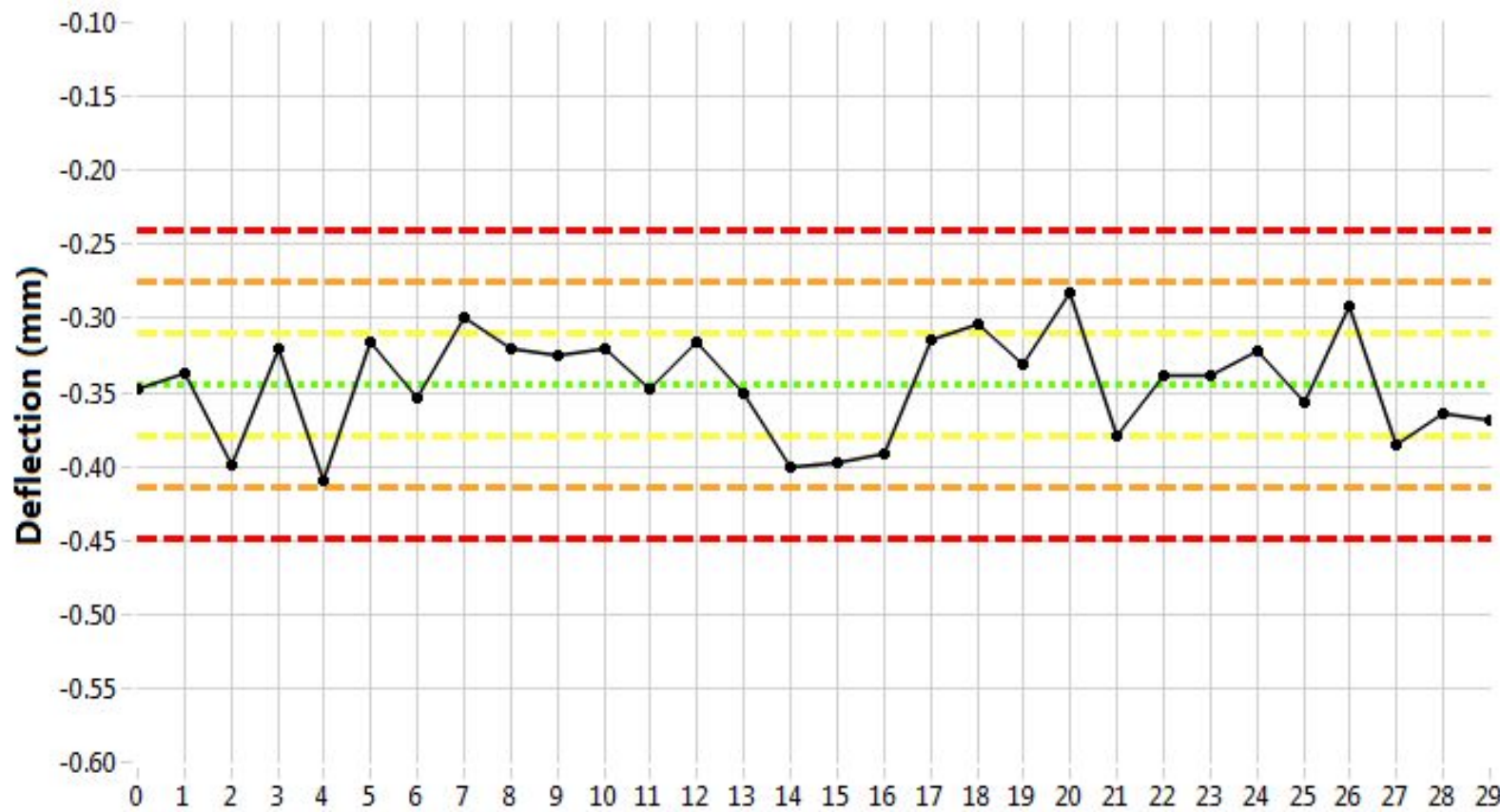

Figure C-7. Split disc deflection $(\mathrm{mm})$, mean $=-0.3445$, standard deviation $=0.0349$. 